\title{
DOE/ET/28354-1/2
}

TR-809-2

\section{USER'S MANUAL FOR COVARIANCE AND HYPOTHESIS TESTING PROGRAM}

\author{
June 1978
}

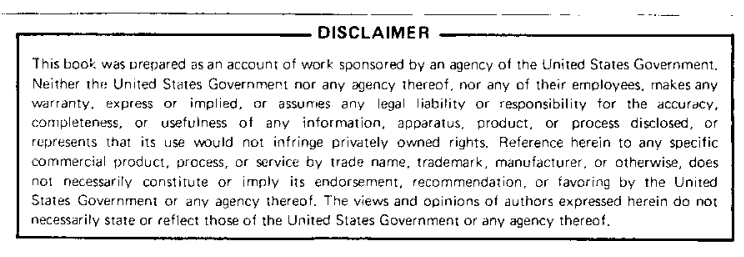

Prepared Under:

Contract No. E(11-1)-4084

for

UNITED STATES DEPARTMENT OF ENERGY

Washington, DC

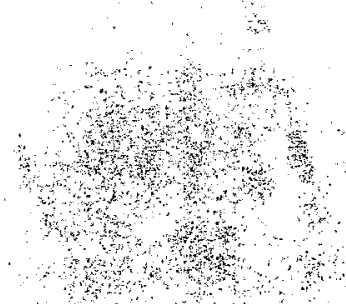

Prepared by:

J. Thomas Parr

Gary P. Bogar

David H. Johnson

Approved by:

Arthur A. Sutherland, Jr. Joel M. Winett

THE ANAYYTIC SCIENCES CORPORATION

Ar. Six Jacob Way

Readmg, kassachusetts 01867

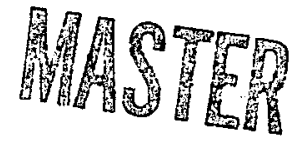




\section{DISCLAIMER}

This report was prepared as an account of work sponsored by an agency of the United States Government. Neither the United States Government nor any agency Thereof, nor any of their employees, makes any warranty, express or implied, or assumes any legal liability or responsibility for the accuracy, completeness, or usefulness of any information, apparatus, product, or process disclosed, or represents that its use would not infringe privately owned rights. Reference herein to any specific commercial product, process, or service by trade name, trademark, manufacturer, or otherwise does not necessarily constitute or imply its endorsement, recommendation, or favoring by the United States Government or any agency thereof. The views and opinions of authors expressed herein do not necessarily state or reflect those of the United States Government or any agency thereof. 


\section{DISCLAIMER}

Portions of this document may be illegible in electronic image products. Images are produced from the best available original document. 
This document comprises the user manual for the computer programs developed under Contract No. 18706(14-08-0001-15049) for the U.S. Geological Survey and Contract No. E (11-1) - 4084 for the U.S. Department of Energy. These programs were exercised using geophysical data for geothermal exploration. Most recent results of that study are reported in a companion report, TR-809-1. 


\section{TABLE OF CONTENTS}

FOREWORD

Page

No.

List of Figures

ii

List of Tables

$\mathrm{V}$

vi

1. INTRODUCTION $1-1$

2. COVARIANCE PROGRAM (COVAR) $2-1$

2.1 Purpose

2.2 Mathematical Equations

2.3 COVAR Usage and User Instructions

$2-1$

$2-1$

2.3.1 COVAR Input

2.3.2 COVAR Output

$2-3$

$2-3$

$2-7$

2.4 Program Description

$2-9$

2.4.1 Main Program

$2-9$

2.4.2 Subroutine SCOVAR

$2-9$

2.4.3 Subroutine CHECK

$2-14$

2.4.4 Subroutine PRNTR

$2-14$

2.4.5 Subroutine LEIG

$2-17$

2.4.6 Block Data Routine

$2-19$

2.4.7 Subroutine SVDRS

$2-19$

2.4.8 Subroutine QRBD

$2-19$

2.4.9 Subroutine G1

2.4.10 Subroutine G2

$2-19$

$2-19$

2.4.11 Function DIFF

2.4.12 Subroutine $\mathrm{H} 12$

3. HYPOTHESIS TESTING PROGRAM (LIKE)

$3-1$

3.1 Purpose

3.2 Mathematical Equations

3.3 LIKE Usage and User Instructions

$3-1$

$3-2$

3.3.1 LIKE Input

3.3.2 LIKE Output

3.4 Program Description

3.4.1 Main Program

3.4.2 Subroutine SLIKE

3.4.3 Subroutine SLIKE 1

3.4.4 Subroutine PRNTL

$3-2$

$3-3$

$3-5$

$3-6$

$3-6$

3-7

$3-11$

$3-13$

4. SUMMARY

4-1 


\section{TABLE OF CONTENTS (Continued)}

APPENDIX A - COVARIANCE PROGRAM LISTING

Page

No.

APPENDIX B - SAMPLE EXECUTION OF COVARIANCE PROGRAM

A-1

APPENDIX C - HYPOTHESIS TESTING PROGRAM LISTING

$\mathrm{B}-1$

APPENDIX D - SAMPLE EXECUTION OF HYPOTHESIS TESTING PROGRAM

C-1

APPENDIX E - DESCRIPTION OF THE DELIVERABLE TAPE

D-1

APPENDIX F - JOB CONTROL STATEMENTS

E-1

F-1 


\section{LIST OF FIGURES}

Figure

Page

No.

No.

1-1 Overview of Computer Processing Steps for Hypothesis Testing

$1-3$

2.3-1 Interfaces of Programs COVAR and LIKE

$2-4$

2.4-1 Overview of the Program COVAR

$2-10$

2.4-2 Flowchart of COVAR (Main Program)

$2-11$

2.4-3 Flowchart of the Subroutine SCOVAR

$2-13$

2.4-4 Flowchart of Subroutine CHECK

$2-15$

2.4-5 Flowchart of Subroutine PRNTR

$2-16$

2.4-6 Flowchart of Subroutine LEIG

$2-18$

3.4-1 Overview of the Program LIKE

$3-6$

3.4-2 Flowchart of LIKE (Main Program)

$3-9$

3.4-3 Flowchart of Subroutine SLIKE

$3-10$

3.4-4 Flowchart of Subroutine SLIKE1

$3-12$

3.4-5 Flowchart of Subroutine PRNTL 


\section{LIST OF TABLES}

Table

No.

2.3-1 Interfaces of Programs COVAR and LIKE

2.3-2 Record \#1 Units 31-34

$2-5$

2.3-3 Record \#2-\#21 Units 31-34

$2-6$

2.3-4 Record \#22-END Units 31 and 33

$2-6$

2.3-5 Record \#22 Units 32 and 34

$2-6$

2.3-6 Disposition of Records on Units 31-34

2.4-2 Interface with Program SCOVAR

2.4-3 Interface with Subroutine CHECK

2.4-4 Interface with Subroutine PRNTR

2.4-5 Interface with Subroutine LEIG

3.3-1 Data Input NAMELIST

3.4-2 Interface with Program SLIKE

3.4-3 Interface with Subroutine SLIKE1

3.4-4 Interface with Subroutine PRNTL 
1 .

INTRODUCTION

This document describes the statistical data processing programs that were developed for application of hypothesis testing methods to geophysical exploration. A companion document, TR-809-1, should be referred to for a detailed description of the approach and results of the application to the regional evaluation of geothermal potential in the state of Nevada.

The hypothesis testing approach to analysis of geophysical data is a basis for pattern recognition. In the case of interest, patterns are comprised of combinations of "feature indices" that are generated through a preprocessing step. These feature indices are computed from the various geophysical survey data available and are intended to highlight those characteristics of the survey data that are relevant to the resource in question. A wide variety of preprocessing algorithms are possible, depending on the form of the original data, and the mechanism for association with the resource. Simple spatial density transforming algorithms or more sophisticated transforms such as the Fourier transform to extract spatial frequency components might be appropriate, depending on the specifics of the problem. Details of the preprocessing steps employed in the current study are reported in TR-809-1.

Having defined several feature indices at uniformly spaced, commonly referenced grid points encompassing the region of interest, the indices are interpolated to the hot spring locations. The interpolated index values as well as 
the index values for the entire region are then merged to form two main data bases for more efficient processing in subsequent steps. These data bases consist of

\section{- Index values for the entire region of interest \\ - A selected interpolated set of index values corresponding to locations of known re- sources within the region.}

The later set is sometimes referred to as the learning set.

In the present study for evaluation of regional geothermal potential, the learning set is defined by locations of 17 known hot springs with temperature in excess of $150^{\circ} \mathrm{C}$. Selected feature index values corresponding to these locations are then employed as a representative signature combination in a search to determine other locations with similar features. The steps involved in this evaluation are summarized in Fig. 1-1 and include preprocessing, merging, selection of appropriate sets of feature indices, and finally the statistical evaluation of these sets of the indices in the Fortran programs COVAR and LIKE.

This document includes a description of the two main programs which involve statistical processing. These programs are denoted as the covariance computation step (COVAR) and the hypothesis testing step (LIKE) as illustrated in Fig. 1-1. The program COVAR computes multidimensional means and standard deviations of the selected indices corresponding to the two major data bases described above. Additional computations are included for principle component analysis. The program LIKE is subsequently exercised to compute a likelihood ratio function for the entire region, considering the statistics output from COVAR. The final output is a 
gridded array of likelihood values which indicate relative geothermal potential over the region of study.

$R-25932$

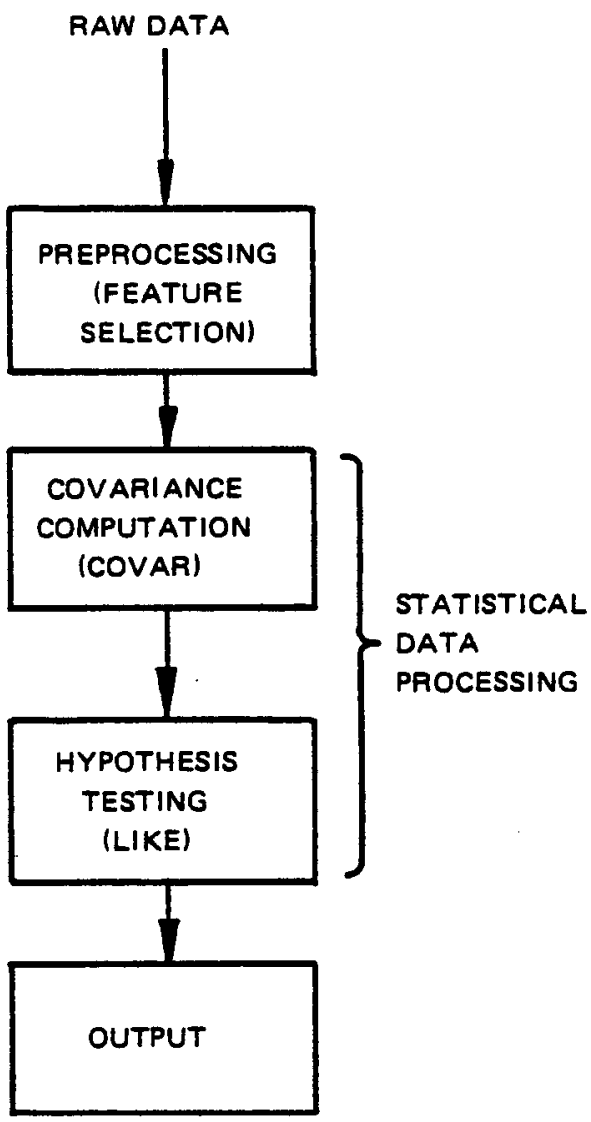

Figure 1-1 Overview of Computer Processing Steps for Hypothesis Testing 
2 . THE COVARIANCE PROGRAM (COVAR)

\subsection{PURPOSE}

The purpose of this program is to compute the statistics and transformation matrices appropriate for selected feature indices to be used in the likelihood evaluation. Estimates of first and second-order multidimensional statistics of the feature indices that pertain to specific locations of known geothermal activity as well as the entire region are generated. In addition, eigenvectors, eigenvalues and transformation matrices for principle component analysis are generated as outputs of this program for use in the subsequent likelihood ratio evaluation.

\subsection{MATHEMATICAL EQUATIONS}

The averages of the selected indices are computed according to

$$
\underline{m}_{j}=\frac{1}{k_{j}} \sum_{s_{j}} \underline{x}
$$

where the vector $x$ contains elements corresponding to the selected indices and the subscript $j$ denotes the $j^{\text {th }}$ hypothesis. $k_{j}$ refers to the number of points evaluated for the $j^{\text {th }}$ hypothesis and $s_{j}$ defines that set of points for which the $j^{\text {th }}$ hypothesis is assumed to be true. Specifically, there are only two hypotheses and we define 


\section{$s_{1}$ - as the set of all points within a region approximated by the state of Nevada (assumed hypothesis: there is no geo- thermal energy). \\ $s_{2}$ as the set of all points within $s_{1}$ that are also known locations of hot springs with temperatures in excess of $150^{\circ} \mathrm{C}$ (assumed hypothesis: there is geothermal energy).}

The covariance matrix is computed from

$$
P_{j}=\frac{1}{\left(k_{j}-1\right)} \sum_{s_{j}}\left(\underline{x}-\underline{m}_{j}\right)\left(\underline{x}-\underline{m}_{j}\right)^{T}
$$

and has a dimension $\mathrm{n} \times \mathrm{n}$ where $\mathrm{n}$ is the number of features extractable from the data.

The correlation matrix provides an obvious indication of the relative redundancy of selected feature indices and is directly computed for each data base from the relevant covariance matrix.

$$
C=S P S
$$

where $\mathrm{S}$ is a diagonal matrix and data base subscripts are omitted for clarity with

$$
S_{i i}=1 /\left(P_{i i}\right)^{\frac{1}{2}} \quad, \quad i=1,2, n \text {. }
$$

The eigenvalues and eigenvectors are computed for the correlation matrix $C$ using a singular value decomposition method. The eigenvectors are normalized to a unit length and used to form an orthonormal modal matrix, $B$.

$$
B=\left[\underline{e}_{1}, \underline{e}_{2}, \ldots \underline{e}_{n}\right]
$$


where $\underline{e}_{1}, \ldots, \underline{e}_{n}$ are the normalized eigenvectors of the positive definite correlation matrix, $C$, corresponding to eigenvalues $\lambda_{1}, \ldots, \lambda_{n}$.

The elements $S_{i i}$ and $\lambda_{i}$, as well as the transformation matrix $B$, computed for both data bases are then output for direct usage in the Hypothesis Testing Program.

\subsection{COVAR USAGE AND USER INSTRUCTIONS}

The program COVAR has been written to compute a covariance matrix, standard deviation, correlation matrix, a matrix of eigenvectors, and a set of eigenvalues for each of two data bases. The averages, standard deviations, eigenvectors, and eigenvalues are then saved for program LIKE. Figure 2.3-1 contains an overview of the COVAR and LIKE interfaces.

\subsubsection{COVAR Input}

Input to COVAR takes two forms:

- Card image input

- Tape and/or disk inputs.

The card image input is on Fortran logical unit 5 and consists of a selection vector to choose the parameters in computing a covariance matrix. The selection vector is input using the NAMELIST identified as DATA and described in Table 2.3-1.

The data bases reside on Fortran logical units 31 through 34. That on units 31 and 32 (Data Base 1) must be the general data base (e.g. for the gridded state of Nevada), 


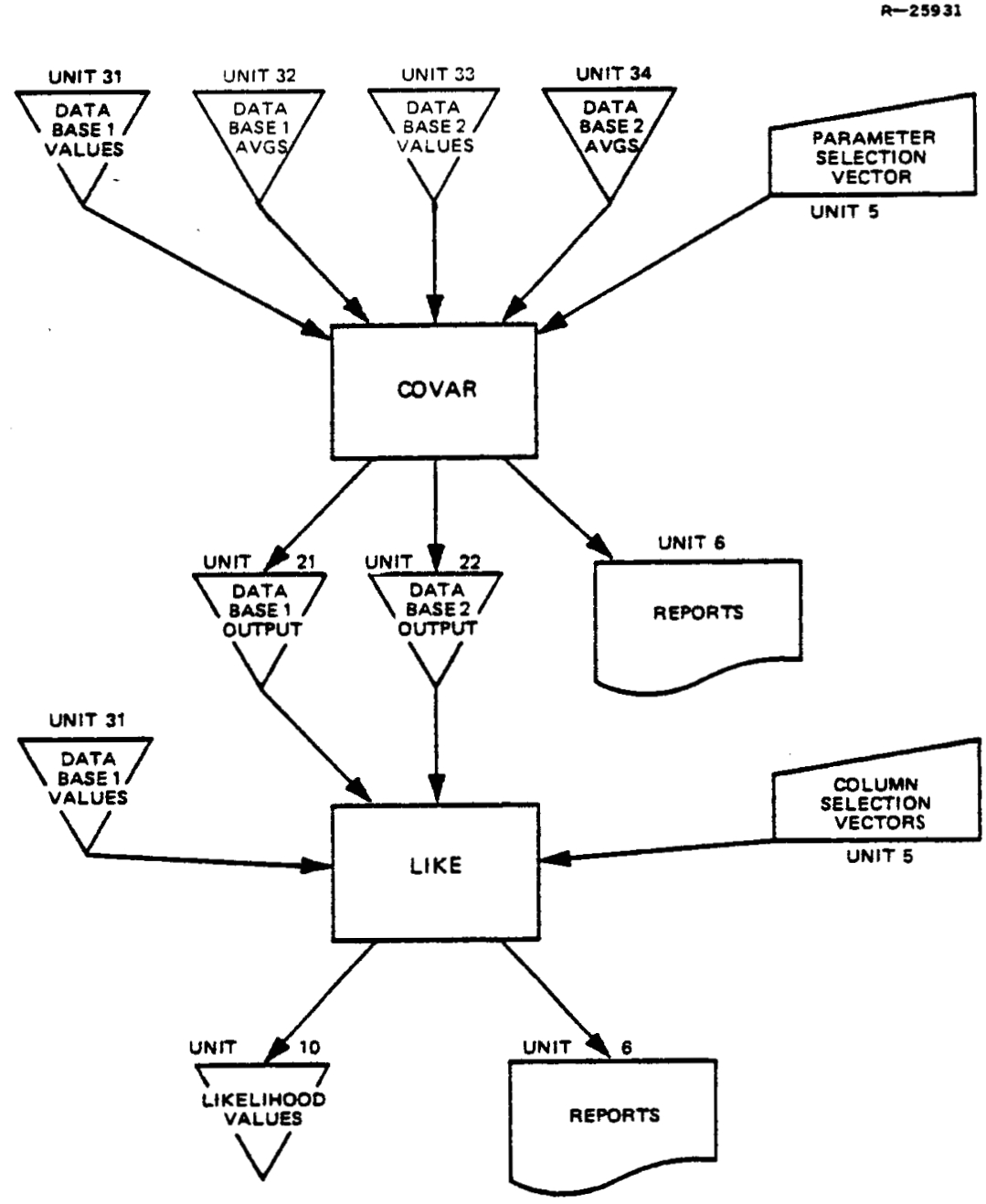

Figure 2.3-1 Interfaces of Programs COVAR and LIKE

TABLE $2.3-1$

DATA INPUT (NAMELIST)

$\mathrm{T}-0617$

\begin{tabular}{|c|c|c|}
\hline VARIABLE & \multicolumn{1}{|c|}{ DESCRIPTION } & DEFAULT \\
\hline SEL(I) & $\begin{array}{l}\text { Number of the parameter selected to } \\
\text { compute the covariance matrix. SEL(I) } \\
\text { is dimensioned 100 and is input using } \\
\text { standard NAMELIST convention. }\end{array}$ & \\
\hline
\end{tabular}

*0 terminates selection vector, i.e., no other values of SEL(I) are used. 
while the data base on units 33 and 34 is the specialized one (e.g., for the hot springs locations in Nevada).

Each of the files ( 31 through 34 ) have file descriptors on the first 21 records. These file descriptors are necessary to ensure that the proper files are being used and passed to the program LIKE. The $22^{\text {nd }}$ record on units 32 and 34 contains the averages for the index values on units 31 and 33 , respectively. The files on units 31 and 33 start on the $22^{\text {nd }}$ record. Each record corresponds to a location and each variable corresponds to some criterion.

The same Fortran format is used for all the records on units 31 to 34 (100A4). Each data base can contain up to 100 feature indices generated by preprocessing of geophysical or other appropriate data. Descriptions of the various records are shown in Tables 2.3-2, 2.3-3, 2.3-4, and 2.3-5. Table 2.3-6 shows the disposition of the records on the various files.

TABLE 2.3-2

RECORD \#1 UNITS $31-34$

$\mathrm{T}-0618$

\begin{tabular}{|l|l|}
\hline \multicolumn{1}{|c|}{ VARIABLE } & \multicolumn{1}{|c|}{ DESCRIPTION } \\
\hline IDT(1) & Month file was updated \\
IDT(2) & Day file was updated \\
NDT(3) & Year file was updated \\
IDT(4) & Seconds of the day file was updated \\
MDM(1) & First dimension of data base \\
MDM(2) & Second dimension of data base \\
NDM(3) & Total number of points in data base \\
NPAR & Number of parameters actually present on data base \\
IDB(1) & Alphanumeric information either (DB 1) or (DB 2) \\
IDB(2) & for data base 1 or 2 \\
DTITLE(90) & Title of this particular file \\
\hline
\end{tabular}


TABLE $2.3-3$

RECORDS \#2-\#21 UNITS 31-34

$\mathrm{T}-0619$

\begin{tabular}{|l|l|}
\hline VARIABLE & \multicolumn{1}{|c|}{ DESCRIPTION } \\
\hline TITLE $(I, J)$ & $\begin{array}{l}\text { Jth word (4 letters, numbers, } \\
\text { etc.) of the title of the Ith } \\
\text { parameter. } \\
\text { Title is dimensioned }(100,20)\end{array}$ \\
\hline
\end{tabular}

TABLE 2.3-4

RECORD \#22-END UNITS 31 AND 33

\begin{tabular}{|l|l|}
\hline VARIABLE & \multicolumn{1}{|c|}{ DESCRIPTION } \\
\hline \hline YY(I) & $\begin{array}{l}\text { Value of Ith parameter. (Note } \\
\text { values of over 1.E50 mean data } \\
\text { point is not to be used.) } \\
\text { YY is dimensioned (100) }\end{array}$ \\
\hline
\end{tabular}

TABLE 2.3-5

RECORD \#22 UNITS 32 AND 34

\begin{tabular}{|c|c|}
\hline VARIABLE & \multicolumn{1}{c|}{ DESCRIPTION } \\
\hline \hline YY(I) & $\begin{array}{l}\text { Average of Ith parameter. } \\
\text { YY is dimensioned (100) }\end{array}$ \\
\hline
\end{tabular}


TABLE 2.3-6

DISPOSITION OF RECORDS ON UNITS $31-34$

\begin{tabular}{|c|c|c|c|}
\hline UNIT 31 & UNIT 32 & UNIT 33 & UNIT 34 \\
\hline $\begin{array}{l}\text { Data Base } 1 \\
\text { Values file }\end{array}$ & $\begin{array}{l}\text { Data Base } 1 \\
\text { Averages File }\end{array}$ & $\begin{array}{l}\text { Data Base } 2 \\
\text { Values File }\end{array}$ & $\begin{array}{l}\text { Data Base } 2 \\
\text { Averages File }\end{array}$ \\
\hline $\begin{array}{l}\text { Record } \# 1 \\
\text { File Descrip- } \\
\text { tors }\end{array}$ & $\begin{array}{l}\text { Record \#1 } \\
\text { File Descrip- } \\
\text { tors }\end{array}$ & $\begin{array}{l}\text { Record } \# 1 \\
\text { File Descrip- } \\
\text { tors }\end{array}$ & $\begin{array}{l}\text { Record } \# 1 \\
\text { File Descrip- } \\
\text { tors }\end{array}$ \\
\hline $\begin{array}{l}\text { Record \#2-\#21 } \\
\text { Parameter } \\
\text { Titles }\end{array}$ & $\begin{array}{l}\text { Record } \# 2-\# 21 \\
\text { Parameter } \\
\text { Titles }\end{array}$ & $\begin{array}{l}\text { Record } \# 2-\# 21 \\
\text { Parameter } \\
\text { Titles }\end{array}$ & $\begin{array}{l}\text { Record } \# 2-\# 21 \\
\text { Parameter } \\
\text { Titles }\end{array}$ \\
\hline $\begin{array}{l}\text { Record } \# 22 \text { to } \\
\text { end } \\
\text { Values of } \\
\text { Parameters }\end{array}$ & $\begin{array}{l}\text { Record } \# 22 \\
\text { Averages of } \\
\text { Parameters }\end{array}$ & $\begin{array}{l}\text { Record \#22 to } \\
\text { end } \\
\text { Values of } \\
\text { Parameters }\end{array}$ & $\begin{array}{l}\text { Record } \# 22 \\
\text { Averages of } \\
\text { Parameters }\end{array}$ \\
\hline
\end{tabular}

Record number 1 on units 31 to 34 contains the file descriptors. This record is used to ensure that the proper files are read.

\subsubsection{COVAR Output}

The COVAR output takes two forms:

- Printed output on Fortran logical unit 6

- Saved output on tape, disk, or cards on Fortran logical units 21 and 22

The normal printed output consists of the following:

- File descriptors 
- Titles of parameters used

- Covariance matrices

- Averages

- Standard deviations

- Correlation matrices

- Eigenvector matrices

- Eigenvalues

- Eigenvalues matrices

If the correct files are not read in proper sequence, the program terminates and an error message indicating the problem is printed.

For each data base, the saved output (in format 20A4) consists of the following.

- Descriptors of the original data base used

- Dimension of the covariance matrix

- Dates that the data bases were updated

- Dimensions of the data bases

- Number of parameters present in the data bases

- Parameter selection vector used

- Titles of the parameters used

- Averages and standard deviations

- Eigenvalues

- Eigenvectors 
The organization of the data on the records depends on the dimension of the covariance matrix. The format $20 \mathrm{~A} 4$ was chosen to facilitate the punching of these saved data sets, if necessary. If a covariance matrix is computed using the maximum dimension of 50 , there would be $190 \mathrm{cards}$ for each data base or a total of 380 cards punched; whereas, for a dimension of ten, there would be a total of 44 cards punched.

\subsection{PROGRAM DESCRIPTION}

COVAR consists of a main program, eleven subroutines, and a block data routine. Figure 2.4-1 gives an overview of the program.

\subsubsection{Main Program}

The main program contains all of the matrices used, dimensioned to their maximum allowable size of 50 . The selection vector is then read using NAMELIST and checked for errors. If there are no errors, then the subroutine scovar is called and the actual dimension of the matrices to be used, NDIM, is passed via COMMON. Figure 2.4-2 is a flowchart of the main program.

\section{4 .2 Subroutine SCOVAR}

SCOVAR is the main computational routine. The matrices used are dimensioned by the actual main routine. The functions of SCOVAR include:

Setting the unit numbers for the input and output files

Reading of the standards for the file descriptors 


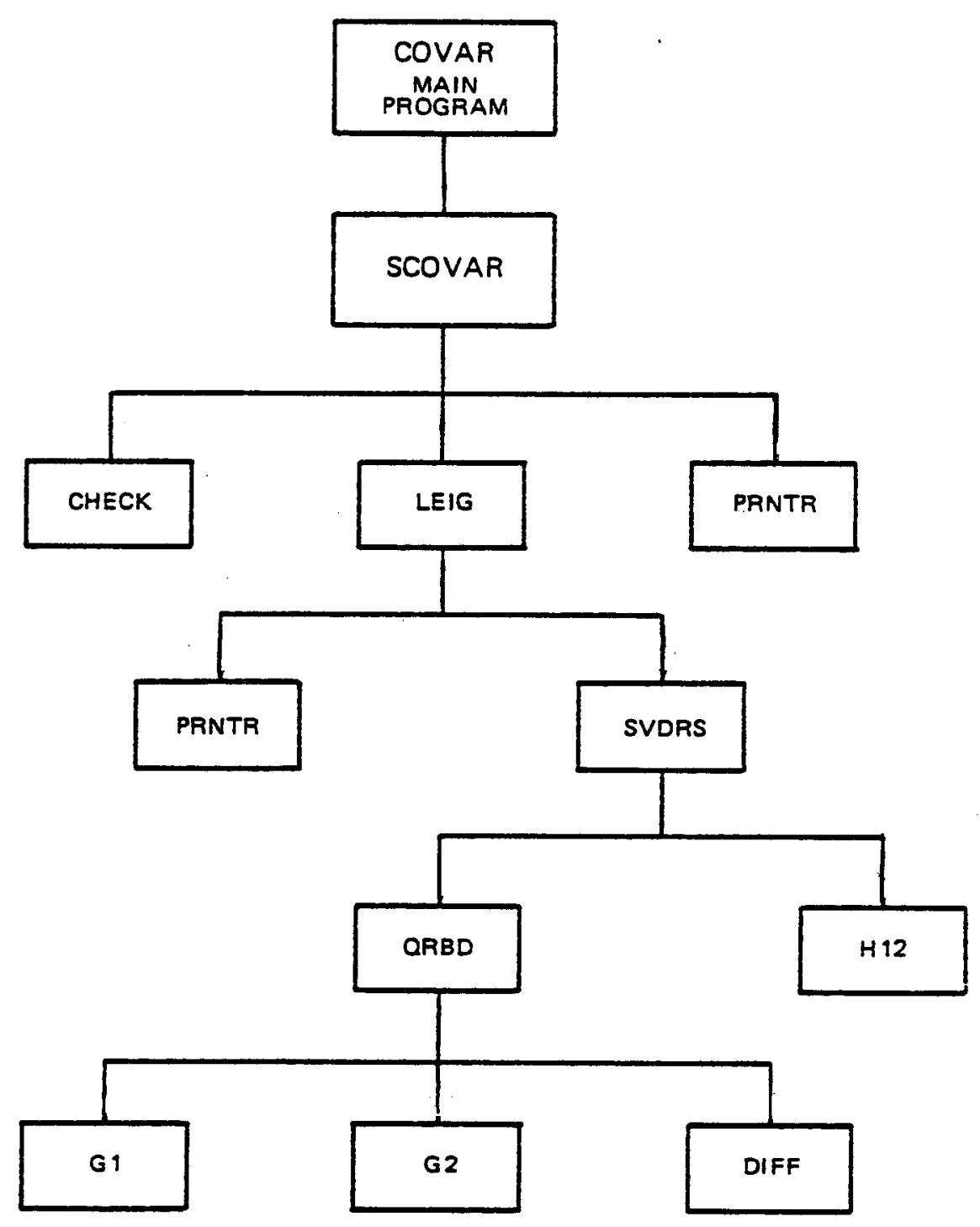

Figure 2.4-1 Overview of the Program COVAR 


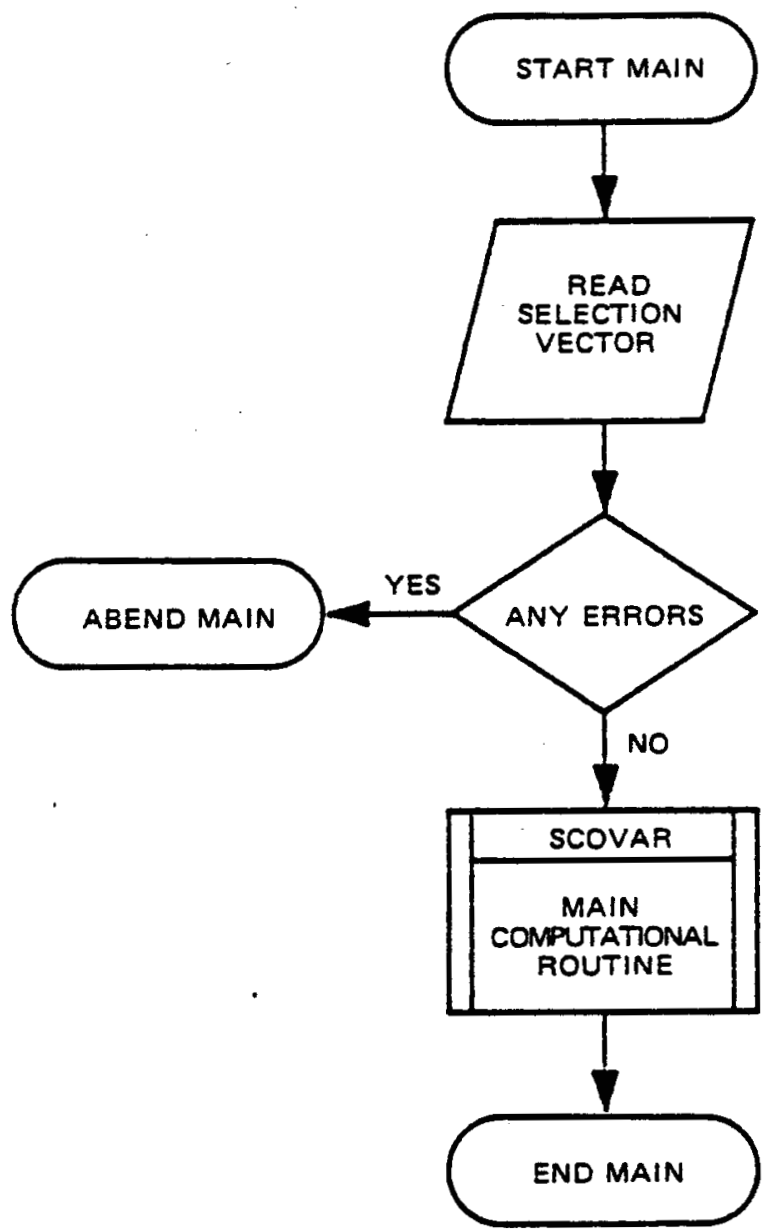

Figure 2.4-2 Flowchart of the Main Program

- Printing out the file descriptors and the titles of the parameters used

- Calling the subroutine CHECK which reads each file descriptor and checks them against the standard

- Choosing the averages to be used based on the selection vector

- Saving the file descriptors for each data base for use in the program LIKE

- Initializing the eigenvalue matrix and covariance matrix

- Reading the values of each data base using the selection vector to choose the parameter desired 
- Rejecting any values which have values over 1.E50

- Computing the covariance matrix

- Computing the correlation matrix

- Computing the standard deviation

- Calling the subroutine LEIG which is used for calculation of the eigenvectors and eigenvalues

- Printing the covariance matrix, averages, standard deviations, and correlation matrix using subroutine PRNTR

- Printing appropriate messages for errors

Figure 2.4-3 is a flowchart of the subroutine SCOVAR. Table 2.4-2 contains the variables passed as an argument list to SCOVAR.

$\begin{array}{cl}\text { TABLE } & 2.4-2 \\ \text { INTERFACE WITH } & \text { PROGRAM SCOVAR }\end{array}$

$\mathrm{T}-0623$

\begin{tabular}{|l|l|}
\hline VARIABLE & \multicolumn{1}{|c|}{ DESCRIPTION } \\
\hline COVM & $\begin{array}{l}\text { Covariance matrix to be calculated } \\
\text { VAL }\end{array}$ \\
& $\begin{array}{l}\text { Values used from the data bases to calcuiate the } \\
\text { covariance matrix }\end{array}$ \\
CORM & Correlation matrix to be calculated \\
AVG & The averages of the data base to be read and used \\
SD & To be used for computing standard deviations \\
S & To be used in calculating eigenvalues \\
BB & Dummy matrix \\
EIGVAL & Eigenvalue matrix
\end{tabular}




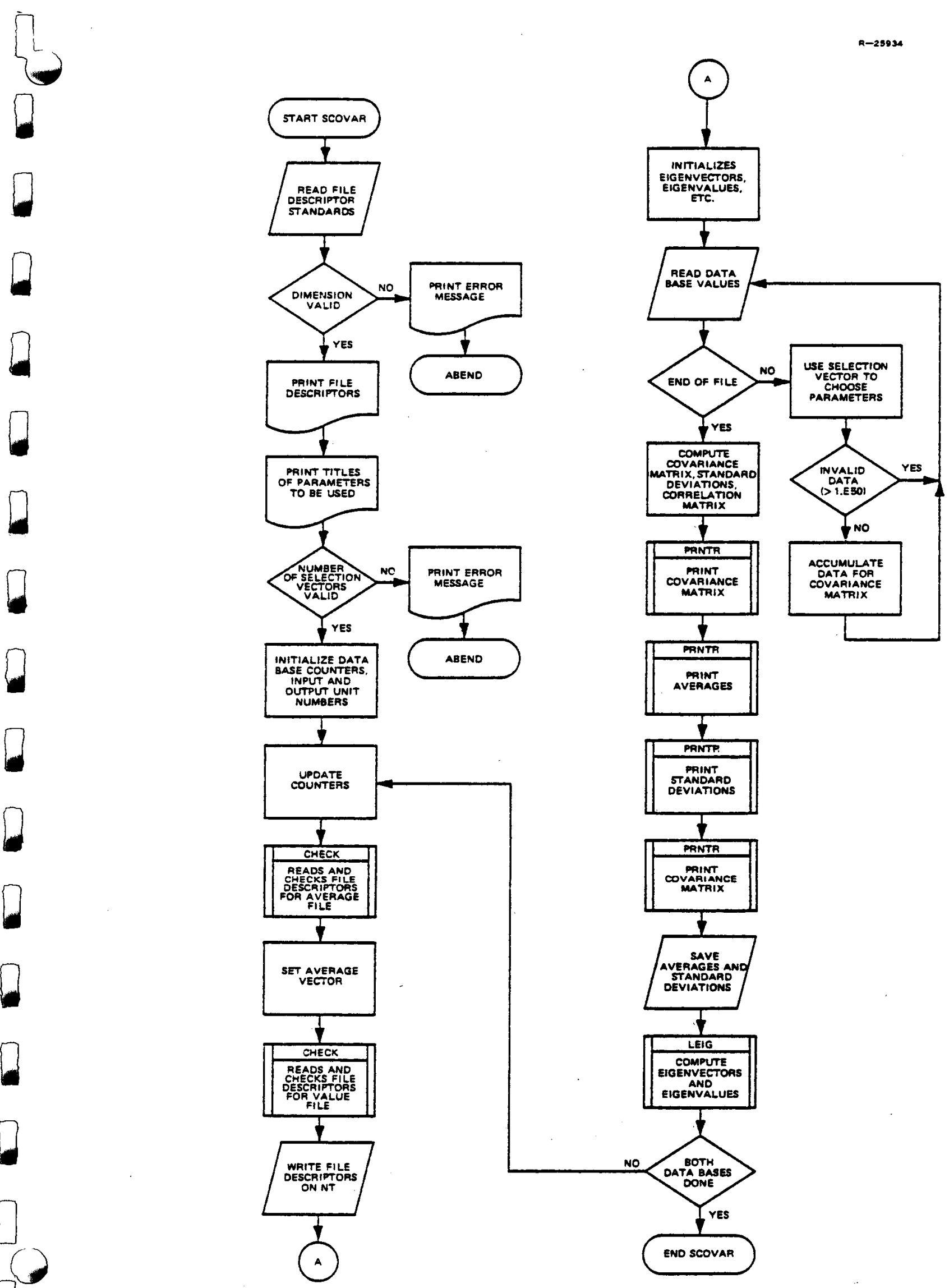

Figure 2.4-3 Flowchart of Subroutine SCOVAR 


\subsubsection{Subroutine CHECK}

Subroutine CHECK is used to read the file descriptors for each file and check them against the descriptors on File 21 which will be used as a standard. If an error occurs, an appropriate error message is written and the progran terminates. Figure 2.4-4 is a flowchart of the subroutine, while Table 2.4-3 contains the interface with subroutine CHECK.

TABLE 2.4-3

INTERFACE WITH SUBROUTINE CHECK

$\mathrm{T}-0624$

\begin{tabular}{|l|l|}
\hline VARIABLE & \multicolumn{1}{|c|}{ DESCRIPTION } \\
\hline \hline MY & Unit number of file to be used \\
NT & Unit number of file to be written \\
IDB & Number of data base being used \\
NVA & Indicator to determine whether value file or \\
& average file is being read \\
& 1 - value file \\
& $2-$ average file \\
\hline
\end{tabular}

\subsubsection{PRNTR Subroutine}

PRNTR is used to print out a matrix, the dimensions of the matrix, and a title describing the matrix. PRNR also prints out column headings which can be used to relate the particular columns with the parameters used in calculating them. Figure 2.4-5 is a flowchart of subroutine PRNTR, while Table 2.4-4 contains the interface with subroutine PRNTR. 


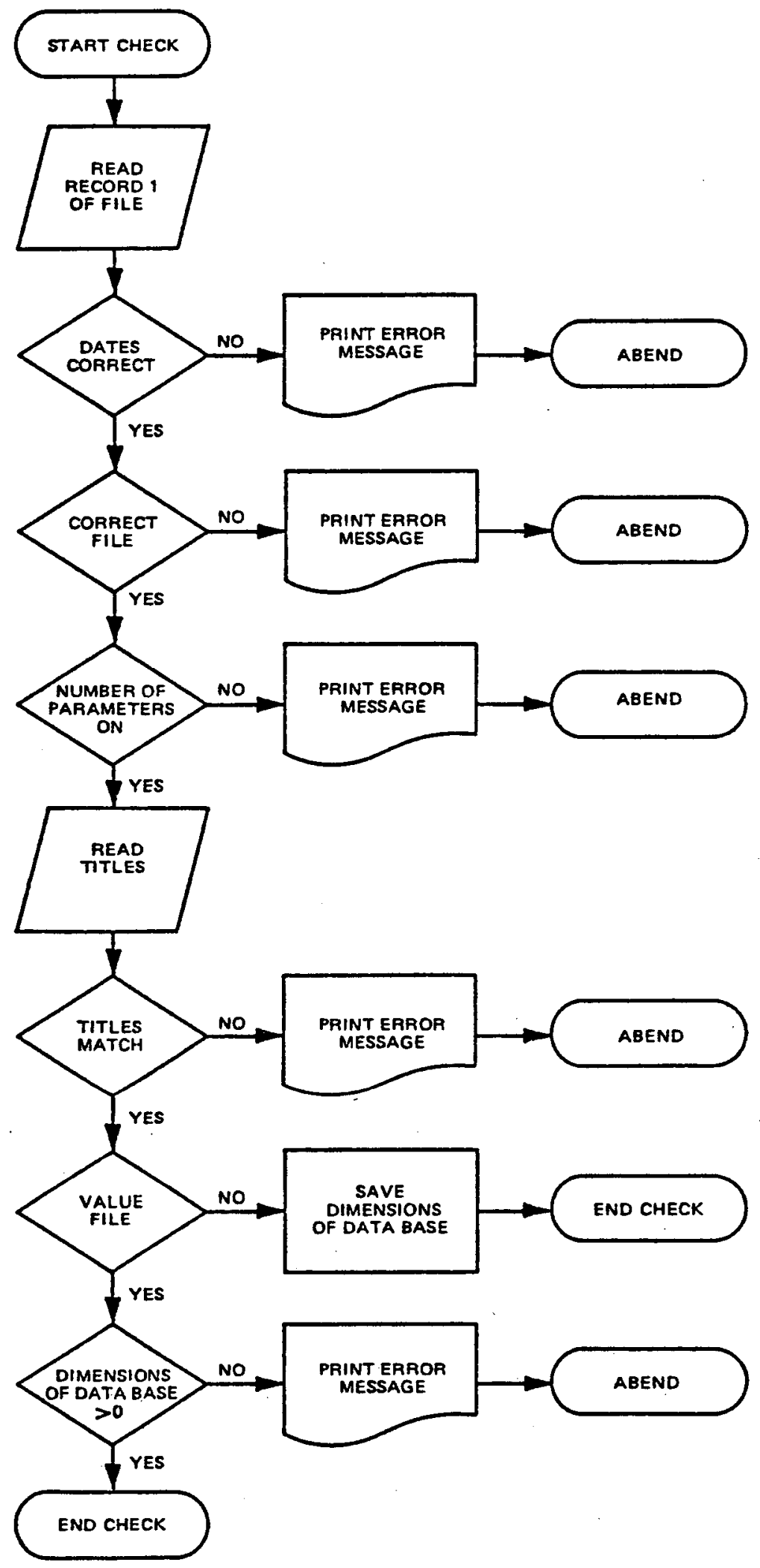

Figure 2.4-4 Flowchart of Subroutine CHECK 


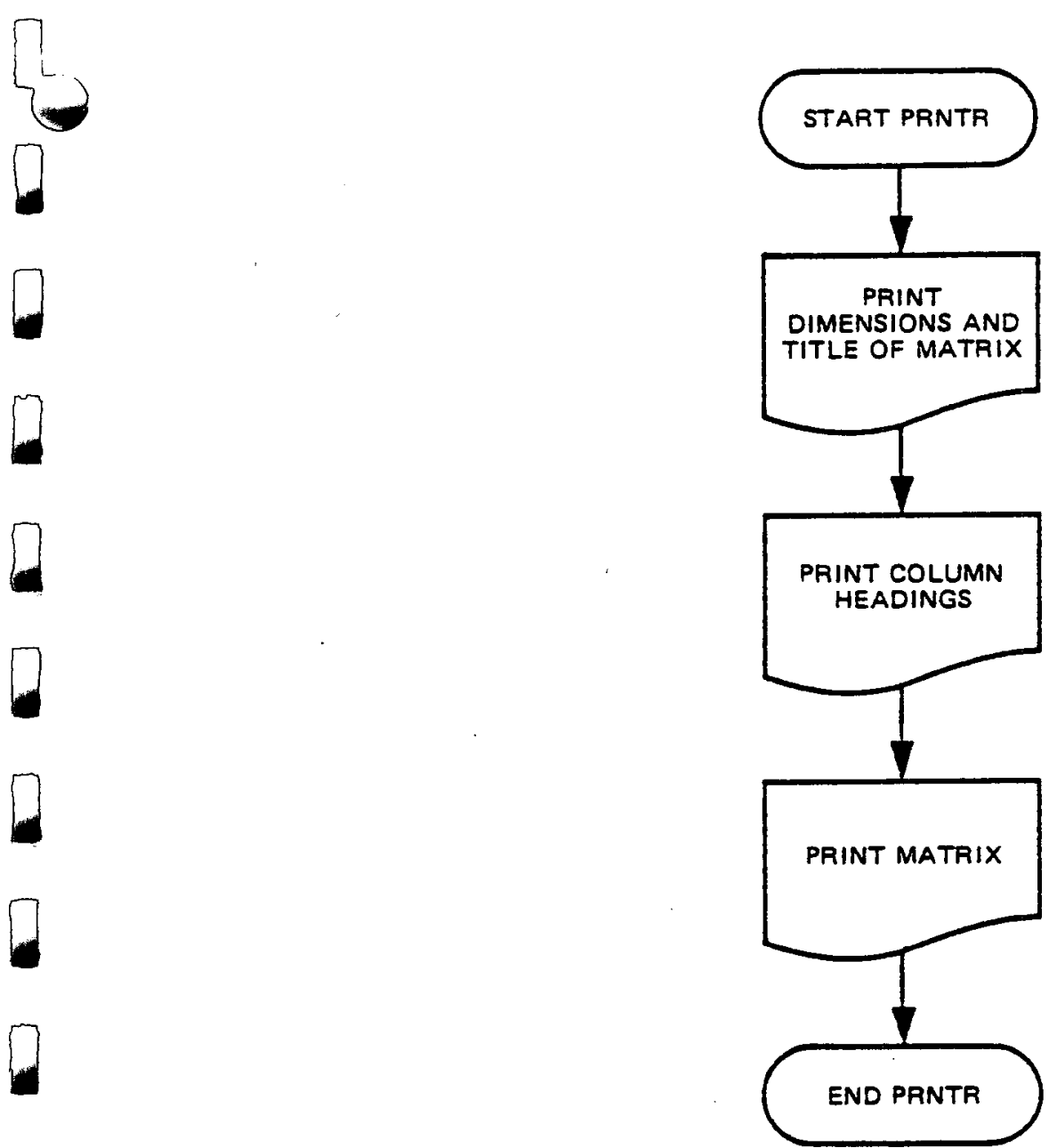

Figure 2.4-5 Flowchart of Subroutine PRNTR

TABLE 2.4-4

INTERFACE WITH SUBROUTINE PRNTR

\begin{tabular}{|l|l|}
\hline \multicolumn{1}{|c}{ DARIABLE } & \multicolumn{1}{|c|}{ DESCRIPTION } \\
\hline XMAT & Name of matrix to be printed \\
NROW & Number of rows of matrix \\
NCOL & Number of columns of matrix \\
TITLE & Alphanumeric title of matrix \\
N & Number of characters in title \\
\hline
\end{tabular}




\subsubsection{LEIG Subroutine}

LEIG performs the following functions:

- Initializes the identity matrix and eigenvector matrix

- Calls SVDRS which calculates the eigenvectors and eigenvalues

- Normalizes the eigenvectors

- Computes the eigenvalue matrix as a check (the diagonals must be equal to the eigenvalues computed by SVDRS and the off diagonal elements should be within roundoff accuracy of zero)

- Calls PRNTR to print the eigenvectors, eigenvalue matrix, and eigenvalues

- Saves the eigenvalues and eigenvectors for program LIKE.

Figure 2.4-6 is a flowchart of the subroutine LEIG, while Table 2.4-5 contains the interface with subroutine LEIG.

TABLE 2.4-5

INTERFACE WITH SUBROUTINE LEIG

$\mathrm{T}-0627$

\begin{tabular}{|l|l|}
\hline VARIABLE & \multicolumn{1}{|c|}{ DESCRIPTION } \\
\hline \hline COVM & Covariance matrix which is replaced by the \\
CORM & eigenvector matrix \\
NT & Correlation matrix \\
S & Output unit number file \\
BB & Eigenvalues \\
EIGVAL & Dummy matrix \\
\hline
\end{tabular}



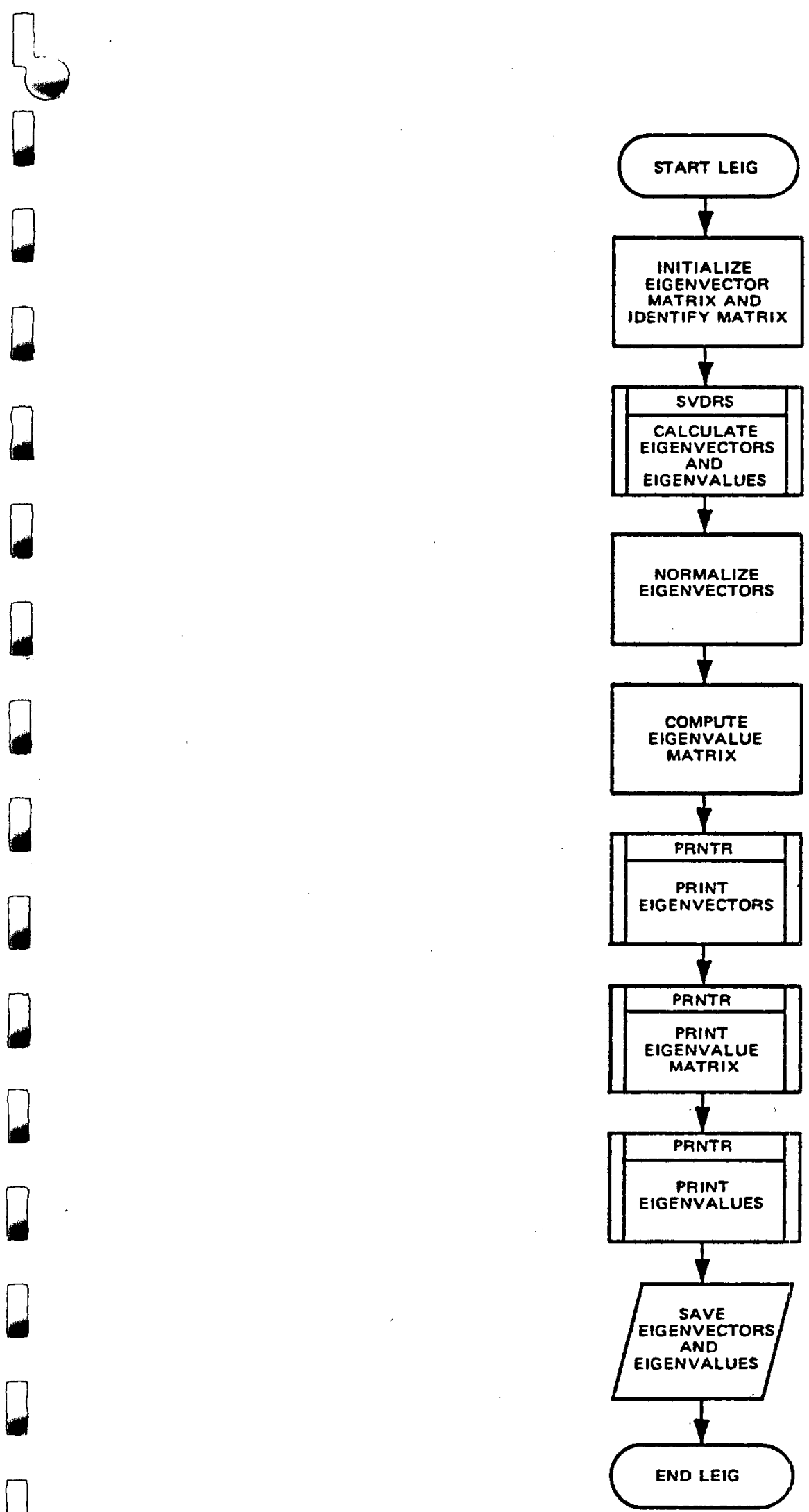

Figure 2.4-6 Flowchart of Subroutine LEIG 


\section{4 .6 Block Data Routine}

The block data routine is used to initialize the column headings in the named common statement CDATA. These column headings are used to correlate the columns of matrix printouts with the parameters used in calculating them.

\subsubsection{Subroutine SVDRS}

SVDRS is used to compute eigenvalues and eigenvectors for a symmetric, positive-semi-definite matrix using a singular value decomposition method. SVDRS calls the subroutine $\mathrm{H} 12$ which is used to perform Householder transformations and the subroutine $\mathrm{QRBD}$ which computes the singular value decomposition of the bidiagonal matrix. If convergence does not occur, an error message is printed and the program abends.

\subsubsection{Subroutine QRBD}

QRBD is used to compute the singular value decomposition of square bidiagonal matrix. QRBD calls the subroutines G1 and $G 2$ and the function DIFF.

\section{4 .9 Subroutine G1}

G1 is used to construct an orthogonal rotation matrix.

\subsubsection{Subroutine G2}

G2 is used to perform a matrix-vector product given the orthogonal rotation matrix constructed in subroutine G1. 


\subsubsection{Function DIFF}

DIFF is used to make the test "If $((x+h)-x) \neq 0$ " in place of the test "If $(|h|>p|x|)$ " where $p$ is the relative precision of the machine floating point arithmetic.

\subsubsection{Subroutine H12}

H12 is used either to compute a Householder transformation or, if one has been defined, to multiply the Householder transformation by a set of m-vectors. 
3

HYPOTHESIS TESTING PROGRAM (LIKE)

\subsection{PURPOSE}

The purpose of this program is to compute the ratio of relative likelihood function values for alternate hypotheses at each gridded location within a given region of interest. The likelihood function pertaining to each of the two alternate hypotheses is computed from the multidimensional set of indices and first- and second-order statistics pertaining to that hypothesis. These statistics are output from COVAR. Principle component transformations also specified by COVAR are incorporated in LIKE for ease in eliminating extraneous components that may be subject to roundoff errors, leading to erroneous results.

The output of the program comprises a two-dimensional array of scalar relative likelihood ratio values. Each of these values correspond to an evaluation of a multidimensional feature index vector relative to the statistical distributions of two classes of data relating to the alternate hypotheses. The relative likelihood ratio is expressed as $\mathrm{P}_{2} / \mathrm{P}_{1}$, where $\mathrm{P}_{1}$ and $\mathrm{P}_{2}$ are the relative likelihoods that hypotheses $\mathrm{H}_{1}$ and $\mathrm{H}_{2}$ are true respectively. This ratio has a value of unity if equal likelihood is computed for each of the alternate hypotheses. A ratio greater that unity would indicate that hypothesis 2 is more likely, whereas an opposite conclusion may be inferred from ratios less than unity. 


\subsection{MATHEMATICAL EQUATIONS}

The likelihood ratio, $\Lambda$, is computed from

$$
\Lambda(\mathrm{x}, \mathrm{y})=\exp \left\{-\frac{1}{2}\left(\mathrm{~F}_{2}-\mathrm{F}_{1}\right)\right\}
$$

$F_{1}$ and $F_{2}$ are scalar values computed from

$$
F_{J}=\sum_{I=1} \operatorname{NSEL}(I) y_{J}(I) 2 / \lambda_{J}(I)
$$

where NSEL(I), I=1,2, .,N, are elements of a selection vector for specifying which principal components are to be used for the likelihood function calculation. The values of NSEL(I) are either zero or one. The subscript, $J$ denotes one of the two data bases and $I=I, 2, \ldots, N$, denotes the $n$ components of the difference vector, $\underline{y}_{J} \cdot \lambda_{J}(I)$ are the $n$ eigenvalues for the $J^{\text {th }}$ data base and $y_{J}(I)$ is the $i^{\text {th }}$ element of $\underline{y}_{J}$.

For each point in the gridded region, the signature difference vector $\underline{y}_{J}$ relevant to the $J^{\text {th }}$ data base is defined

$$
\underline{y}_{J}=B_{J}^{T}\left(\underline{x}-\underline{m}_{J}\right)
$$

where $B_{J}$ is the modal transformation matrix defined by COVAR and the superscript $T$ denotes the transpose. The vector $\underline{m}_{J}$ is an $\mathrm{n}$ dimensional vector comprised of mean values of selected indices from the $J^{\text {th }}$ data base. The vector $\underline{x}$ is an $n$ dimensional vector comprised of the values of the selected indices, corresponding to a specific location of interest within the region of interest.

\subsection{LIKE USAGE AND USER INSTRUCTIONS}

LIKE computes a likelihood function using the data saved by program COVAR. This data includes the averages, 
standard deviations, eigenvectors, and eigenvalues for each of the two data bases. See Fig. 2.3-1 for the interface between programs COVAR and LIKE.

\section{3 .1 LIKE Input}

Input to LIKE takes the following forms:

- Card image input

- COVAR-generated data on any appropriate device

- Tape or disk input containing Data Base 1 values

The card image input on Fortran logical unit 5 consists of selection vectors to use or delete columns and associated rows of eigenvectors that were output from program COVAR. The selection vectors are input using the NAMELIST, DATA. Table 3.3-1 describes the input data on unit 5 .

The output from COVAR resides on logical units 21 and 22 as derived from Data Base 1 and Data Base 2, respectively.

This COVAR output consists of the following:

- Dimension of the covariance matrix generated by COVAR

- Dates that the data bases used by COVAR were updated

- Dimensions of the data bases

- Number of parameters present in the data bases 
TABLE $3.3-1$

DATA INPUT NAMELIST

\begin{tabular}{|c|c|c|}
\hline & & $T-0628$ \\
\hline VARIABLE & DESCRIPTION & DEFAULT \\
\hline IISELA (I ) & $\begin{array}{l}\text { Value of the Ith index relating to the } \\
\text { Ith column of the eigenvector matrix } \\
\text { for Data Base } 1 \\
\quad 1 \text { - use (default value) } \\
0 \text { - do not use }\end{array}$ & 1 \\
\hline $\operatorname{NSELB}(I)$ & $\begin{array}{l}\text { Value of the Ith index relating to the } \\
\text { Ith column of the eigenvector matrix } \\
\text { for Data Base } 2 \\
\quad 1 \text { - use (default value) } \\
\quad 0 \text { - do not use }\end{array}$ & 1 \\
\hline ICARD & $\begin{array}{l}\text { ICARD = } 1 \text { means output from COVAR is on } \\
\text { cards (to stop REWINDS) } \\
\text { ICARD } \neq 1 \text { means output from COVAR is } \\
\text { not on cards }\end{array}$ & 0 \\
\hline
\end{tabular}

- Parameter selection vector used

- Titles of the parameters

Note that all of the above input make up the descriptors of a file. COVAR output also contains the following:

- Averages and standard deviations

- Eigenvalues

- Eigenvectors

The format for this data is 20A4. No table is furnished because the placement of the data depends on the dimension of the eigenvector matrix which is variable. If the proper files are not used, appropriate error messages are printed. 
The tape or disk input is the Data Base 1 value file which resides on unit 31. Refer to Tables 2.3-2, 2.3-3, and 2.3-4 for descriptions of the records. The format for this data is $100 \mathrm{~A} 4$.

\subsubsection{LIKE Output}

The LIKE output takes two forms:

1. Printed output on Fortran logical unit 6

2. Saved output on tape or disk on Fortran logical unit 10

The normal printed output consists of the following:

- File descriptors

- Titles of parameters used

- Selector vectors

- Descriptors of each set of statistics from COVAR

- Eigenvalues

- Beta (transpose) matrix

Error messages are printed for any conditions that cause an abnormal termination.

The likelihood values are saved on Fortran logical unit 10 in the same order in which the gridded index values of Data Base 1 occur. The format of this output is 100A4 which is consistent with the input data. 


\subsection{PROGRAM DESCRIPTION}

LIKE consists of a main program and three subroutines. Figure 3.4-1 gives an overview of the program.

R-37952

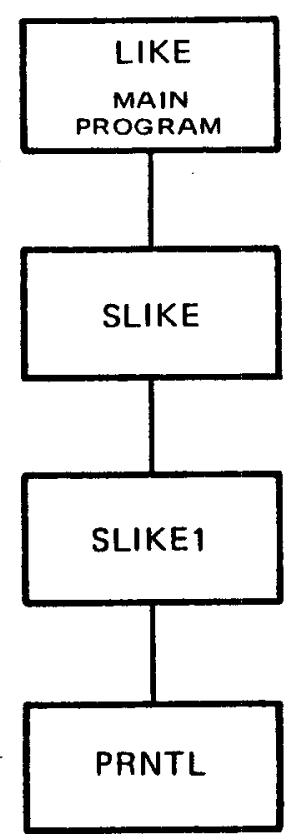

Figure 3.4-1 Overview of the Program LIKE

\subsubsection{Main Program}

The main program contains all of the matrices used, dimensioned to their maximum allowable use. The dimensions cannot be less than the ones used by COVAR. The main program reads in selection vectors for using the eigenvector matrix transpose for each data base. The file descriptors are read to ensure that the proper files are being used. The file descriptors are then compared with the file descriptor standards (those found on File 21) and if there are no errors, the subroutine SLIKE is called. Subroutine SLIKE 
is actually the main computational routine. Figure $3.4-2$ is a flowchart of the main program.

\subsubsection{SLIKE Subroutine}

SLIKE is the main computational routine. The matrices used are dimensioned by the actual main routine. The functions of SLIKE include:

- Calling SLIKE1 which performs input and output on the various matrices

- Reading in the Data Base 1 value file and using the selection vector passed from COVAR to choose the appropriate values

- Computing the likelihood function at each point

- Saving the likelihood function for every point.

Figure 3.4-3 is a flowchart of the subroutine SLIKE. Table 3.4-2 contains the interface with program SLIKE. 
TABLE $3.4-2$

INTERFACE WITH PROGRAM SLIKE

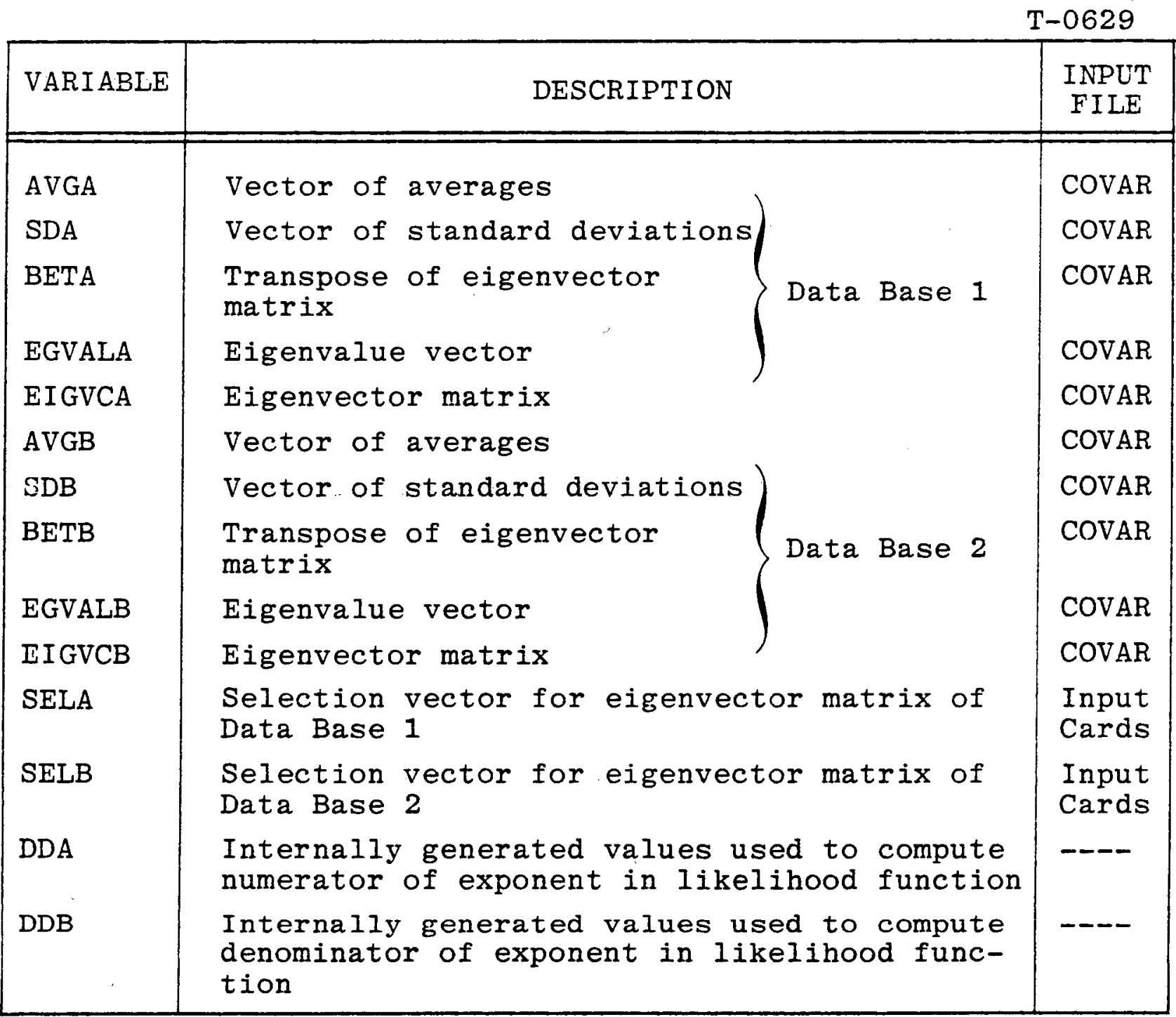




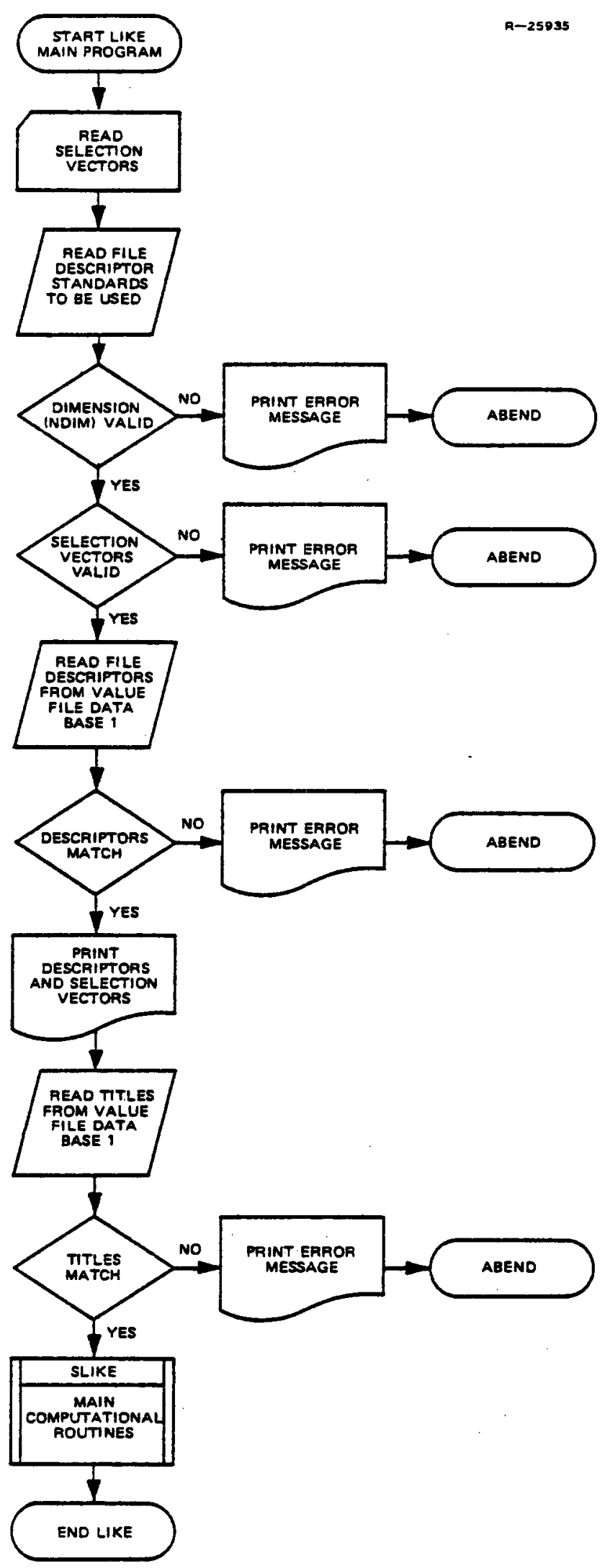

Figure 3.4-2 Flowchart of LIKE (Main Program) 


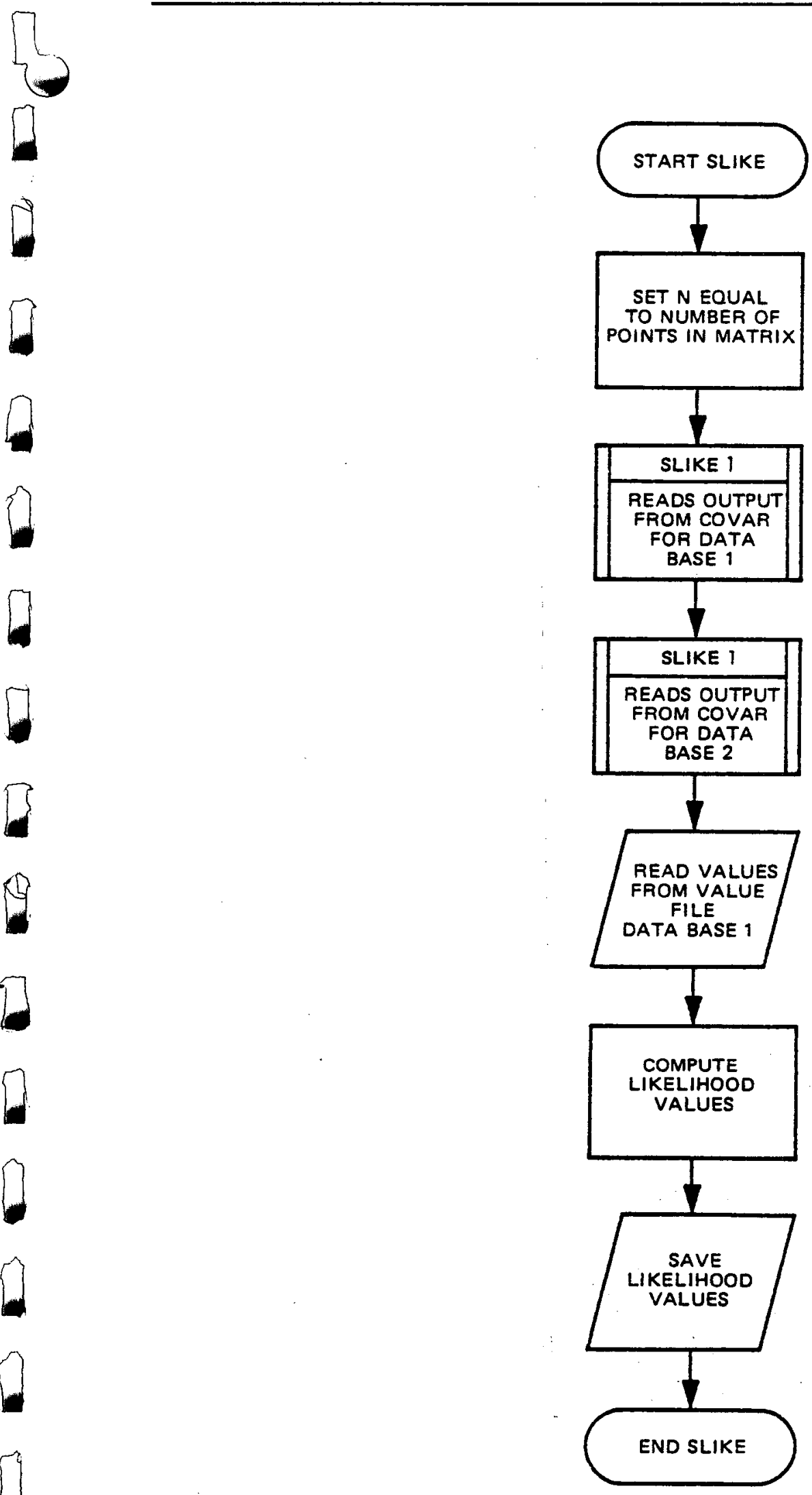

Figure 3.4-3 Flowchart of Subroutine SLIKE 


\subsubsection{SLIKE1 Subroutine}

SLIKE1 has the following functions:

- Reads in the file descriptors from the output of data base computations from COVAR

- Checks the descriptors to ensure use of proper files

- Reads in the average and the standard deviation vectors for each data base

- Reads in the eigenvalue vector and the eigenvectors for each data base

- Prints the eigenvalue vector and the eigenvector matrix for each data base

- Prints error messages for abnormal terminations

The printing of the matrices and vectors is done by subroutine PRNTL. Figure $3.4-4$ is a flowchart of the subroutine SLIKE1 and Table 3.4-3 gives the interface with subroutine SLIKE1.

TABLE $3.4-3$

INTERFACE WITH SUBROUTINE SLIKE1

\begin{tabular}{|l|l|}
\hline VARIABLE & \multicolumn{1}{|c|}{ DESCRIPTION } \\
\hline \hline AVGC & Vector of averages \\
SDC & Vector of standard deviations \\
BETC & Transpose of eigenvector matrix \\
EGVALC & Eigenvalue matrix \\
EIGVCC & Eigenvector matrix \\
TITLE & Name of eigenvalue vector \\
NAME & Name of transpose of eigenvector \\
& matrix \\
\hline
\end{tabular}



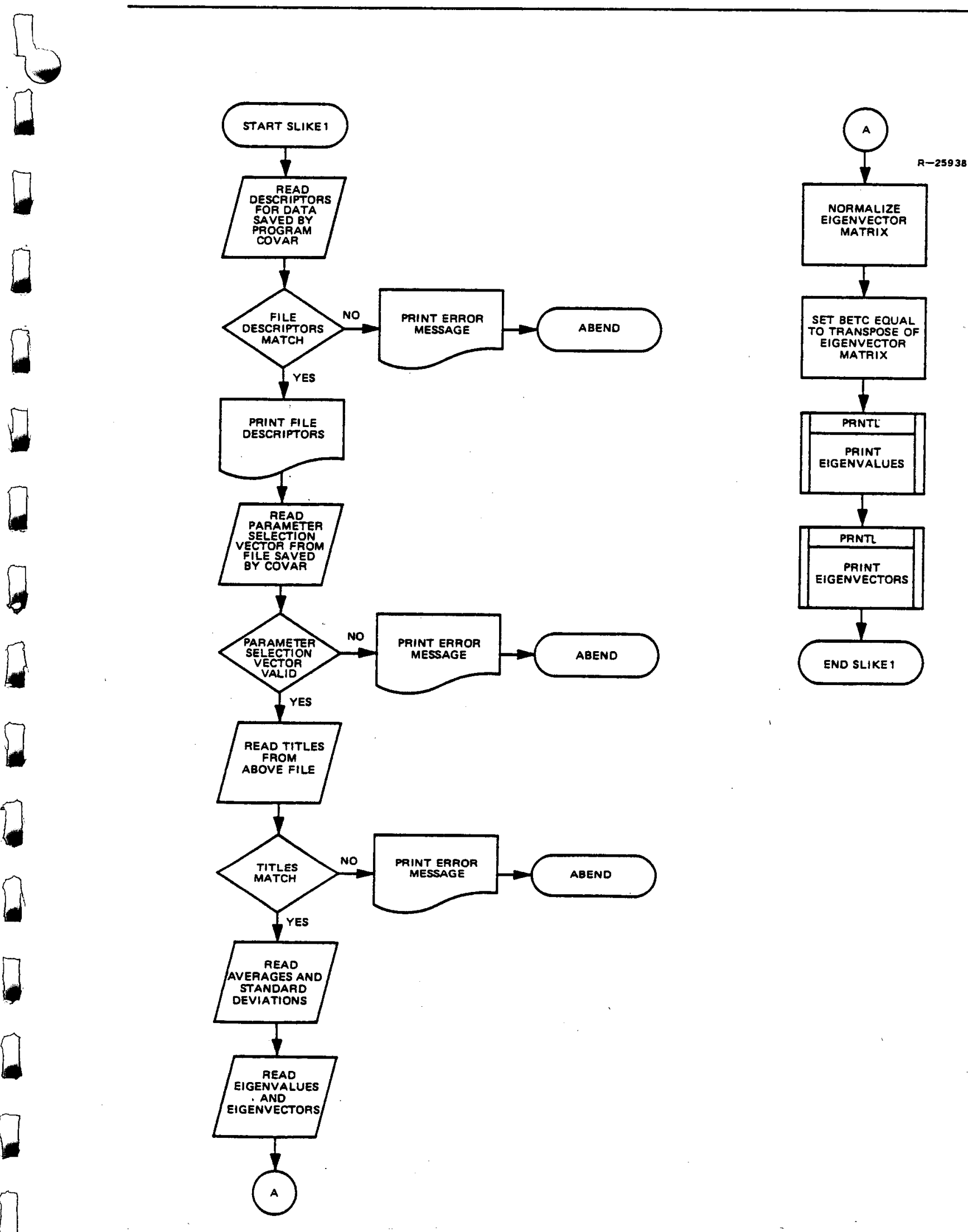

Figure 3.4-4 Flowchart of Subroutine SLIKE1 


\subsubsection{PRNTL Subroutine}

PRNTL is used to print out a matrix, the dimensions of the matrix, and a title describing the matrix. Unlike PRNTR in the program COVAR, PRNTL does not print out column headings since they are not applicable.

Figure $3.4-5$ is a flow chart of subroutine PRNTL and Table 3.4-4 gives the interface with subroutine PRNTL.

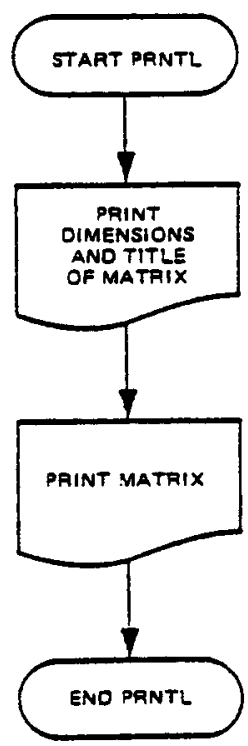

Figure 3.4-5 Flowchart of subroutine PRNTL

TABLE $3.4-4$

INTERFACE WITH SUBROUTINE PRNTL

\begin{tabular}{|l|l|}
\hline VARIABLE & \multicolumn{1}{|c|}{ DESCRIPTION } \\
\hline \hline XMAT & Name of matrix to be printed \\
NROW & Number of rows of matrix \\
NCOL & Number of columns of matrix \\
TITLE & Alphanumeric title of matrix \\
N & Number of characters in the title \\
\hline
\end{tabular}


4.

SUMMARY

The concept of hypothesis testing is useful in evaluating multiple types of geophysical survey data for exploration. This document describes statistical computer programs which are intended for general usage in evaluating multidimensional feature indices for resource potential. In particular, the computer programs comprise a covariance computation program and a likelihood function evaluation program. These programs have been exercised in this study for geothermal exploration, using as many as 34 selected feature indices from a data base that may include up to 100 distinct indices. It is anticipated that many more indices might be considered simultaneously. Practical limitations occur with large covariances due to numerical errors in computing eigenvalues and eigenvectors.

The basic concept of hypothesis testing as formulated in this study is described in the following steps.

\footnotetext{
- Identification of signature parameters

- Measurement of statistics of signature parameters in the general region and in a "learning set" of locations, known to be geothermal resource areas

- Computation of a likelihood (ratio) map indicating the relative closeness of an observed signature to the learning set signature, as opposed to the regional signature.
} 


\section{APPENDIX A \\ COVARIANCE PROGRAM \\ SOURCE LISTING}

A.1 COVAR (MAIN PROGRAM)

Page

No.

A. 2 SCOVAR

A-2

A. 3 LEIG

A-4

A. 4 PRNTR

A-9

A. 5 CHECK

A. 6 SVDRS

A. 7 QRBD

A. $8 \mathrm{H} 12$

A. 9 G1

A-11

A-12

A-15

A-19

A-23

A. $10 \quad$ G2

A-25

A.11 DIFF

A-26

A.12 BLOCK DATA

A-27

A-28 


\section{A.1 COVAR (MAIN PROGRAM)}

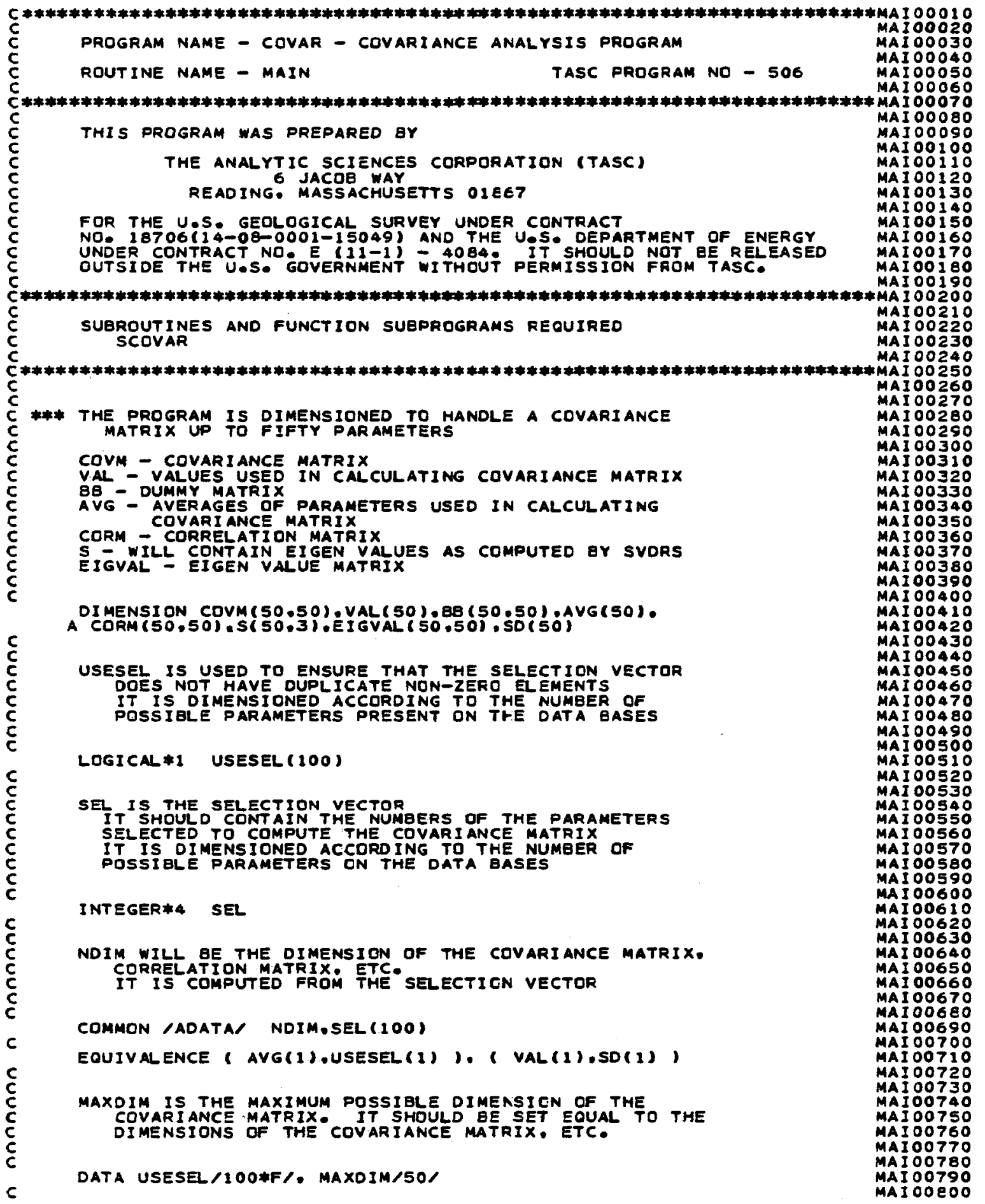




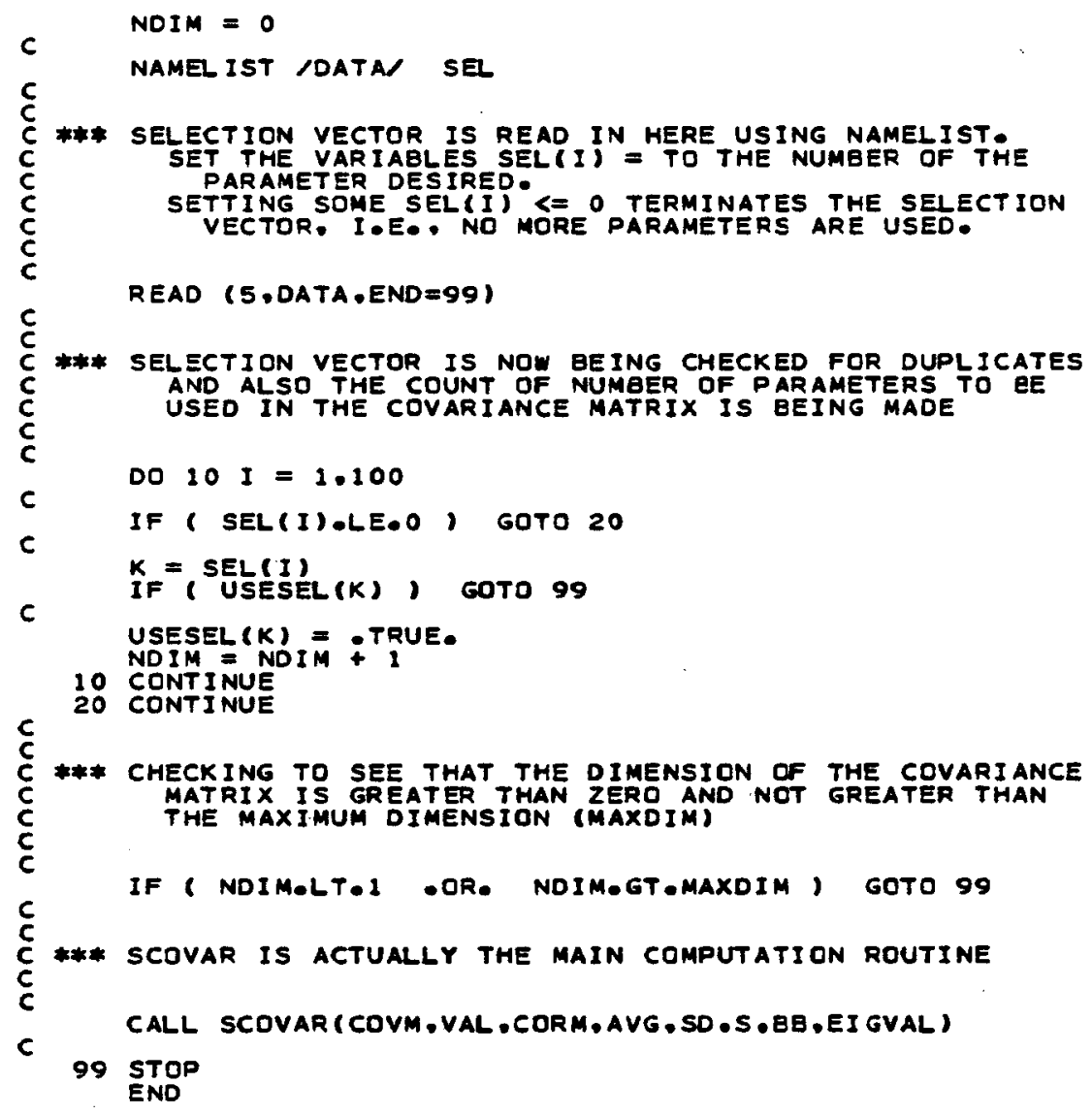

MAI 00810 MAIOOB20 MAI 00830

MAI 00840

MAJ 00850

MAI 00860

MAI 00870

MAI

MAL

MATOOO

MAI00900

MAI 00910

MAI 00920

MAI 00930

MAI 00940

MAI 00950

MAI 00960

MAI 00970

MAI 00980

MA

MAI

MAI

MAIO1010

MAI 01020

MAI 01030

MAIOIO40

MAIOI 050

MAI01060

MAIOI070

MAI 01080

MAI 01090

MAI 1100

MAIOIIO

MAL OI 110

MAIOII20

MAI O1130

MAIOI140

MAIOI150

MAIOI160

MAI 01170

MAIO1180

MAI 01190

MAI 01200

MAI

MAI O1210

MAI 01220

MAI 01230

MAI 01240

MAIO1250

MAI 01260

MAIOL270

MAIOI280 


\section{A. 2 SCOVAR}

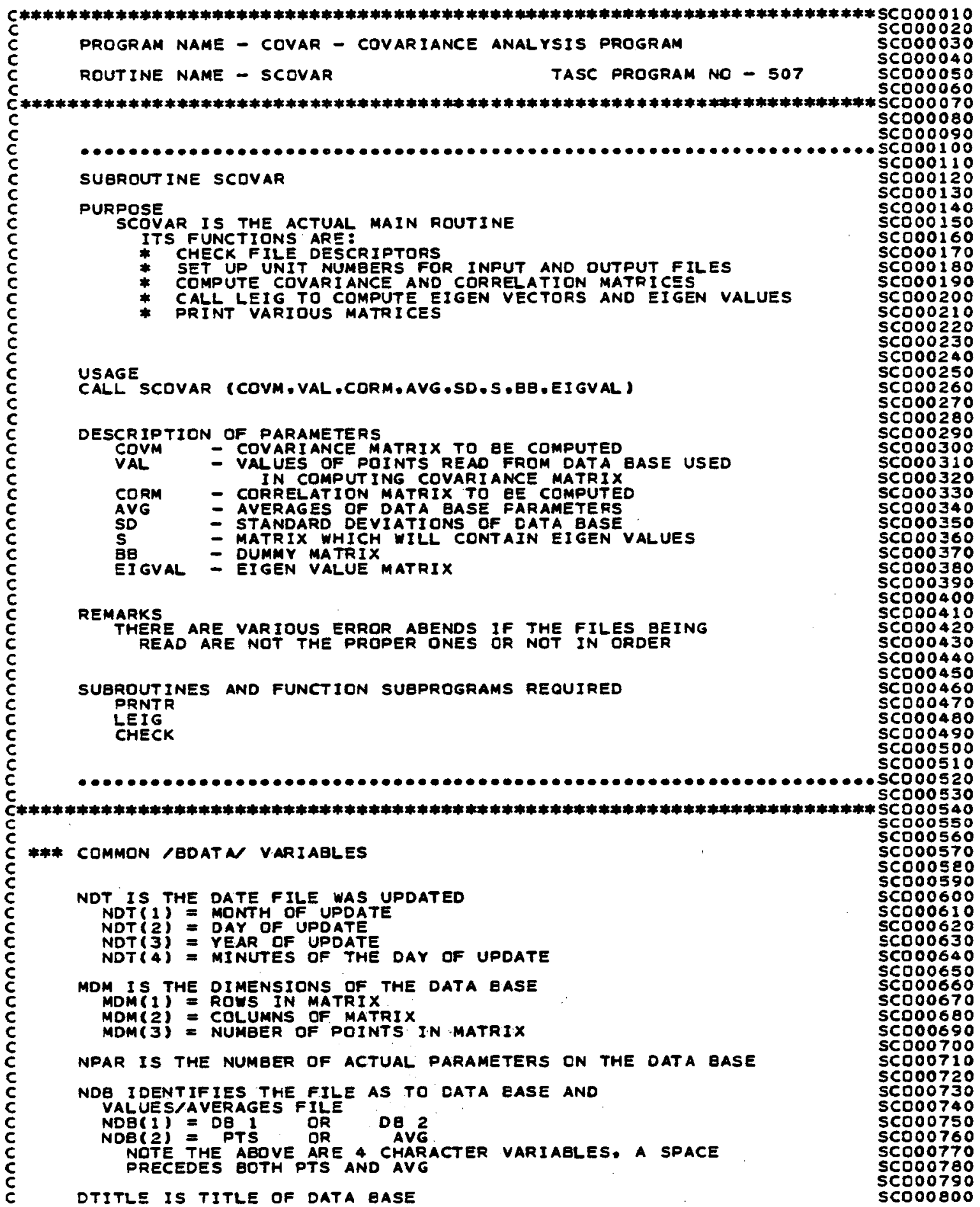




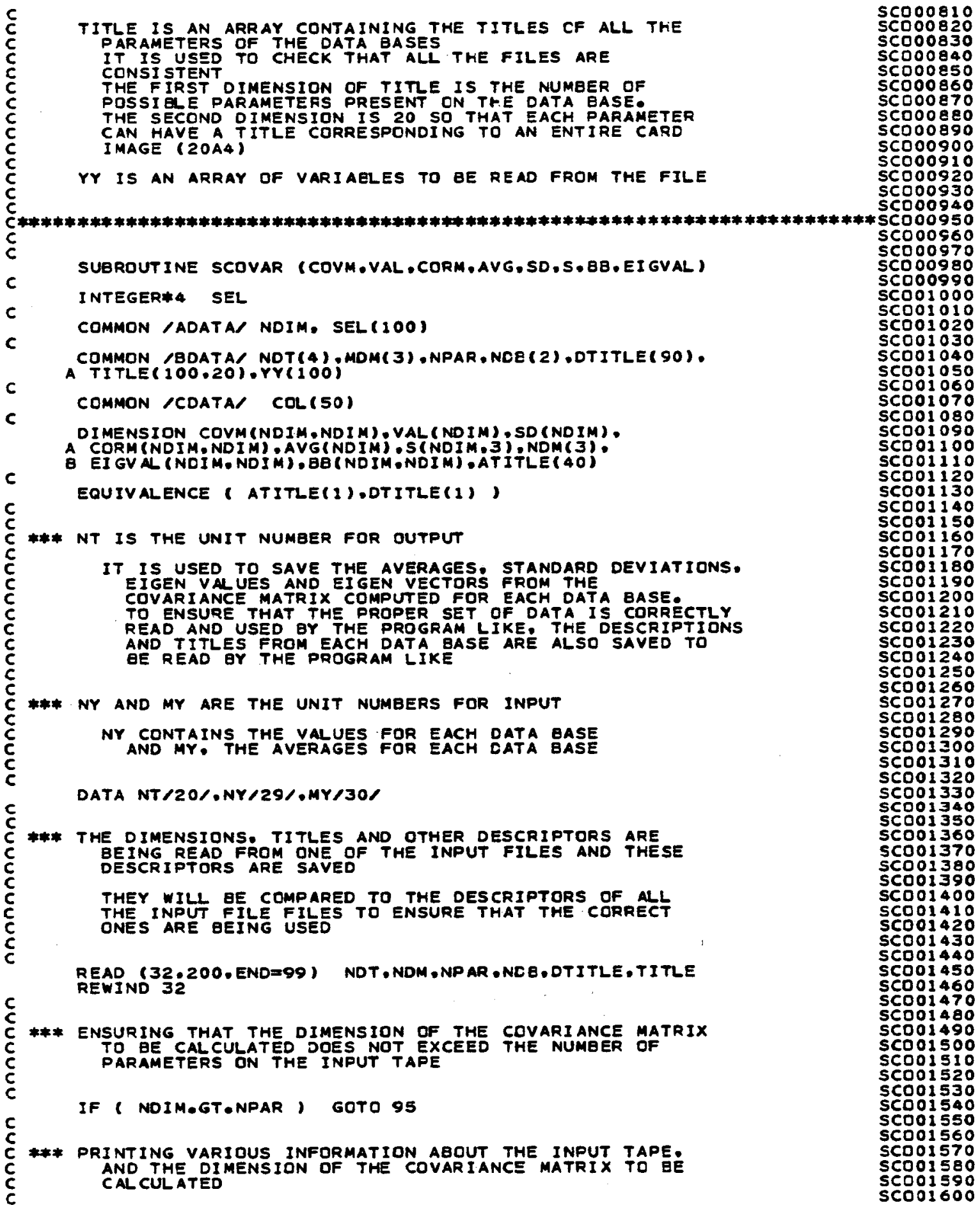




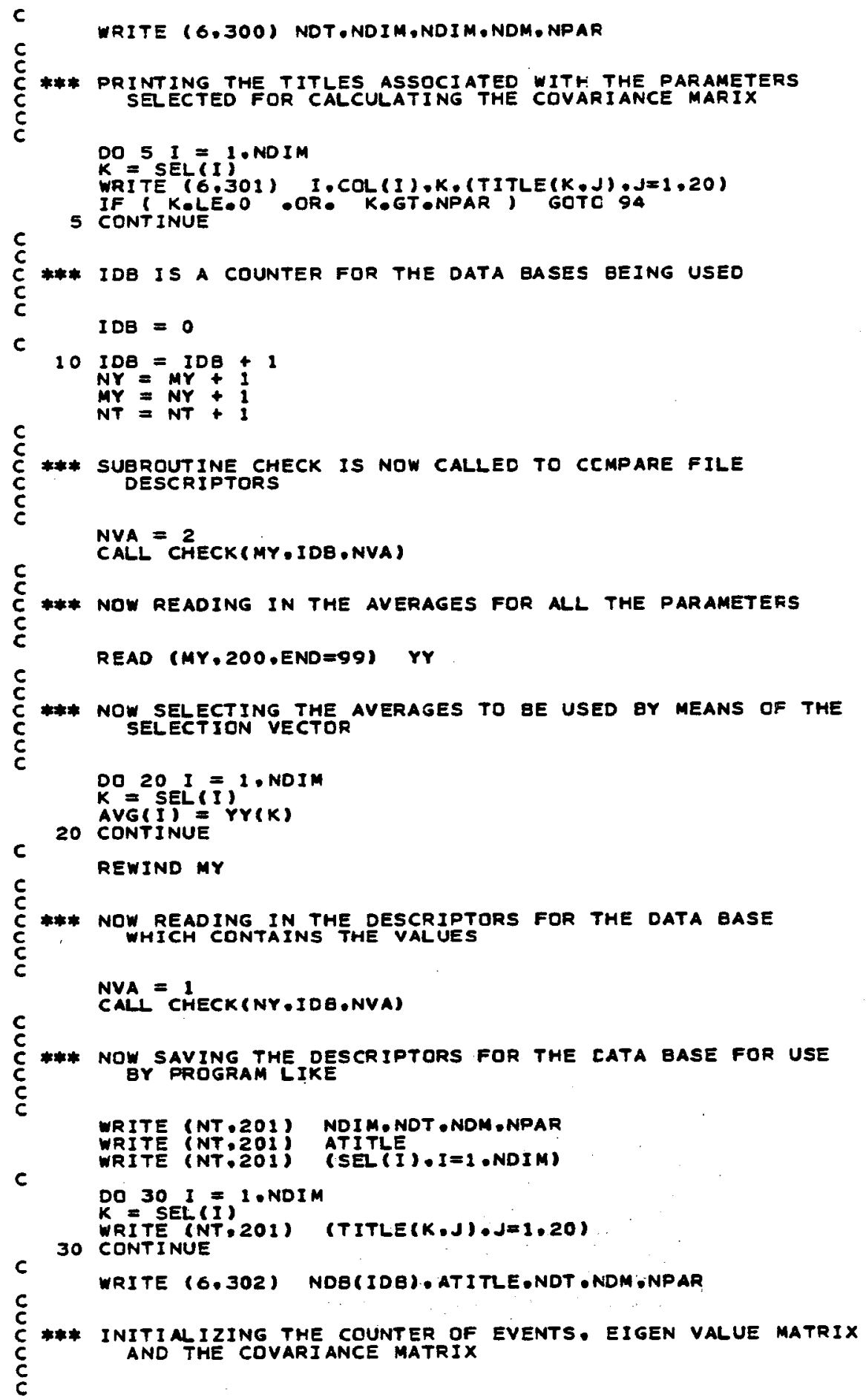

Sc001610 $5 \operatorname{coo} 1620$ SCO01630 5001640 Sco 1650 Scoul650 Scoj 1660 Sc001670 SCO01680 SCO01690 SCOO1700 Sco 01710 SC001720 Sc001730 scoo1740 Sc001750 Sc001750 SCOO1760 sco. 1770 SCO01780 SCO01790 SCO01800 SCO01810 SCO01820 SCO01830 SCO01840 Scool aso SCO01860 SCO01870 SCo.1880 SCO01890 SC001900 SCD01910 SCO01920 SCO01930 SC001940 SCool 950 SC001960 SCOOI 57 scool scrol sco01990 SC002000 SCO02010 SC002020 SC002030 $5 C 002040$ SC002050 SC002060 Sc002070 Scok Sc0 SCD02090 SCO02100 $5 \mathrm{CO} 2110$ SC002120 SCO02130 SCO02140 SCO02150 SCD02160 SCO02170 SCO02180 Sc002190 sco 200 SCO02210 sco sco02230 SCO02240 Sc002250 SC002260 SCD02270 SC002280 SC002290 Sc002300 $5 C 00233$ Sc002320 scor SCD02340 SCO02350 SC002360 SCO02370 SCO02380 SCO02390 $5 C 002400$ 
C NTOT =

DO $45 I=1$, NOIM

DO $40 \mathrm{~J}=\mathrm{I}$. NDIM

EIGVAL $(I, J)=0$

Covm(I.j) $=0$.

40 CONTINUE

c

c

50 READ (NY.200,END=70) YY

$\stackrel{c}{c}$

C *** NOW ONLY USING THE VALUES DETERMINED BY THE SELECTION VECTOR AND THE INDIVIDUAL VALUES EEING ACCEPTABLE

c

DO $55 I=1 . N D I M$

$K=\operatorname{SEL}(I)$

$Y A L(I)=Y Y(K)$

IF ( VAL (I).GT.1.E50) GOTO 50

SS CONTINUE

$A L(I)$ - AVG(I)

C \$\#\# NOW COMPUTING THE COVARIANCE MATRIX USING ONLY

C THOSE VALUES WHICH ARE LESS THAN OR EOUAL TO $1 . E 50$

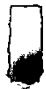

NTOT $=$ NTOT +1

C DO $651=1$. NDIM

$C \quad D O 60 \mathrm{~J}=I, N D I M$

C $\operatorname{COVM}(I \cdot J)=\operatorname{COVM}(I, J)+\operatorname{VAL}(I) * \operatorname{VAL}(J)$

C

60 CONTI NUE

c

CONTINUE

c

GOTO 50

*** covariance matrix now COMPUTED

70 CONTINUE

REWIND NY

C \#\#* NOW NORMALIZING THE COVARIANCE MATRIX

$T=N T D T-1$

DO $80 I=1$.NDIM

C DO $75 J=1 . N D I M$

c

Covm(I.J) $=\operatorname{Covm}(I \cdot J) / T$

75 CONTINUE

c

CONTINUE

*** NOW COMPUTING THE STANDARD DEVIATIONS FROM THE CDVARIANCE MATRIX

DO $85 I=1$ NDIM

c

85 SDII) $=$ SORT (COVM(I,II)

* ** NOW COMPUTING THE CORRELATION MATRIX FROM THE

c COVARIANCE MATRIX AND THE STANDARD DEVIATIONS

DO $90 I=1$. NDIM

SC002410

$5 C 002420$

SCO02430

$5 C 002440$

$5 C 002450$

SCO02460

SCO02470

SC002480

SC002490

$5 C 002500$

Sc002510

Sc002520

5005

sco.

Sco02540

SCO02550

SCD02560

Sco02570

SC002580

SC 02590

SC002600

SC002610

$5 \mathrm{C002620}$

SC002630

500260

5002650

Sc0.2650

SC002660

SC002670

SC002680

SCD02690

SCO02700

SCD02710

SC002720

SC002730

$5 \subset 002740$

sc002750

5c0.2750

scou

sco

SCO02780

Sca02750

SCD02800

SCO02810

SC002820

SCO02830

SCO02840

$5 C 002850$

5c002860

sco02870

Sc0.2870

$5 c 00280$

sco02890

$5 C 002900$

SC002910

5C002920

SCO02930

SCD02940

scoo2950

SCO 02960

SC002970

sco02980

sco02900

ร

scoso

Sc0

SCO03020

Sc003030

$5 C 003040$

5c003050

Sc003060

SC003070

SC003080

SCO03050

SCO03100

Sco03110

Sco03120

5003130

SCO

SCO03140

sc003150

SC003160

$5 C 003170$

SCO03180

Sc003190

SC003200 


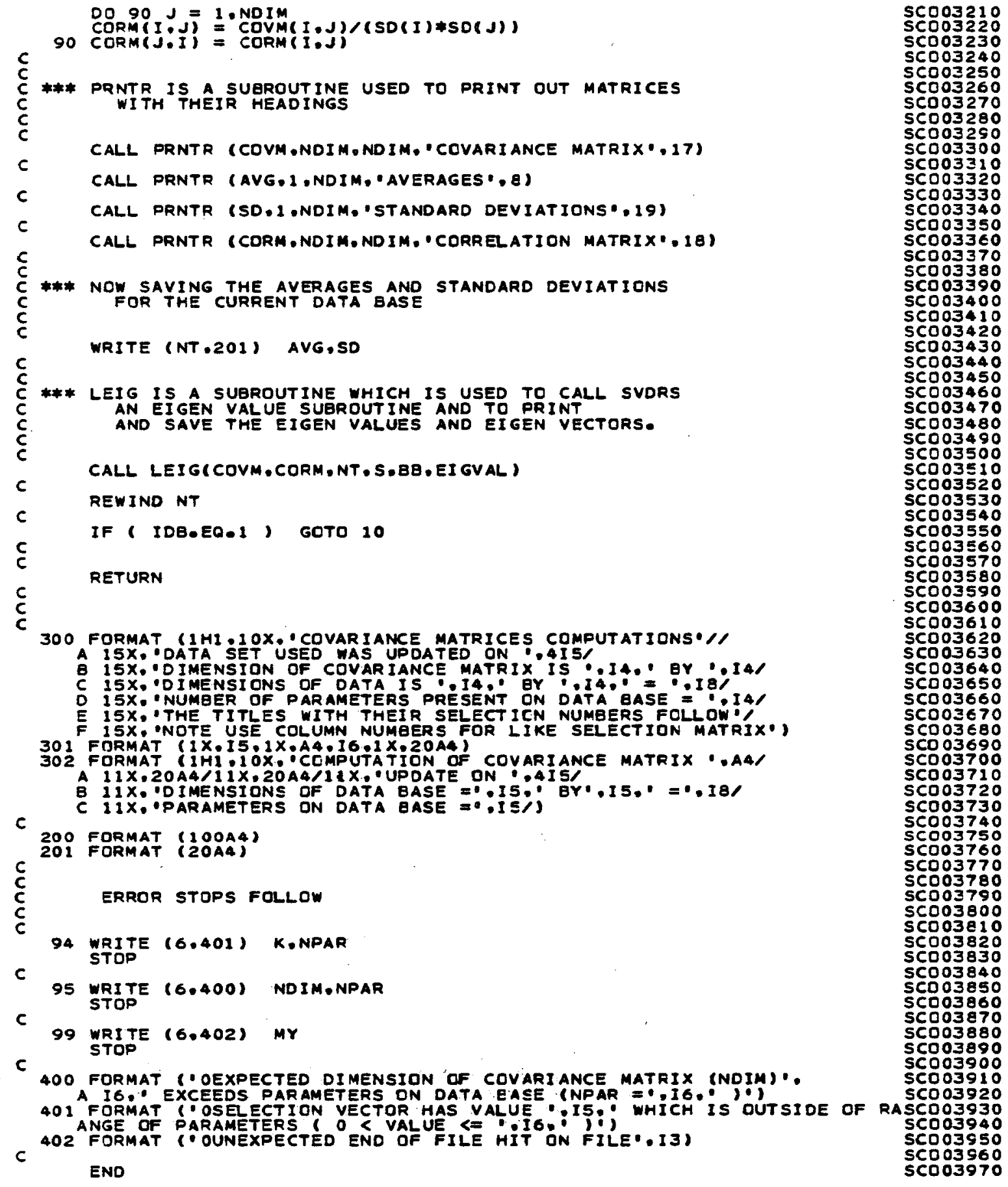




\section{A. 3 LEIG}

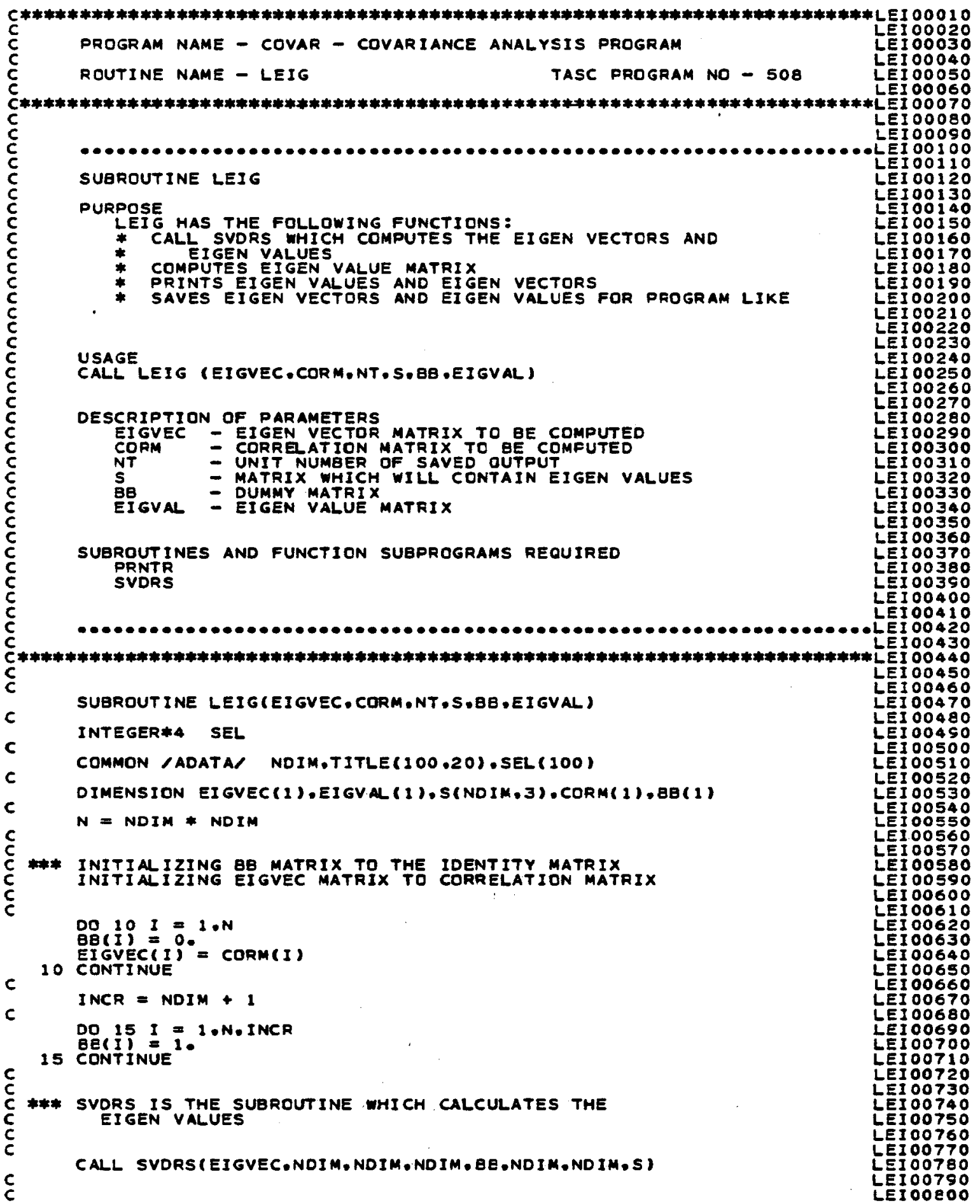




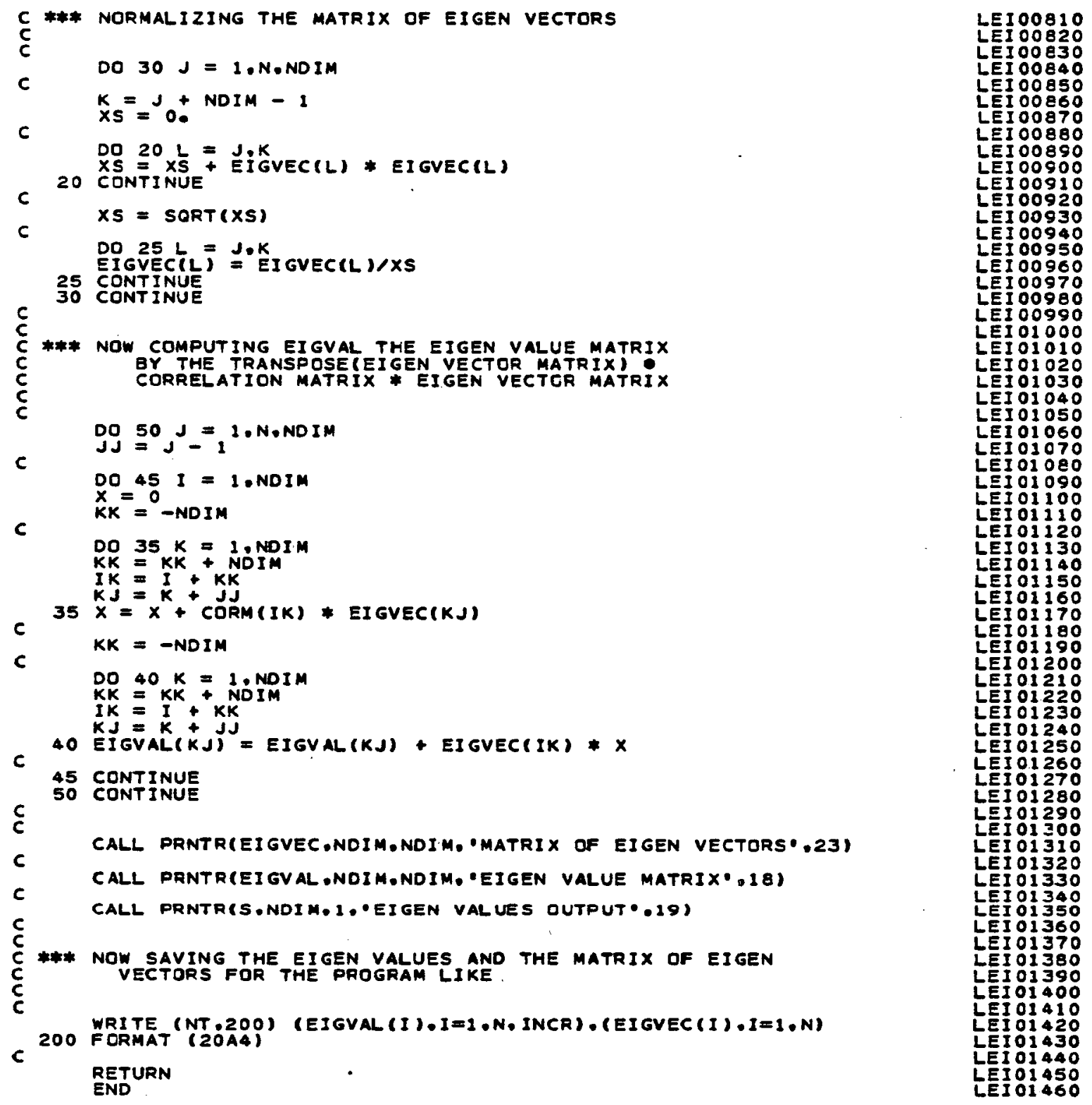




\section{A. 4 PRNTR}

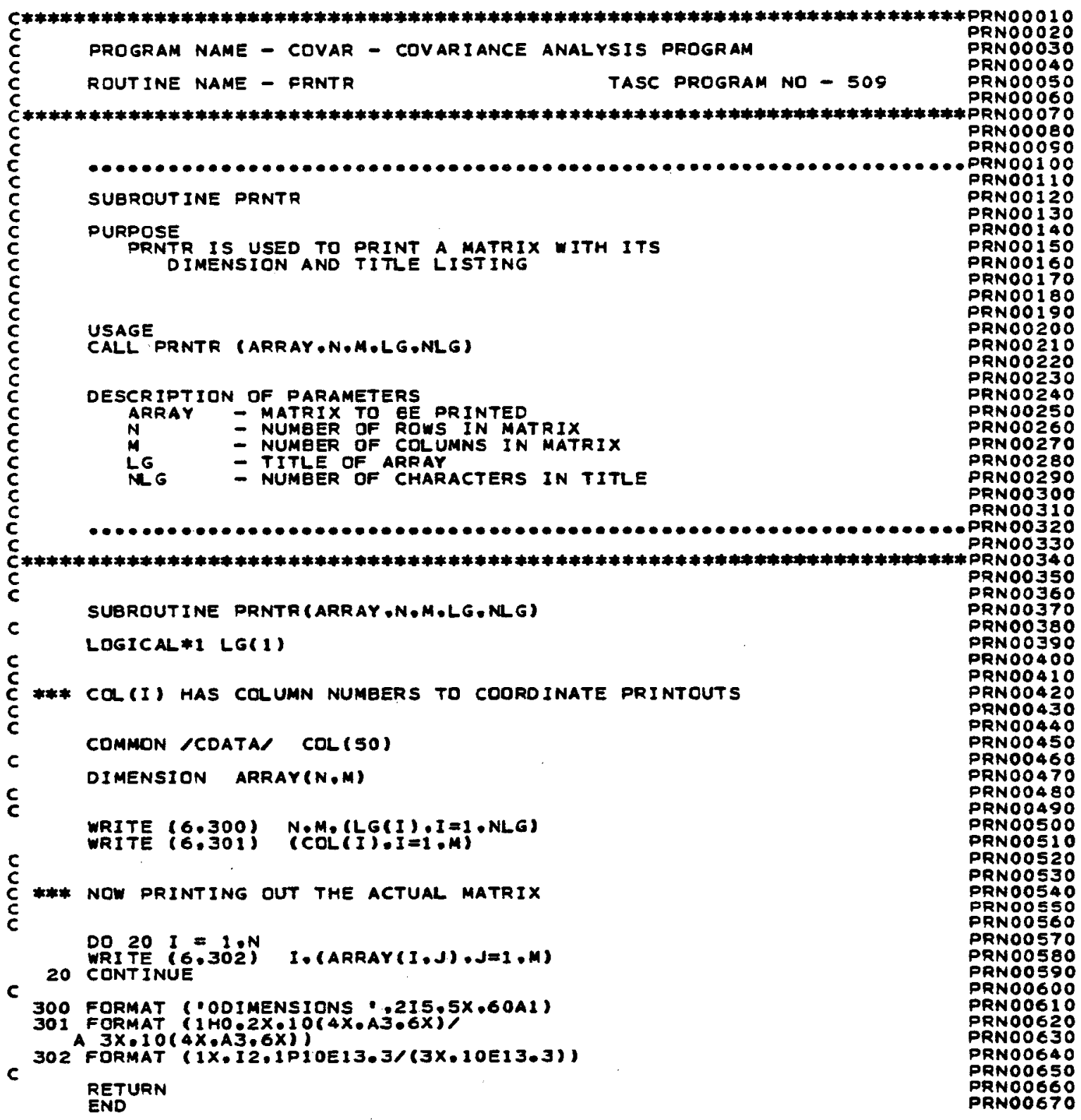




\section{A. 5 CHECK}

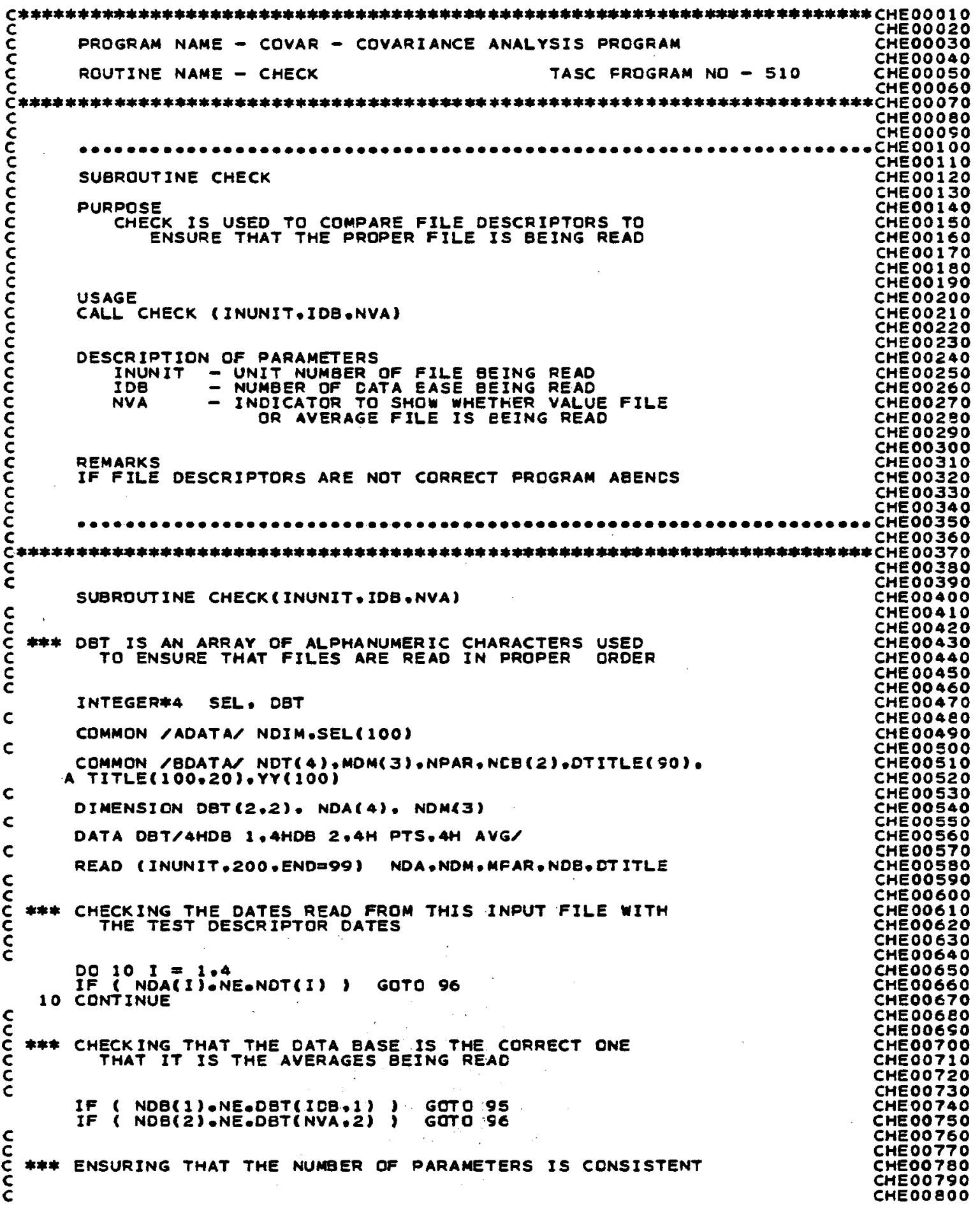




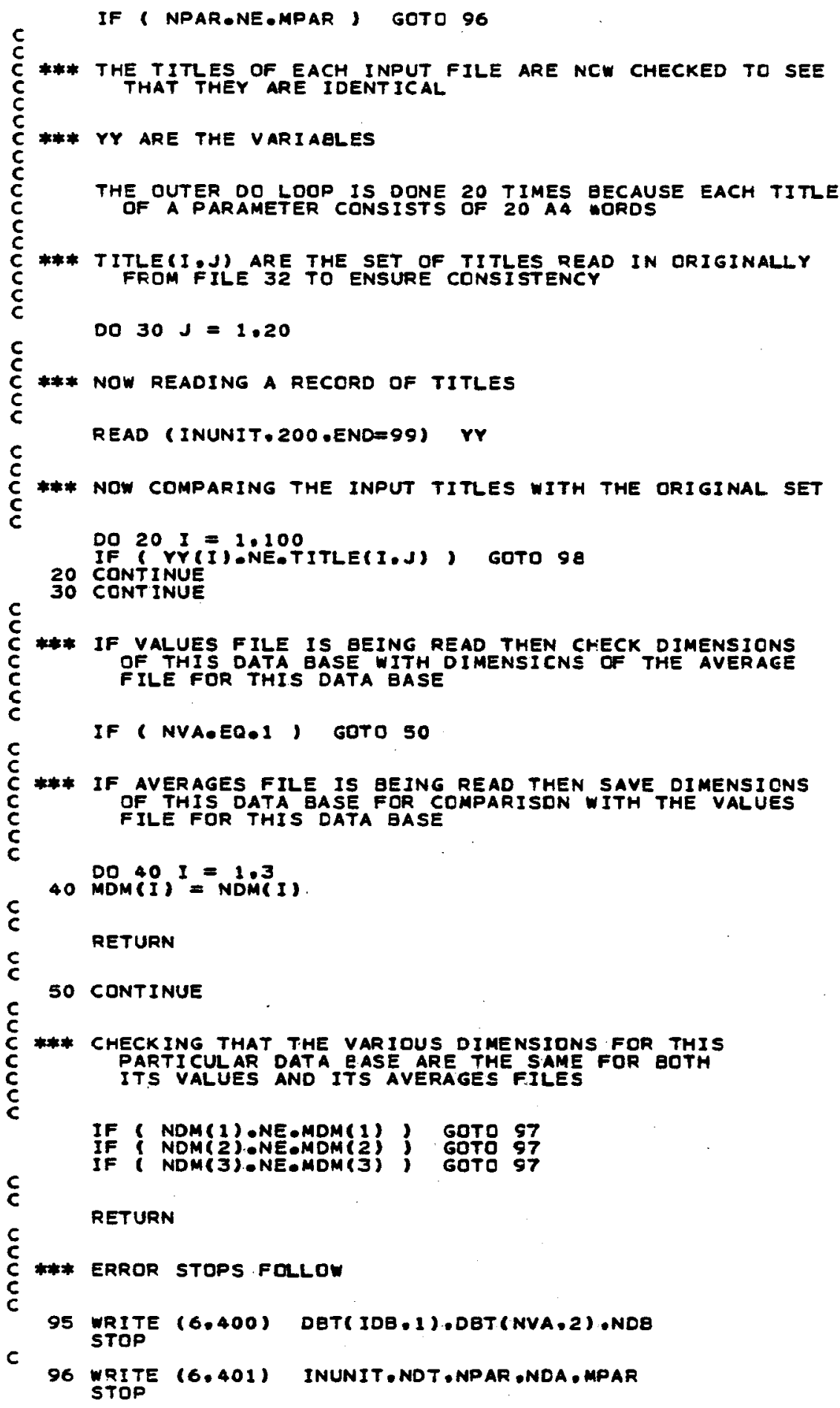

CHEO0810 CHE 00820 CHE00830 CHEOO840 CHE 00850 CHEO0860 CHEO 870 CHE CHEO CHEOO890 CHEOOSOO CHEO0910 CHE 00920 CHE 00930 CHEO0940 CHE00950 CHEOO960 CHE00070 CHEOOSO CHEOOO CHEOO990 CHEO1000 CHEO1010 CHEO1 020 CHEO 1030 CHEO104O CHEO1050 CHEO 060 CHE 01070 CHEO1 080 CHEO1080 CHEOI090 CHEOI100 CMEOI11O CHEO1120 CHEO1130 CHEOI 140 CMEOI150 CHE01160 CHEOI 170 CHEO1180 CHEOI100 CHEO CHEO1200 CHEO1210 CHE01220 CHE01230 CHE01240 CHE 01250 CME 01260 CHE0 1270 CHEOI280 CHE 01290 CHE CHEO1300 CHE CHEO1320 CHE 01330 CHE 01340 CHEO1350 CHE 01360 CHEO1370 CHE 01380 CHE 01390 CHEOI 400 CHE 01410 CHEO1 CHEO 420 CHED CHE 1440 CHEO1450 CHE01460 CHE 01470 CHE 01480 CHE0 01.490 CHE01500 CHE 01510 CHE01520 CHEO1530 CHED CHEO1540 CHEOI560 CMEO1570 CHEO1580 CHEO1590 CHE01600 
c

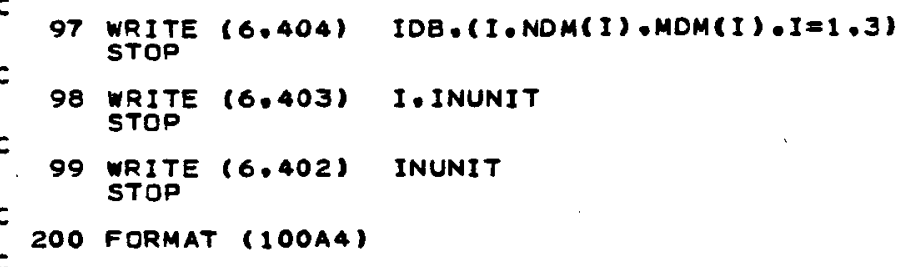

99 WRITE $(6.402)$ INUNIT STOP

200 FORMAT (100A4)

$c$

$C$

$c$

400 FORMAT (POFILE: I3: IS THE WRONG FILE:'

FORMAT (HOON FILE :A4:1X.AATHER THE OATES OR THE NUMBER OF PARAMETCHEO 1750 AERS DO NOT MATCH THOSE OF STANDARDS (FILE 32 ) $\%$

B12X, DATES: $25 X_{*}$ 'NUMBER OF PARAMETERS'

C4X. IFILE 32\%313.15.20X.13\% INPUT FILE'.3I3.15.20X.13)

402 FORMAT ( OUNEXPECTED END OF FILE HIT ON FILEI.I3)

403 FORMAT (:OPARAMETER. I $4 .{ }^{\circ}$ DOES NOT HAVE THE SAME TITLE ON FILE',

403 FORMAT AND THE STANDARDS FTLE 32 \%

$404^{A}$ FORMAT (OODIMENSIONS FOR VALUES AND AVERAGES FILES ON*

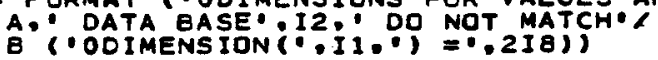

c

END

CHE 01610

CHE 01620

CHEOI 630

CHEO 1640

CHEO 1650

CHE 01660

CHEO1670

CHEO1680

CHEO1690

CHEO 700

CHEO1700

CHEO

CHE01730

CHEO1760

CHEOI 780

CHEOI 790

CHE 01800

CHE O1810

CHEO1810

CHEO1820

CHEOLO

CHEO1840

CHE 01850

CHEOI 160 


\section{A. 6 SVDRS}

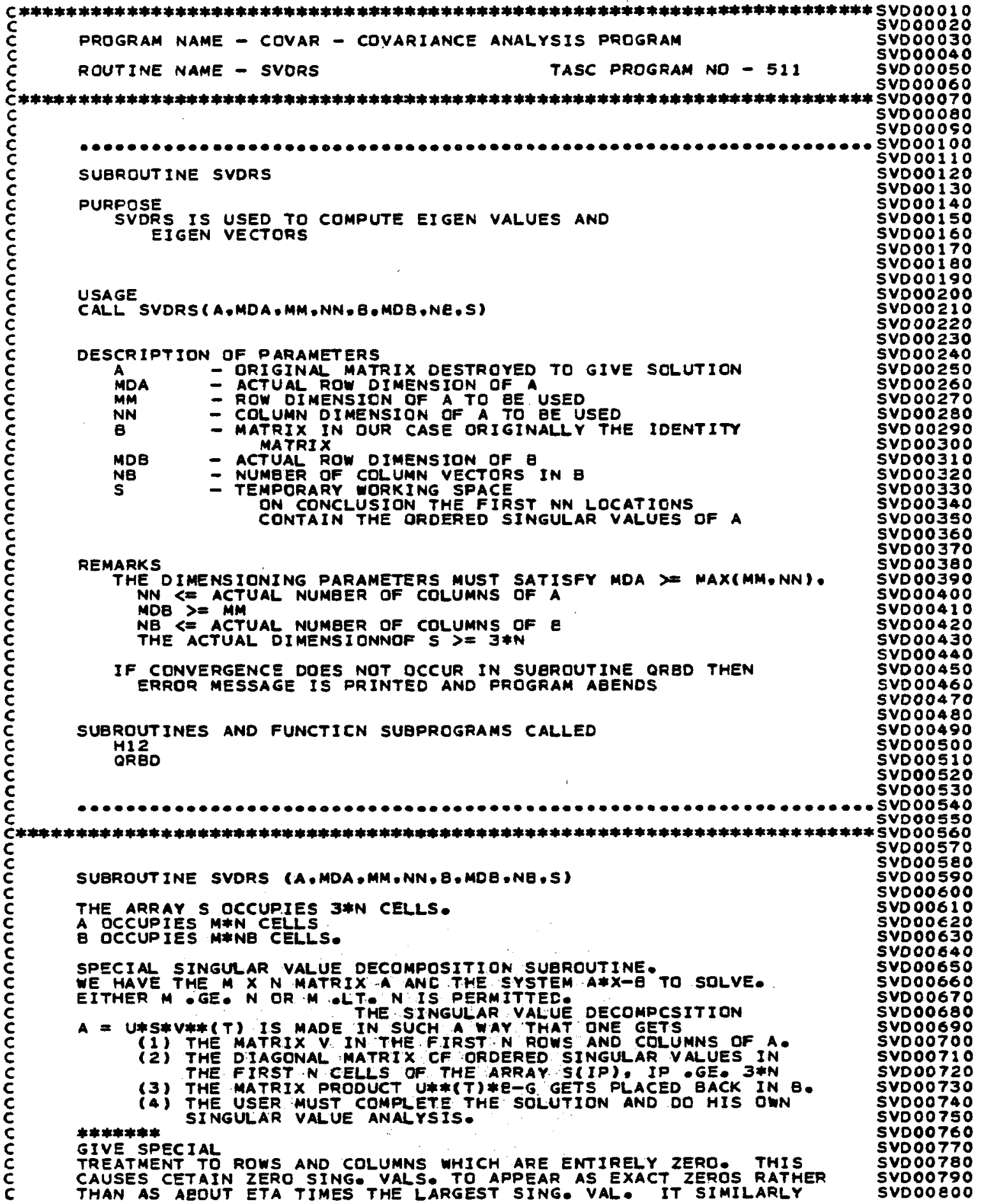




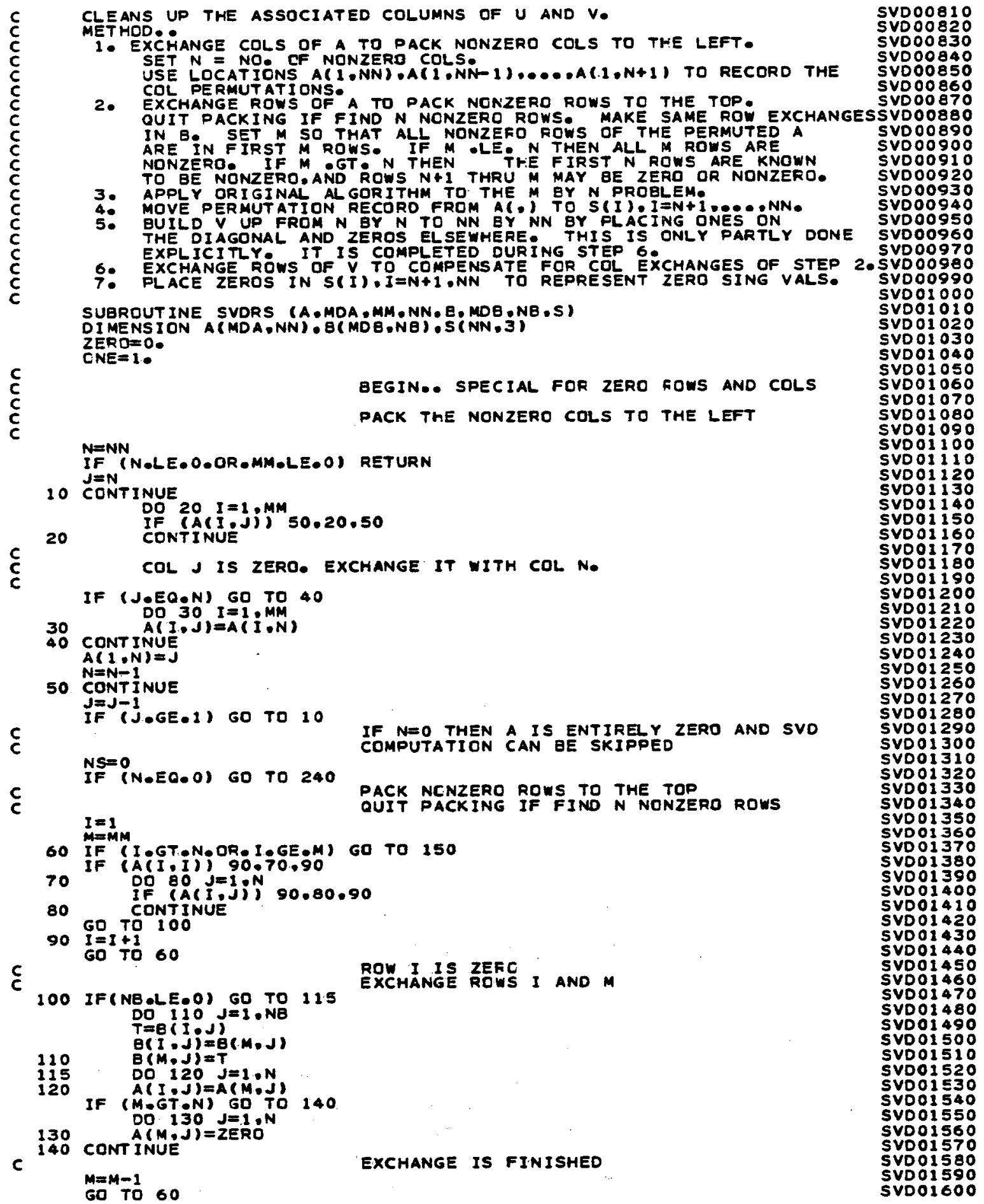




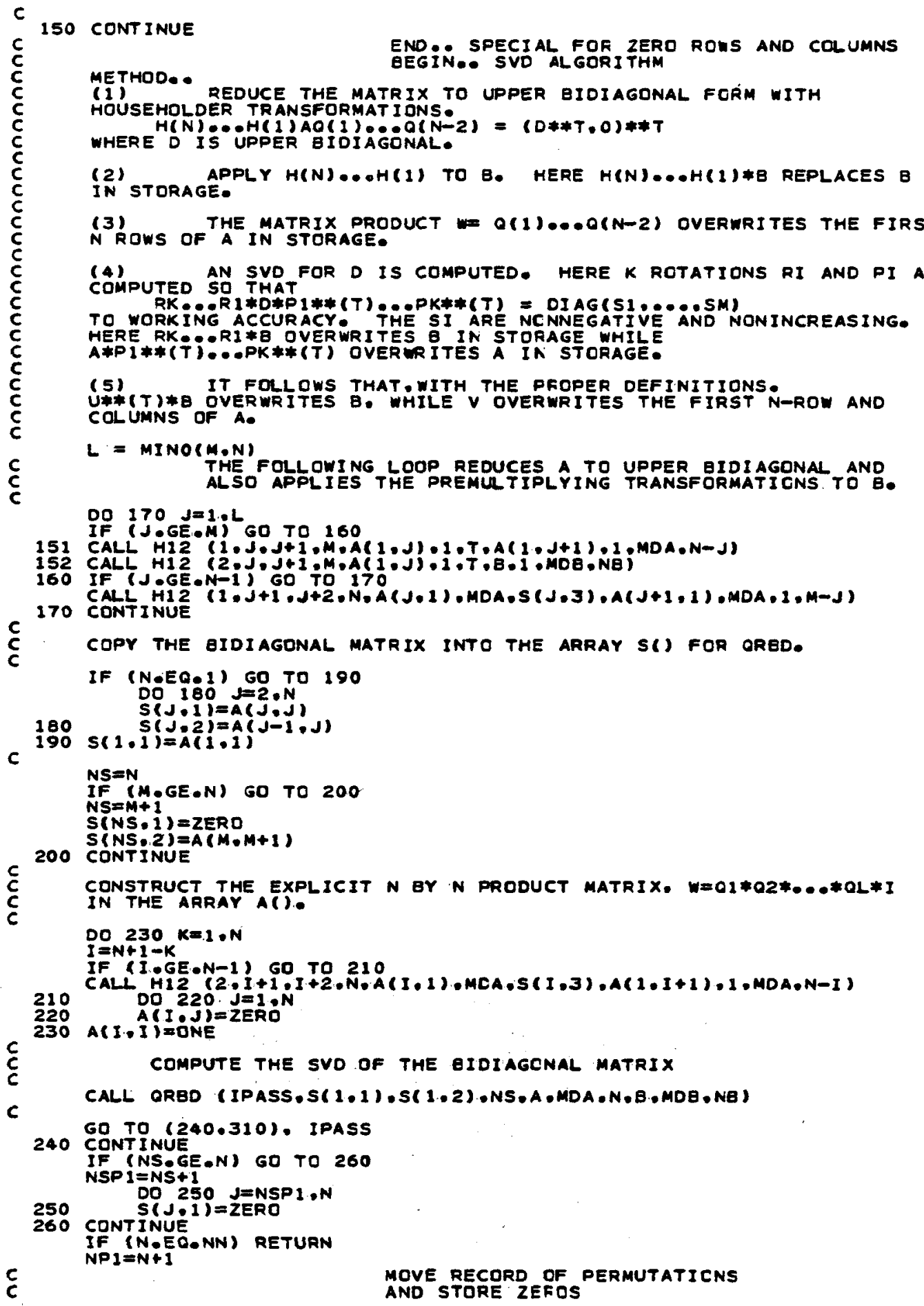

SVo01610 SVDol 62 SVD01630 SVD01640 SVD01650 SVD01660 SVD01670 SVD01680 SVD01600 SVDO1690 SVD01700 SVDOI? SVDo1720 SVD01730 SVDO1740 SVDOI 750 SVD01760 SVD01770 SVDO 778 SVD01790 SVDo1 800 svooj SVDOI SVDO1 820 SVD01830 SVDO1840 SVD01850 SVD01860 SVDO1870 SVD01880 SVD01890 SVDO1900 SVD01910 SVD01920 sVD01930 SVDOI 40 SVDO1940 SVo019s0 Svol960 svol SVO01980 SVD01990 SVD 02000 SVD02010 sVo02020 sV002030 SVD02040 SVD02050 SVDozoso SVD.2060 Svó SVO2080 SVD 02090 SV002100 SVD02110 SVD02120 SVD02130 SVO021 140 SVD02150 SVD02160 sพ002170 SVDo2 180 SVDO2190 SVDO2190 SVDO2200 SVDo2 SVo.2220 SVD02230 SVO02240 SVD02250 SVD 02260 SVD02270 SVD02280 5VD02290 svo02300 SVD02310 svo02320 Svo.2330 SVD02330 svo02340 SVD02350 SVD02360 SVD 02370 SVD 02380 SVD02390 SVD 02400 


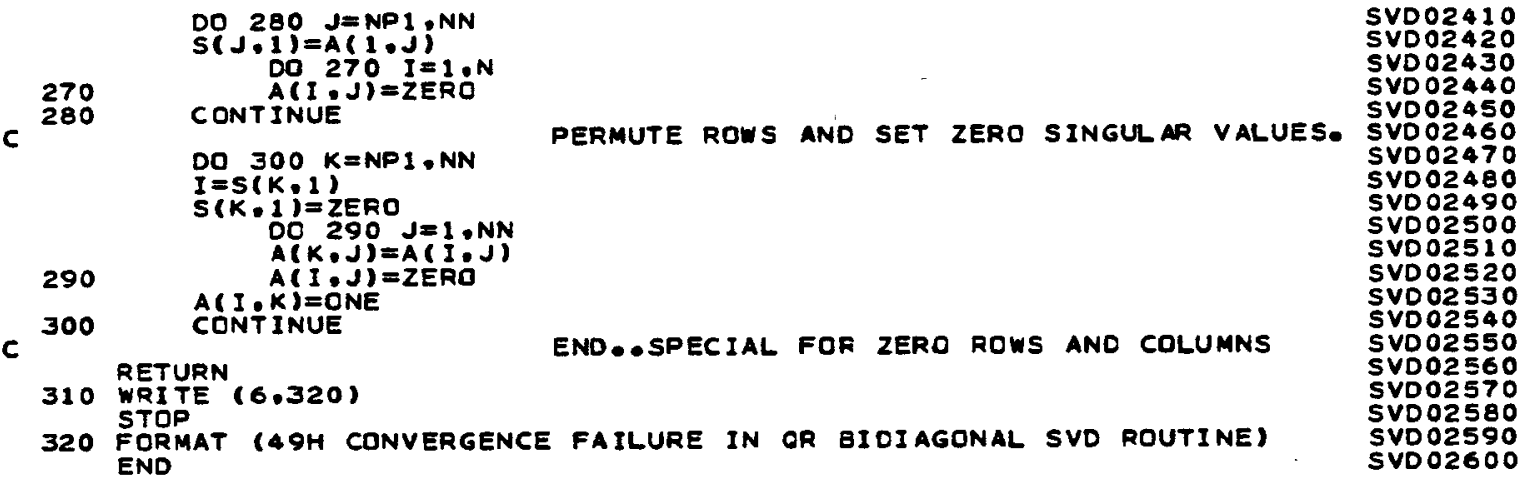




\section{A.7 QRBD}

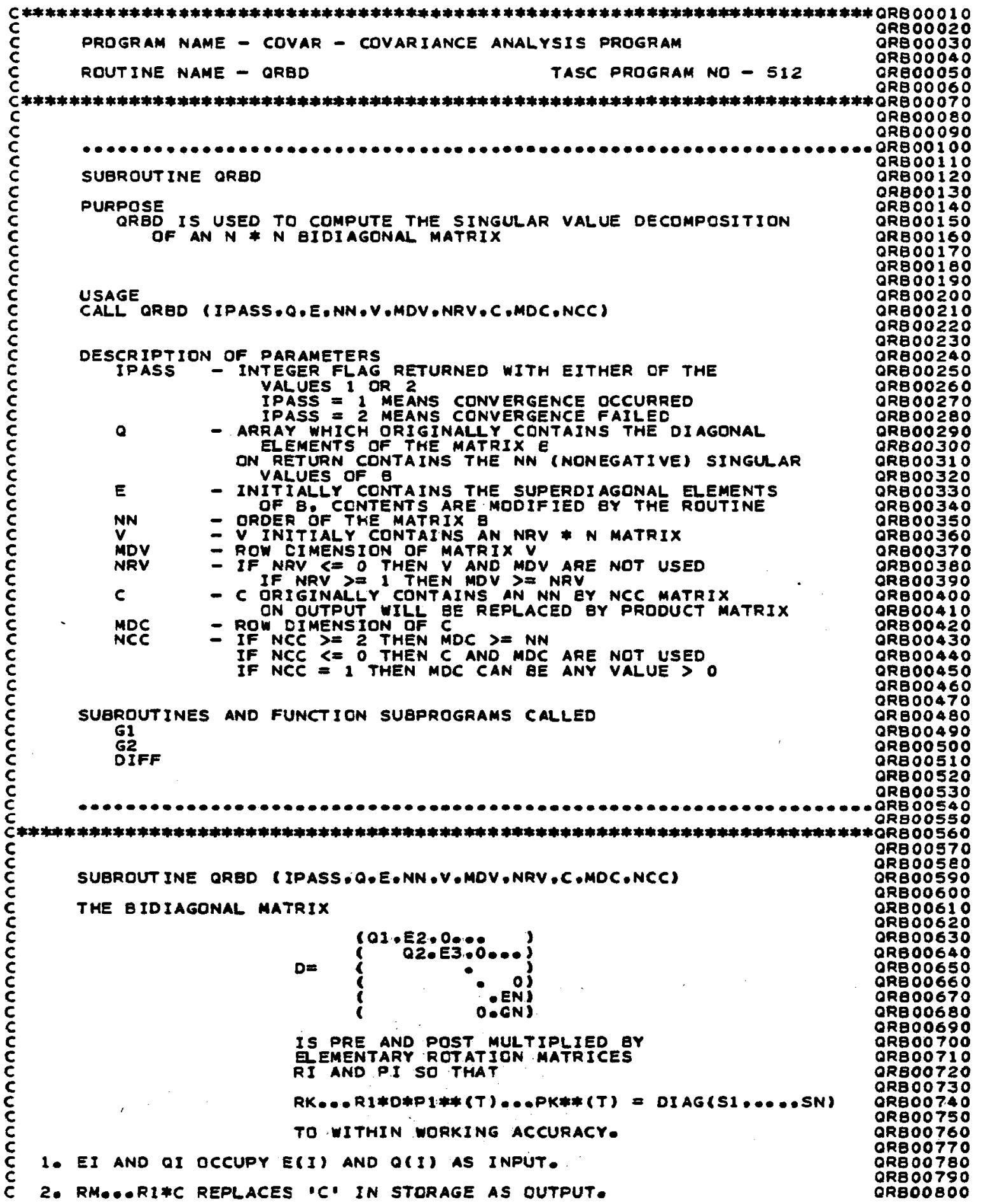




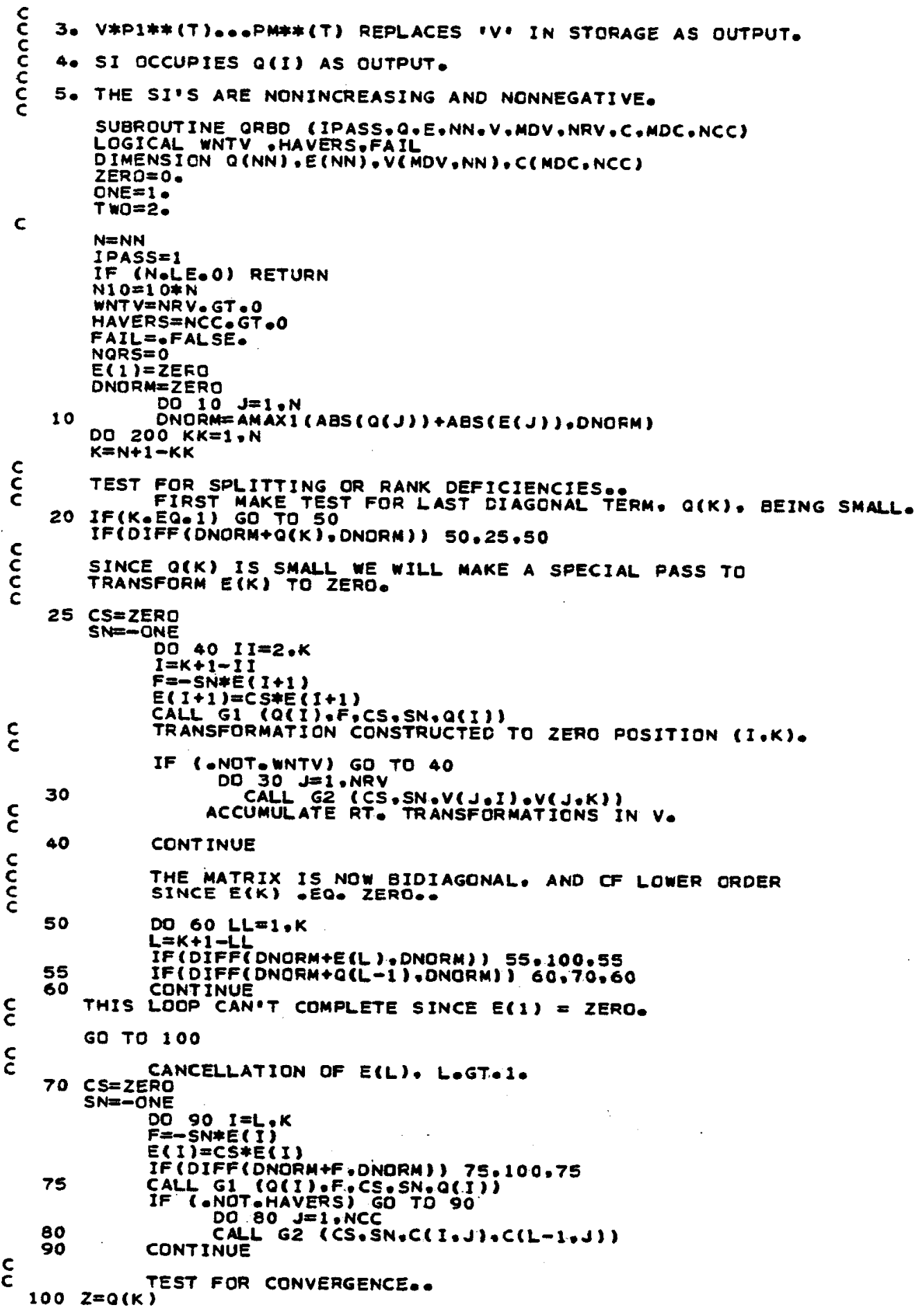

OR日00810 QRBOOB20 ORB 00830 ORBOO 840 ORBOO850 ORB 00860 ORBOOE70 ORBOOB80 QR日O OR日OOB9 ORB OOOO ORB OO910 QRBOO920 ORBOOS30 ORB OO940 ORB 00950 QRB 00960 OR800970 ORB 00980 ORB O0990 OREO1000 ORBO1010 ORBO1:1\% ORBO1020 ORBO1 030 OR日O1040 ORBO1050 ORBO1060 ORBO1070 ORBO1 080 QRBOI090 ORBOIIOO ORB O1110 ORBO1120 ORBOII30 ORBO1130 ORBO1140 ORB 1150 ORBOI 160 ORBO1170 ORBO1180 QRB 01190 OREO1 200 ORBO1210 ORBO1220 ORBO1230 OR日OI240 OR日OI250 ORBO1250 OR日O1260 ORB ORBO1280 GRBO1290 QRBO1300 QR日OI310 QREO1320 QRB 01330 RRBO1340 QRBO 1350 ORBO1360 QR801370 ORBO1380 OR日 1390 R日 01400 ORBO1400 ARBO1410 DRBO 430 ORBO1430 QRBO1 440 QRBO1450 OR日01460 ORBO14TO ORBO1480 ORB 01490 ORE01500 ORBO1510 ORBOI520 OR801530 ORBO1530 OR日01550 DR ORBO1560 OR日O1570 OR日O 1580 ORBO1590 ORE01600 


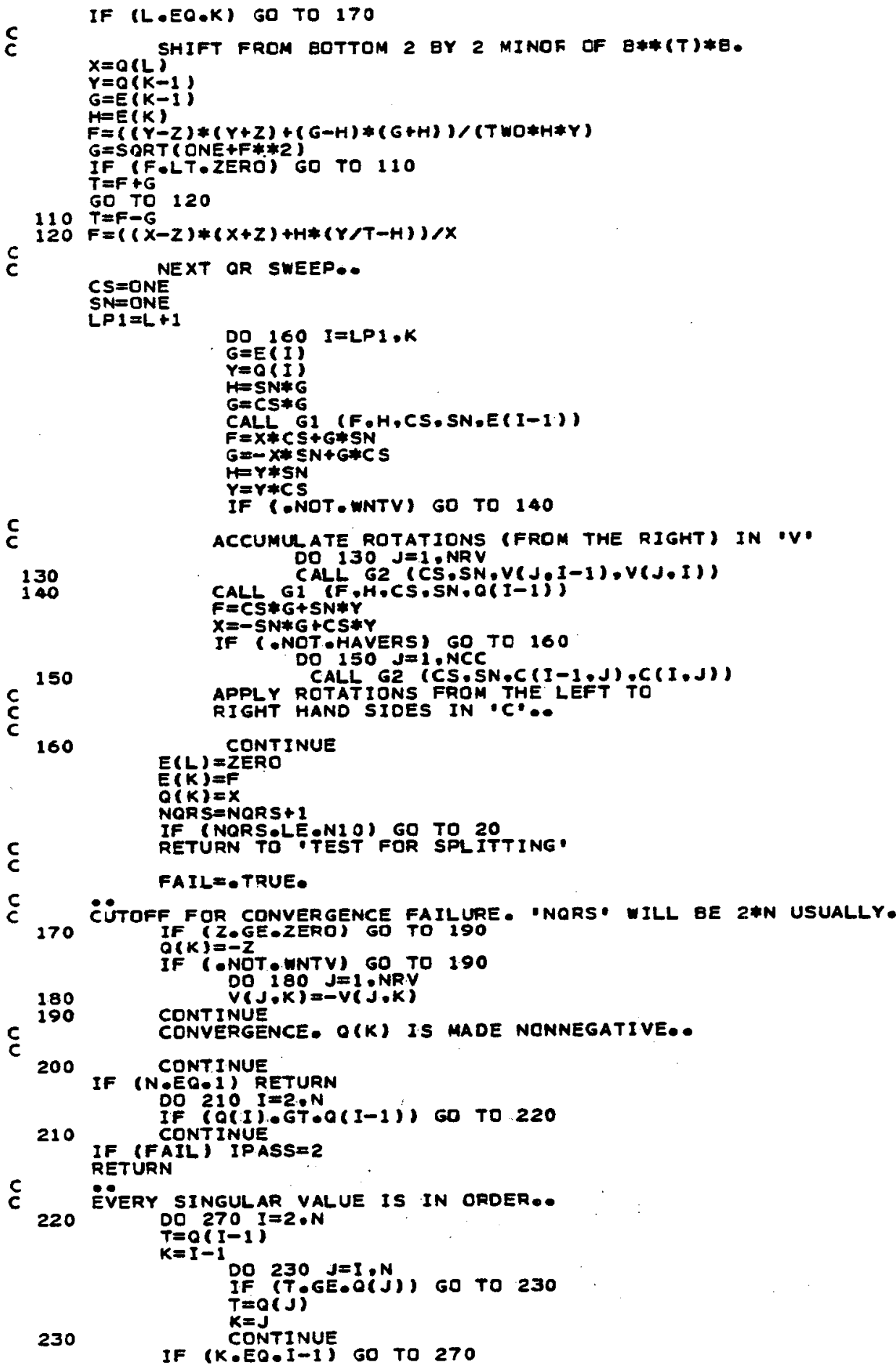

ORB01610

QRBO1620

QRBO1630

ORBO1640

ORBO1650

ORB01660

OR日01670

ORBO1680

ORBO 1690

QR日 01700

GRB

ORB

ORBO1720

ORBO1730

QRBO1740

OREO1750

ORB 01760

ORBO1770

QRB 01780

ORB 01790

OREOI 180

ORBO1810

QReo1 820

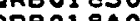

ORBO1840

ORBO1E50

RBO1860

QRBO1E70

ORBO1880

ORB 01 e9O

ORBO1900

RRB 01910

ORBO1920

QRBO1930

ORBO1940

RBO1950

OREO1960

ORBO1970

ORBO1980

ORBOI990

ORBO2000

ORE02010

ORBO2020

QRB 02030

RR日02040

QR日 02050

ORB02060

ORBO2070

ORB02080

ORB02090

ORB02100

ORBO2110

QRBO2120

ORB02130

作

ORBO2140

ORBO2150

CRBY 170

ORBO2 170

ORB

ORB02190

ORE02200

ORB02210

ORE02220

ORB 02230

ORB02240

ORB 02250

ORBO2260

ORBO2 70

ORBO2270

ORB02280

ORBO2290

ARB02300

QRB 02310

ORE02320

QRB 02330 ORB 02340 OR802350 QRB 02360 ORB 02370 ORBO230 AR日O230 ORBO2400 


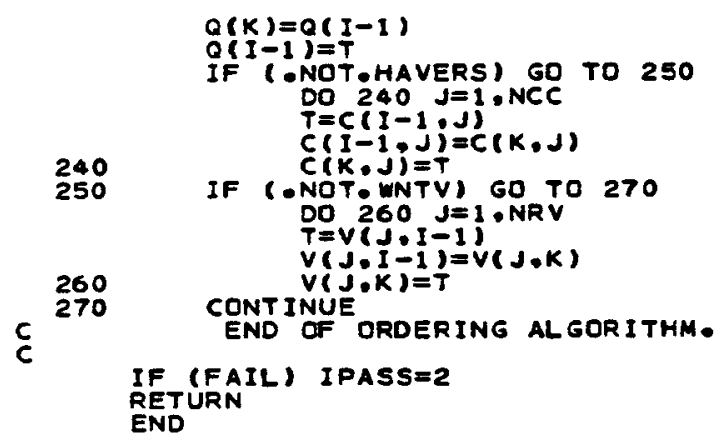

ORB 02410 QRB 02420 ORB 02430 OR日02440 ORBO2450 ORB 02460 ORE02470 ORBO2480 ORBO2490 ORB 02500 ORBO2510 QRB 02520 ORB 02530 ORB (1) OR日O2550 ORBO2560

ORBO2 580

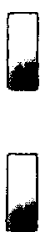
RETURN 


\section{A. $8 \quad \mathrm{H} 12$}

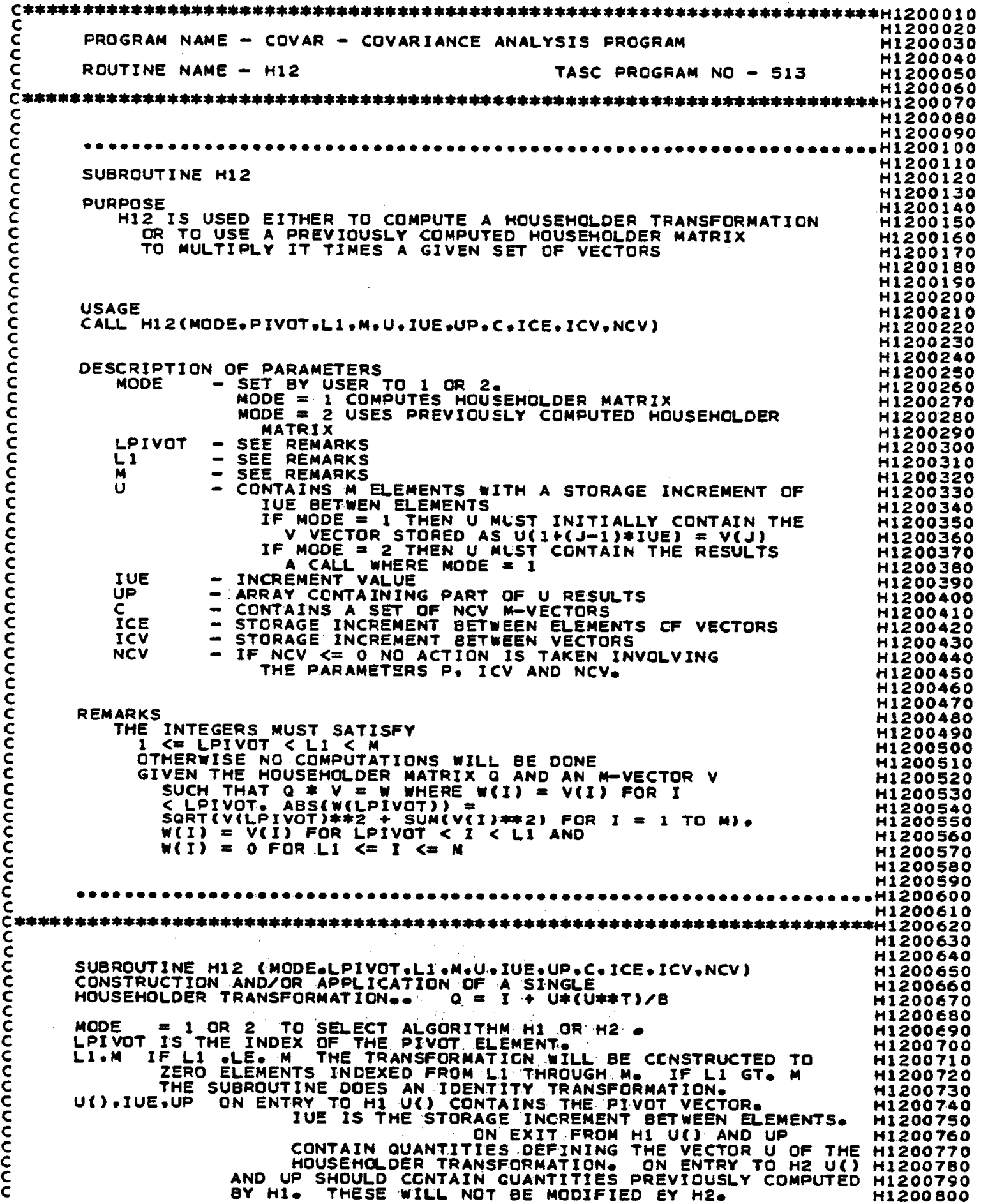




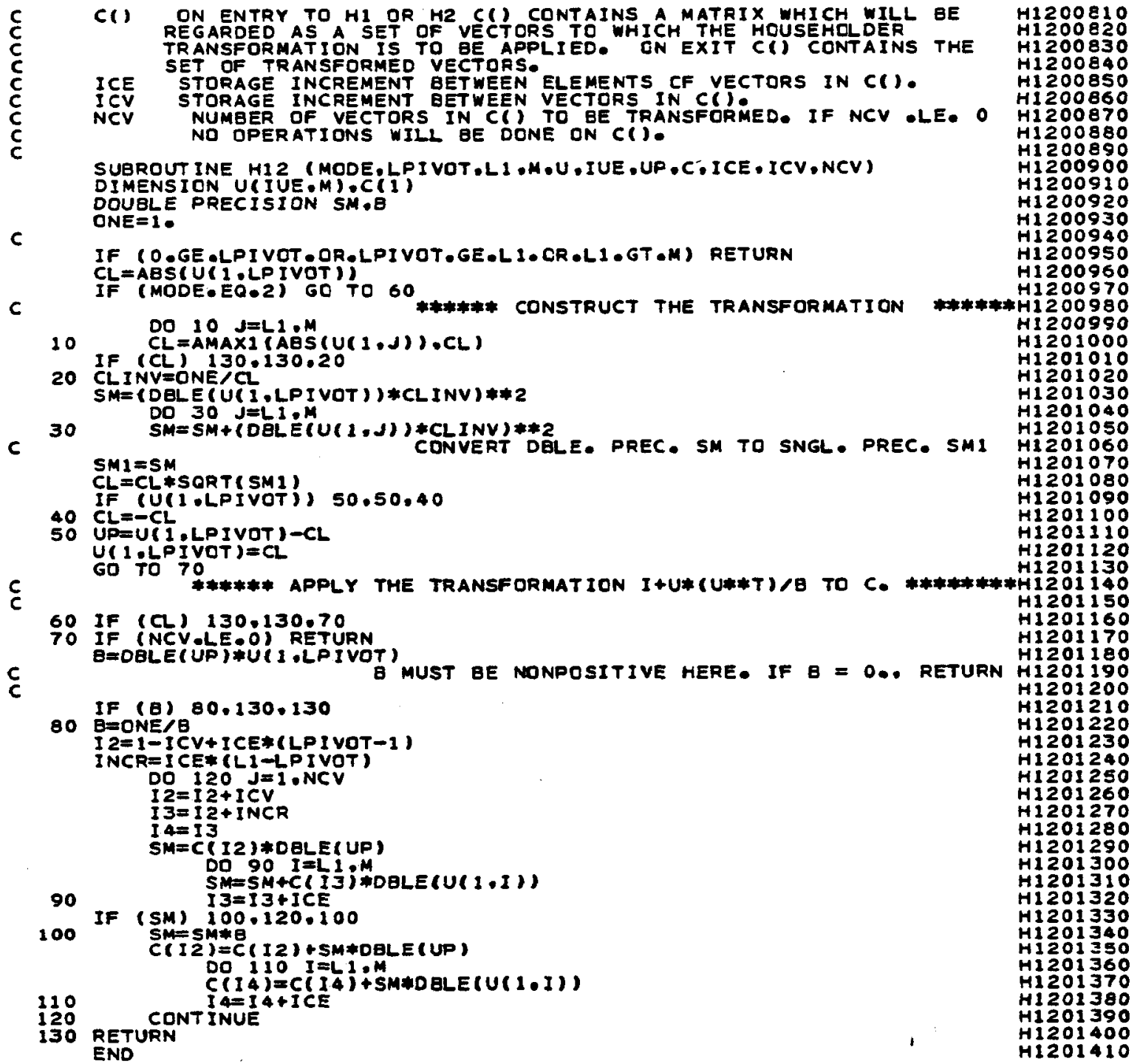




\section{A.9 G1}

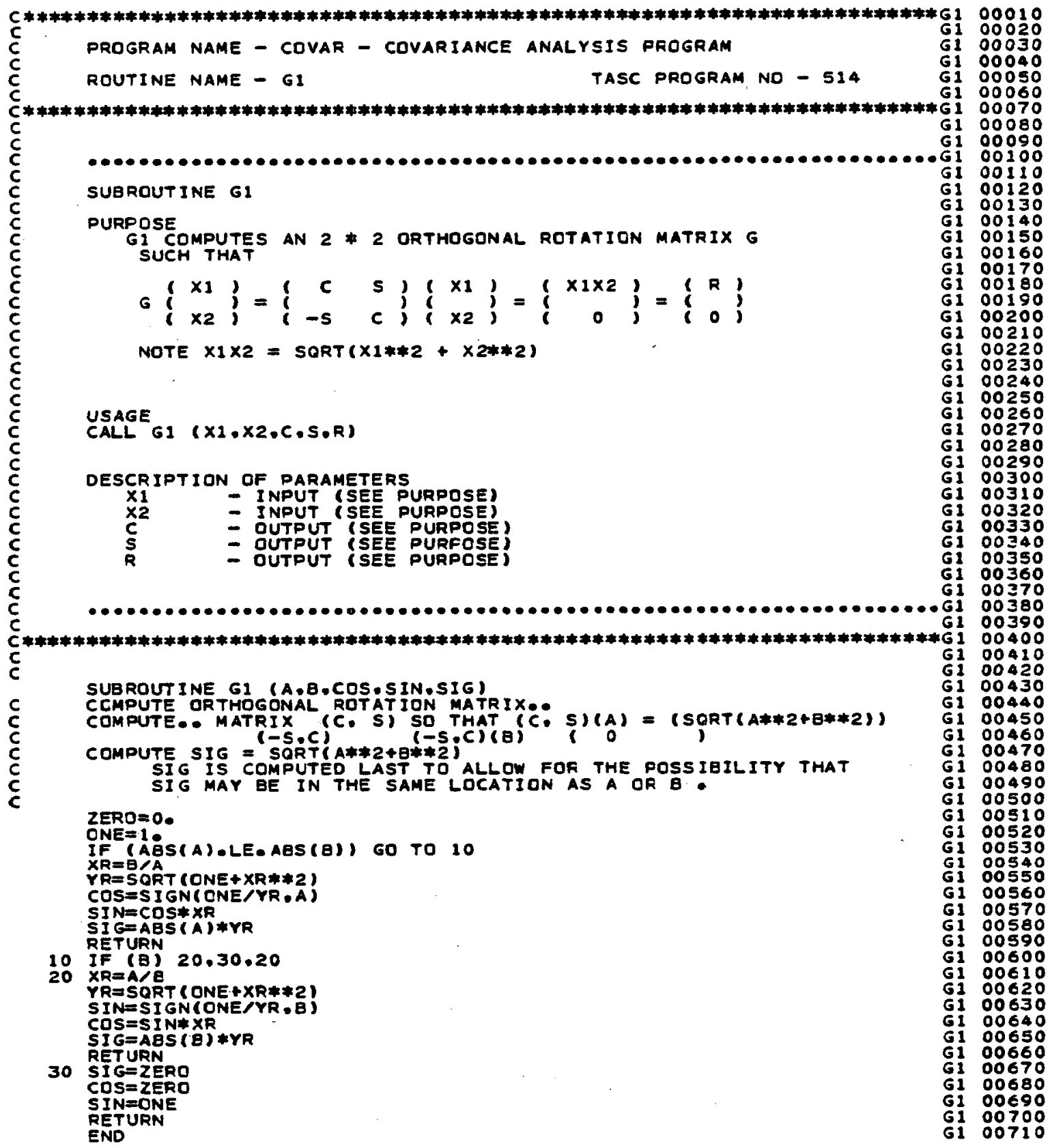




\section{A.10 G2}

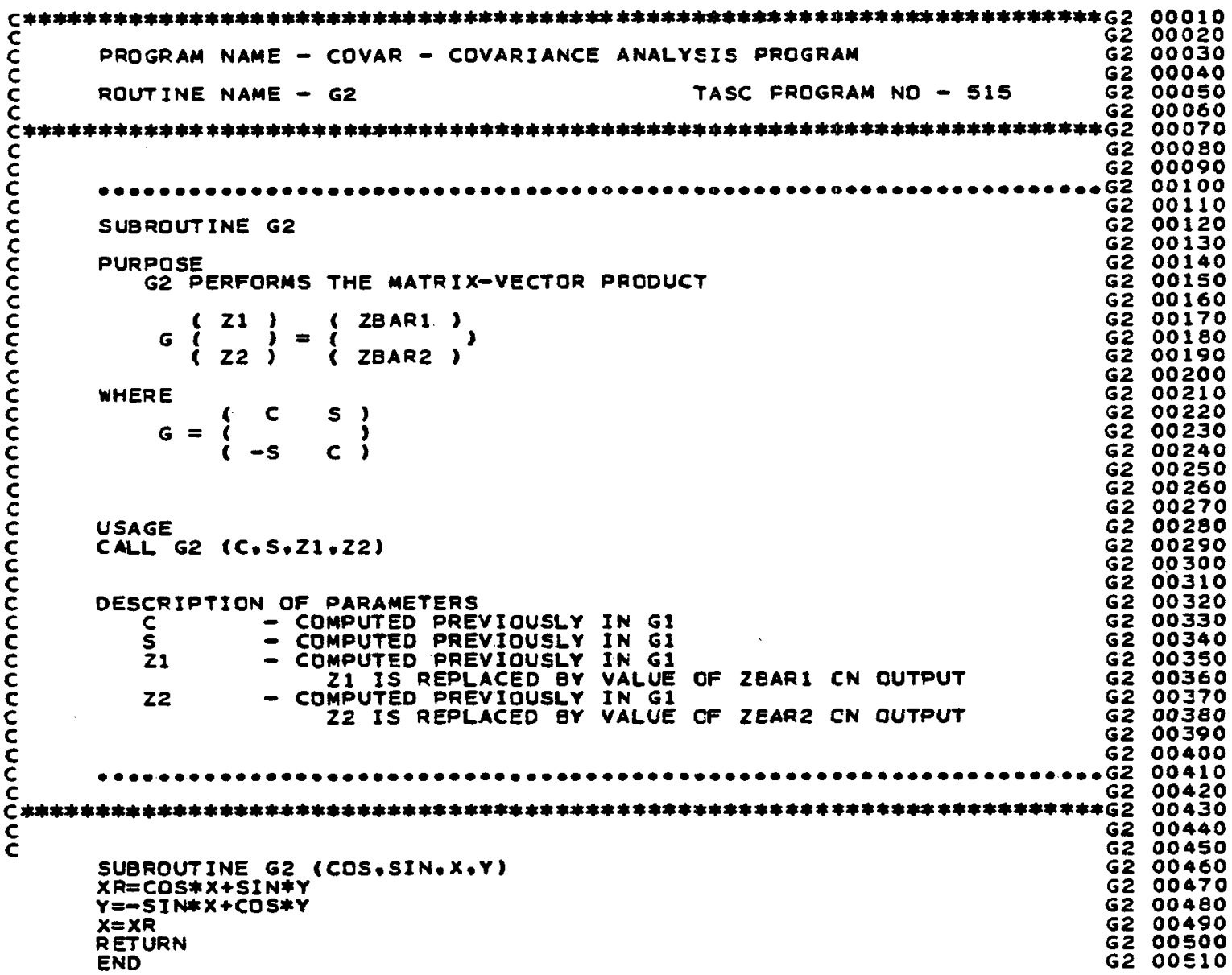




\section{A:11 DIFF}

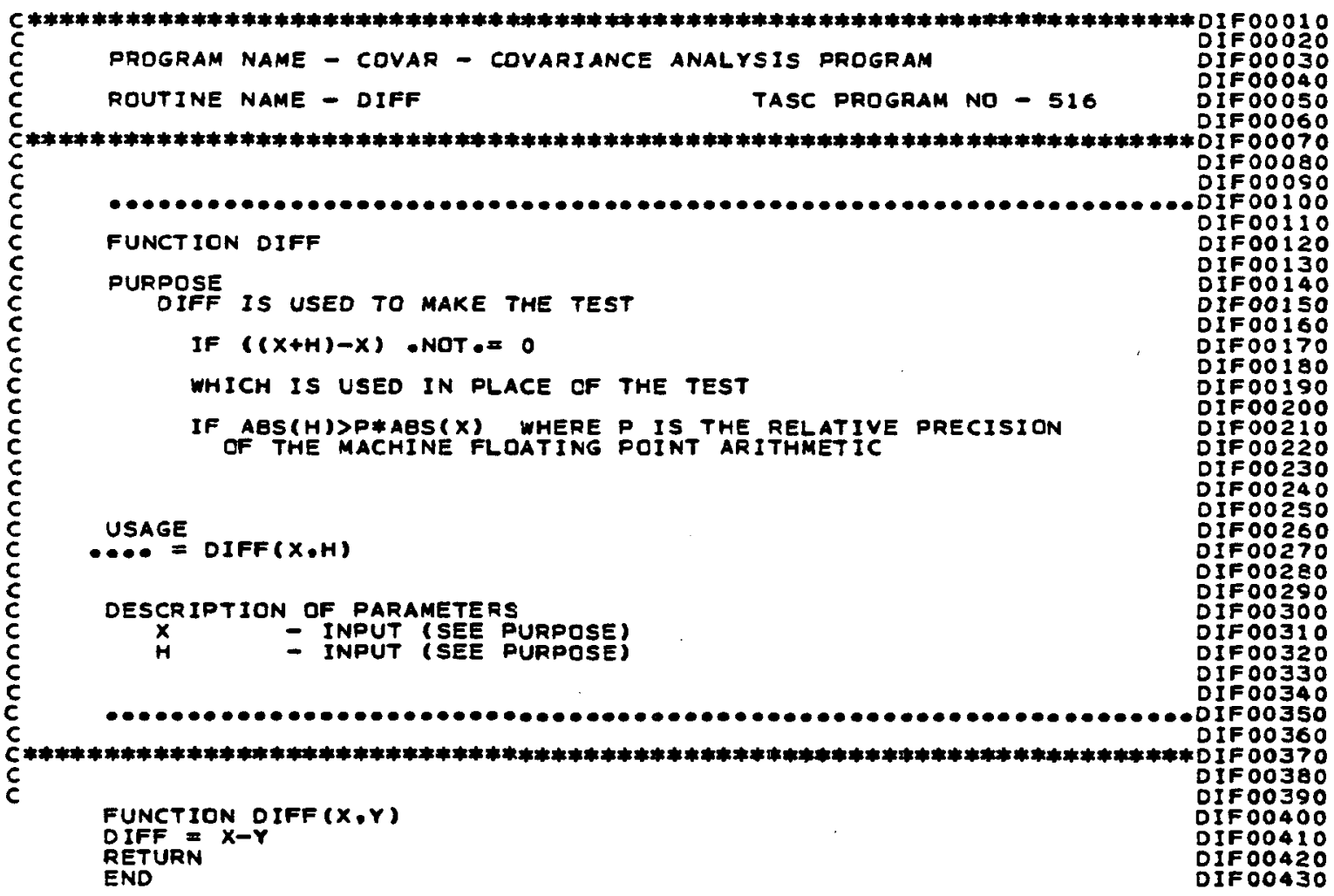




\section{A.12 BLOCK DATA}

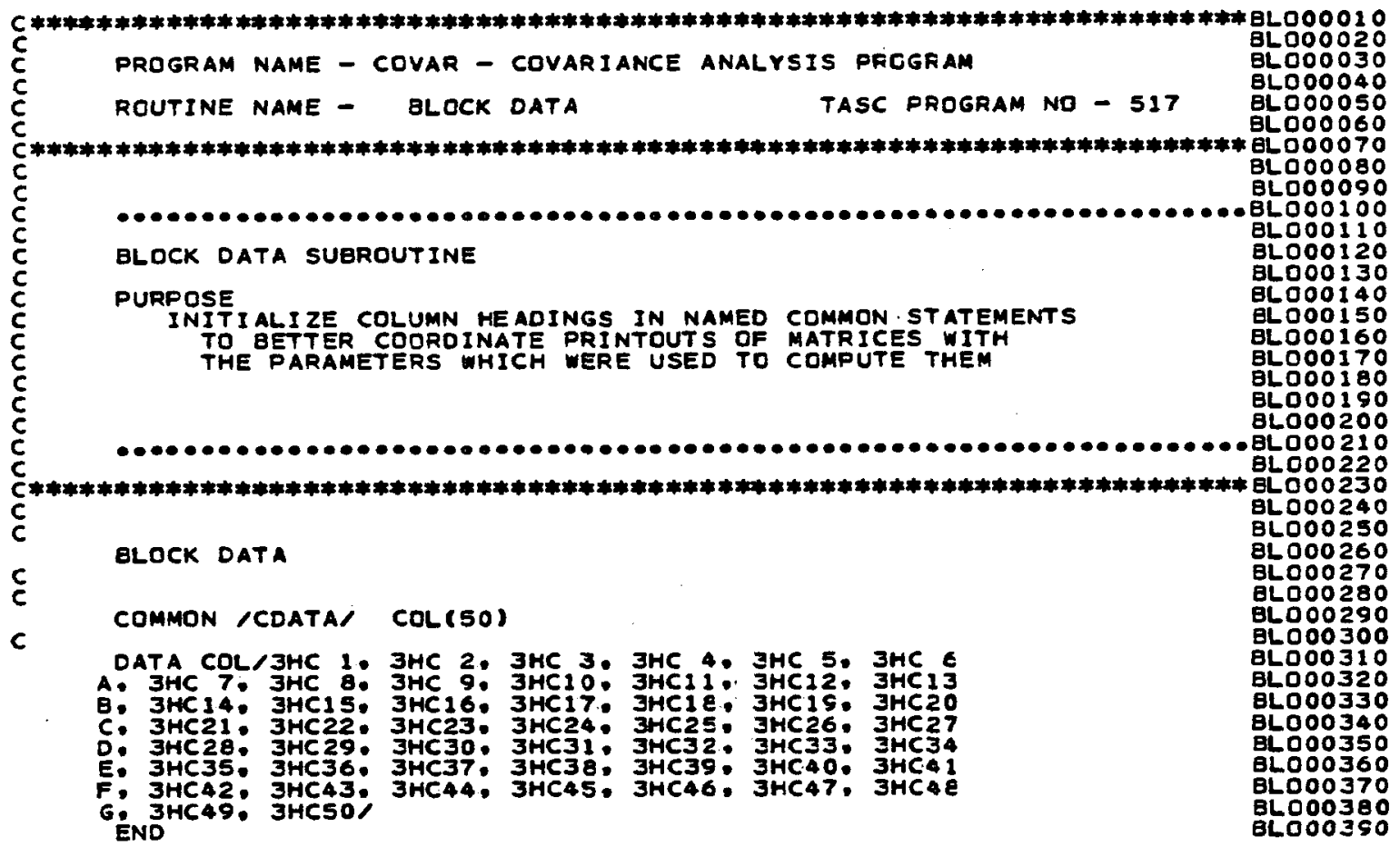


$\mathrm{B}-1$ 
COVARIANCE MATRICES Computaticns

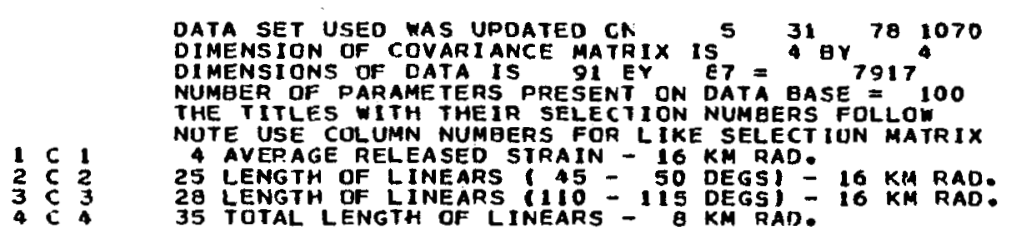

COMPUTATION OF COVARIANCE MATRIX DE 1 IN

GALTHER DVL DATA FOR GR DDDED TEST

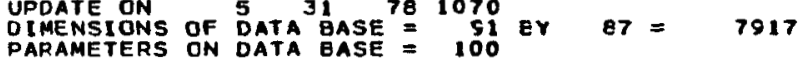

DIMENSIONS

$\rightarrow 4$

COVARIANCE MATRIX

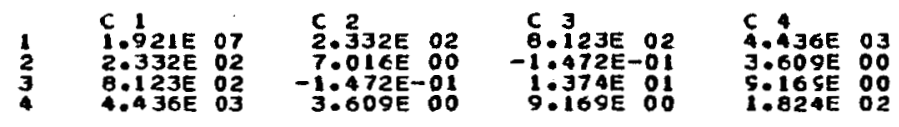

Dimensions 14 aVERAGES

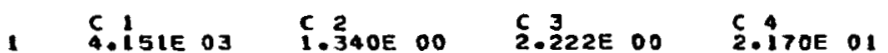

DiMENSIONS 14 STANDARD DEVIATIONS

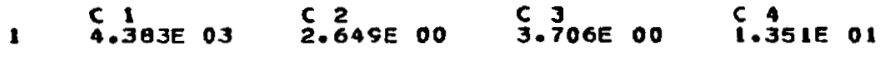

DIMENSIONS 44 CORRELATION MATRIX

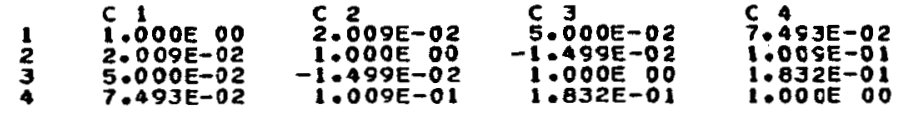

OIMENSIONS 4 MATRIX OF EIGEN VECTORS

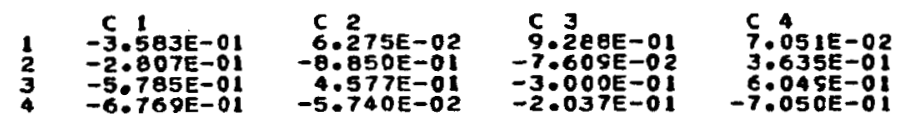

DIMENSIONS 44 EIGEN VALUE MATRIX

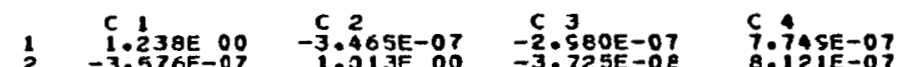

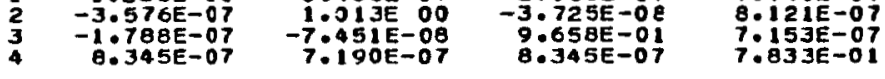

DIMENSIONS 1 EIgen VAlues oltPut

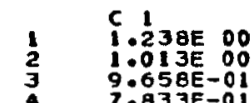


DIMENSIONS 44 COVARIANCE MATRIX

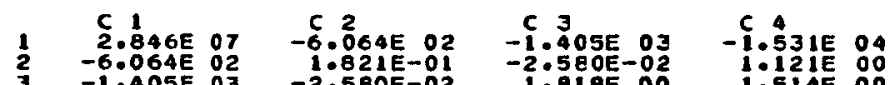

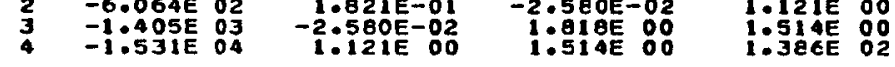
Dimensions 14 aVerages

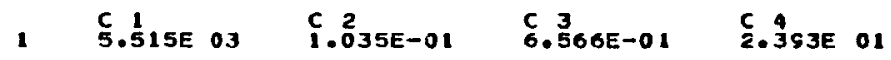

DIMENSIONS 14 STANDARD DEVIATIIONS

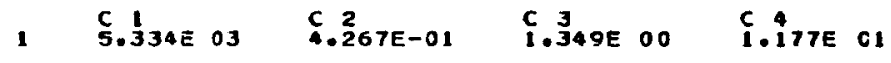
DIMENSIONS 4 CORRELATION MATRIX

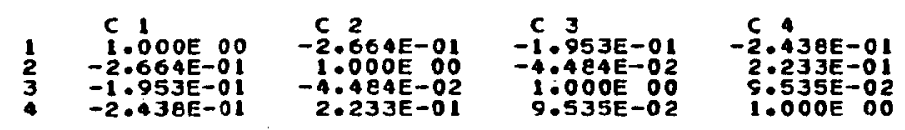

DIMENSIONS 4 M MATRIX DF EIGEN VECTORS

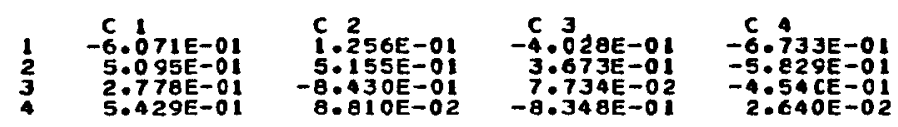

Dimensions 4 4 EIGEN VAlue matrix

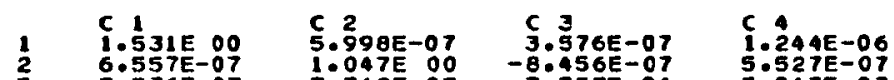

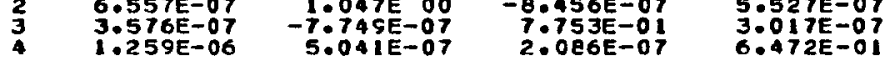

Dimensions 4 - EIGEN VAlues output

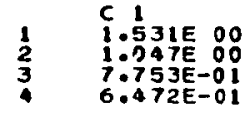




\section{LIKELIHOOD EVALUATION PROGRAM SOURCE LISTING}

$\begin{array}{llc} & & \begin{array}{c}\text { Page } \\ \text { No. }\end{array} \\ \text { C. } 1 & \text { LIKE (MAIN PROGRAM) } & \text { C-2 } \\ \text { C. } 2 & \text { SLIKE } & \text { C-6 } \\ \text { C. } 3 & \text { SLIKE1 } & \text { C-9 } \\ \text { C. } 4 & \text { PRNTL } & \text { C-12 }\end{array}$




\section{C.1 LIKE (MAIN PROGRAM)}

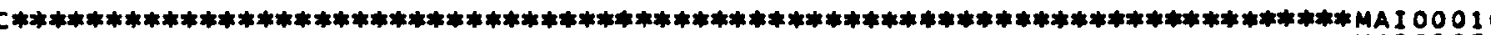

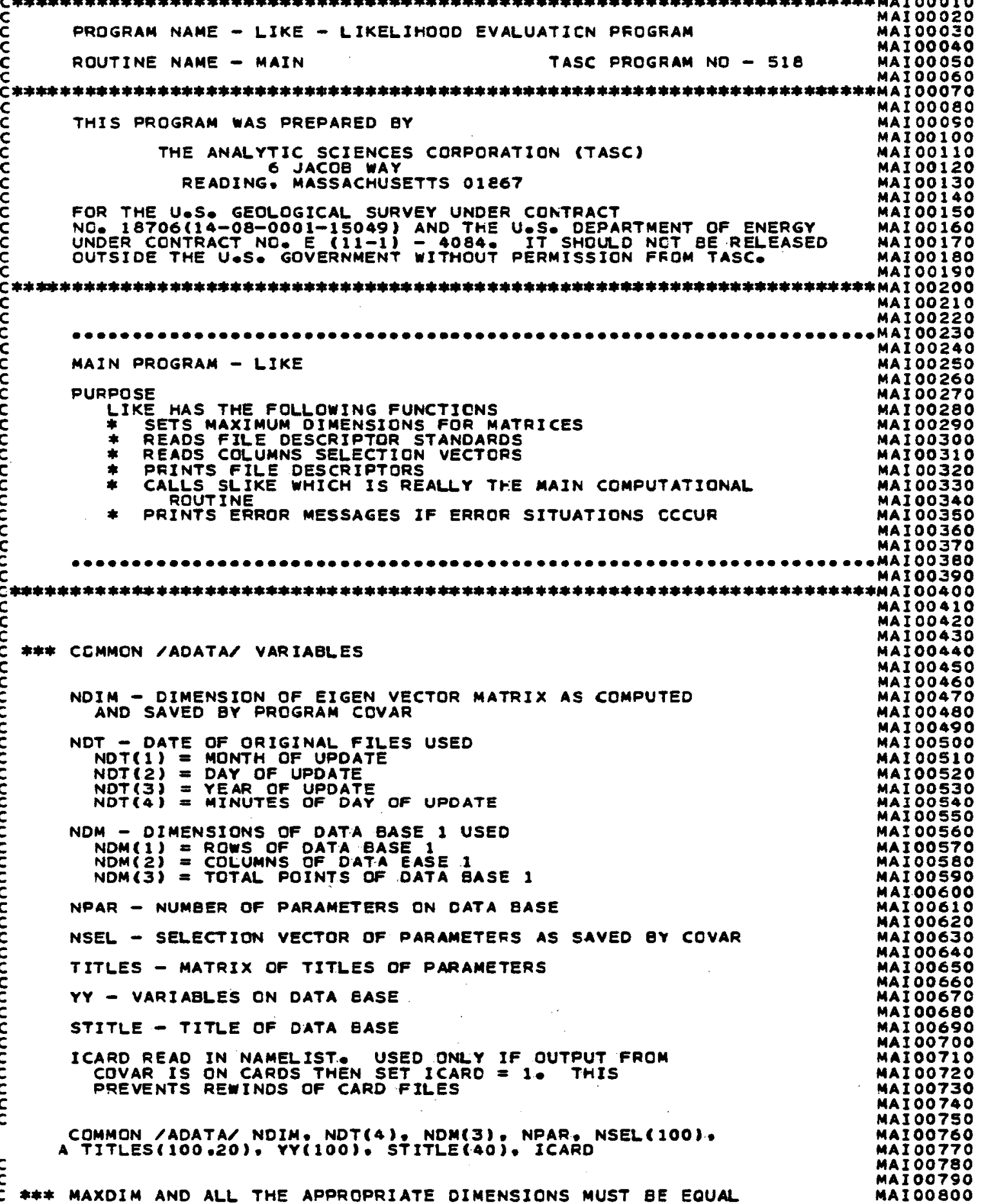




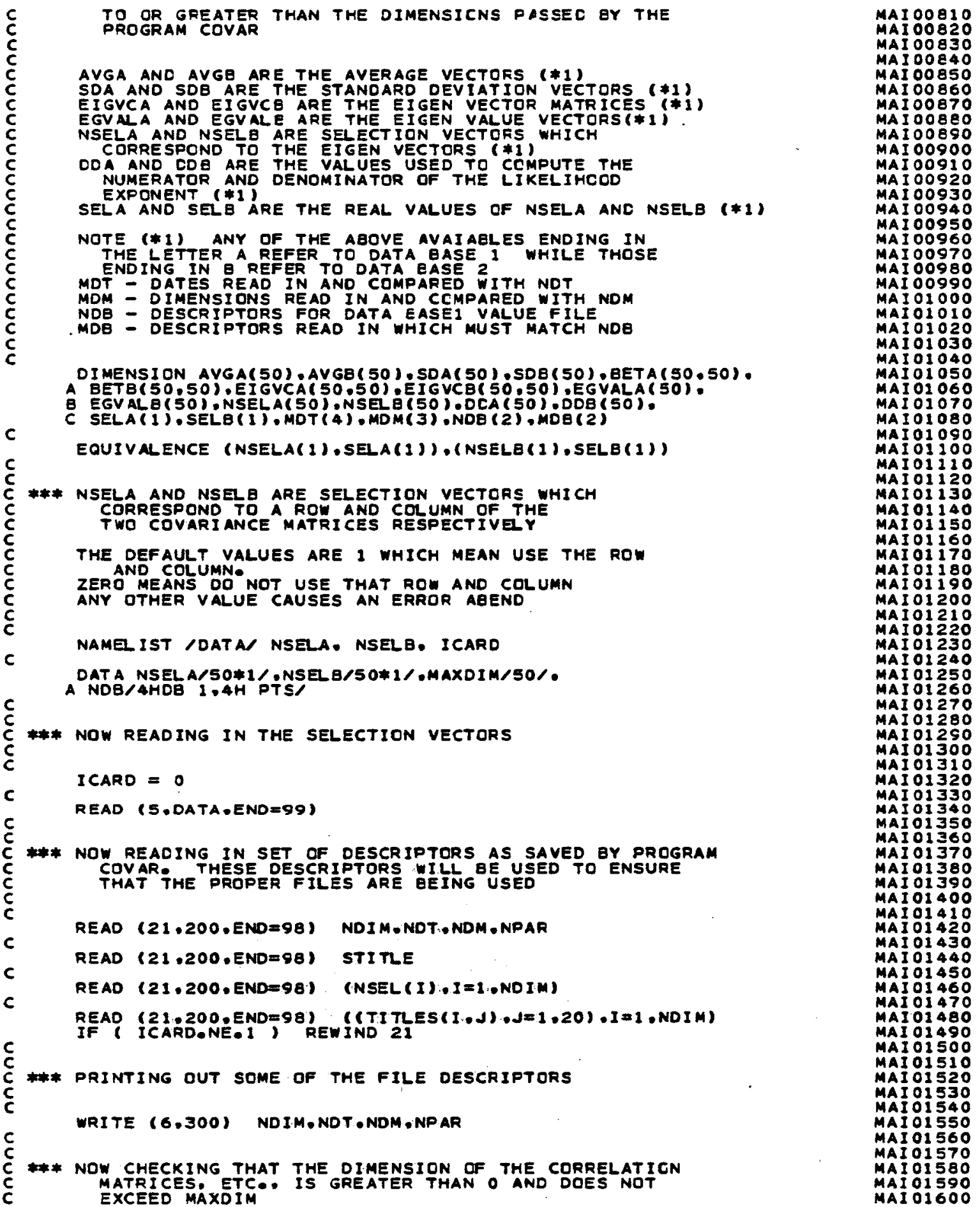




$$
\text { 定 }
$$

IF ( NOIMOLT•I -OR. NDIMEGT•MAXOIM, GOTO 97 *** ENSURING THAT THE SELETION VECTORS HAVE ONLY VALUES OF 1 OR 0

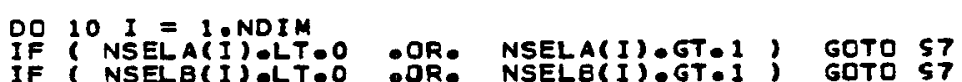

$c$
$c$
$c$
$c$
$c$
$c$
$c$
$c$
$c$
$c$
$c$ 10 CONTINUE

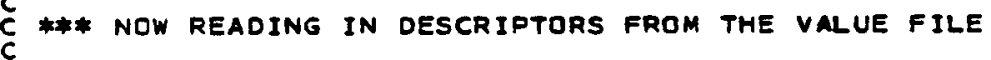




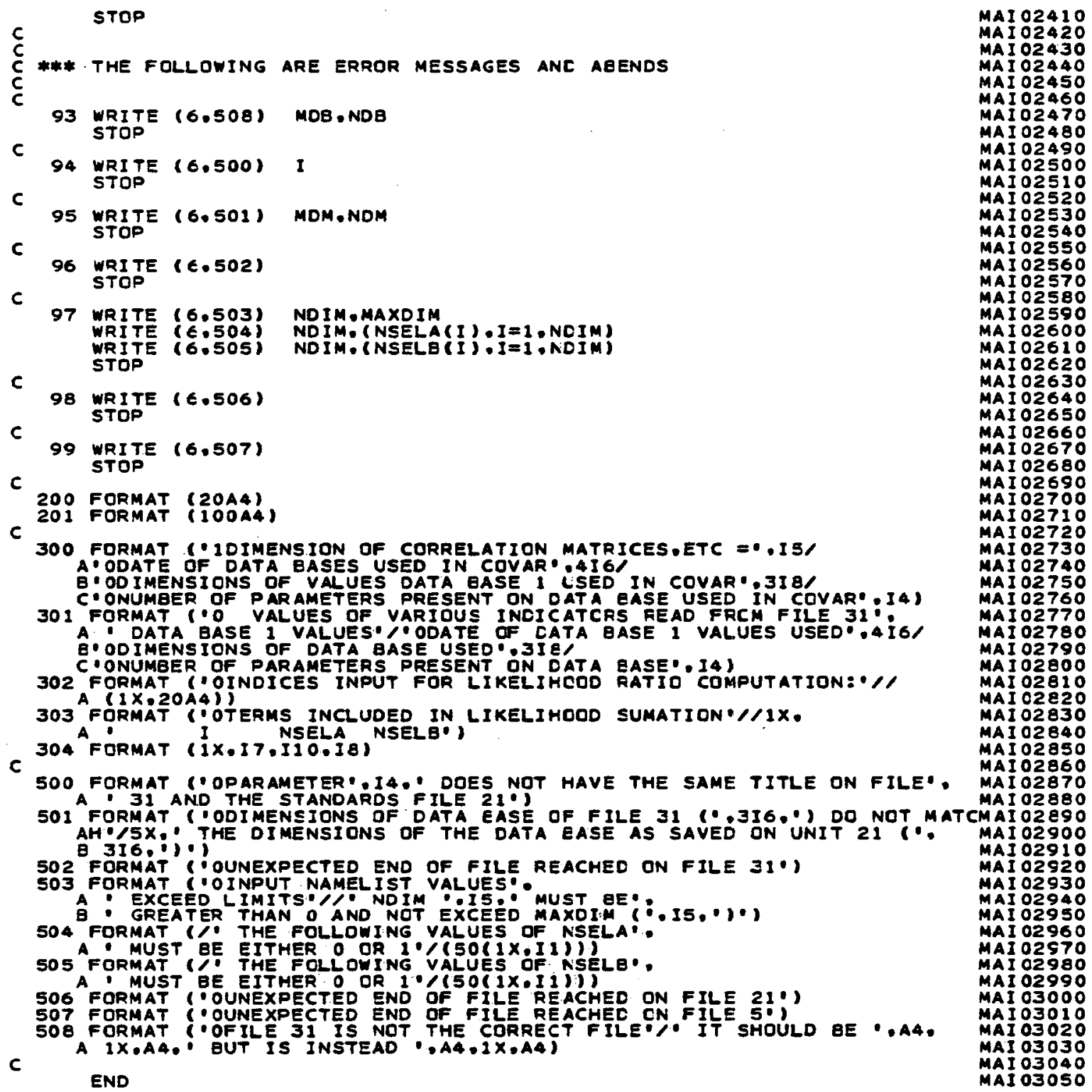




\section{2 SLIKE}

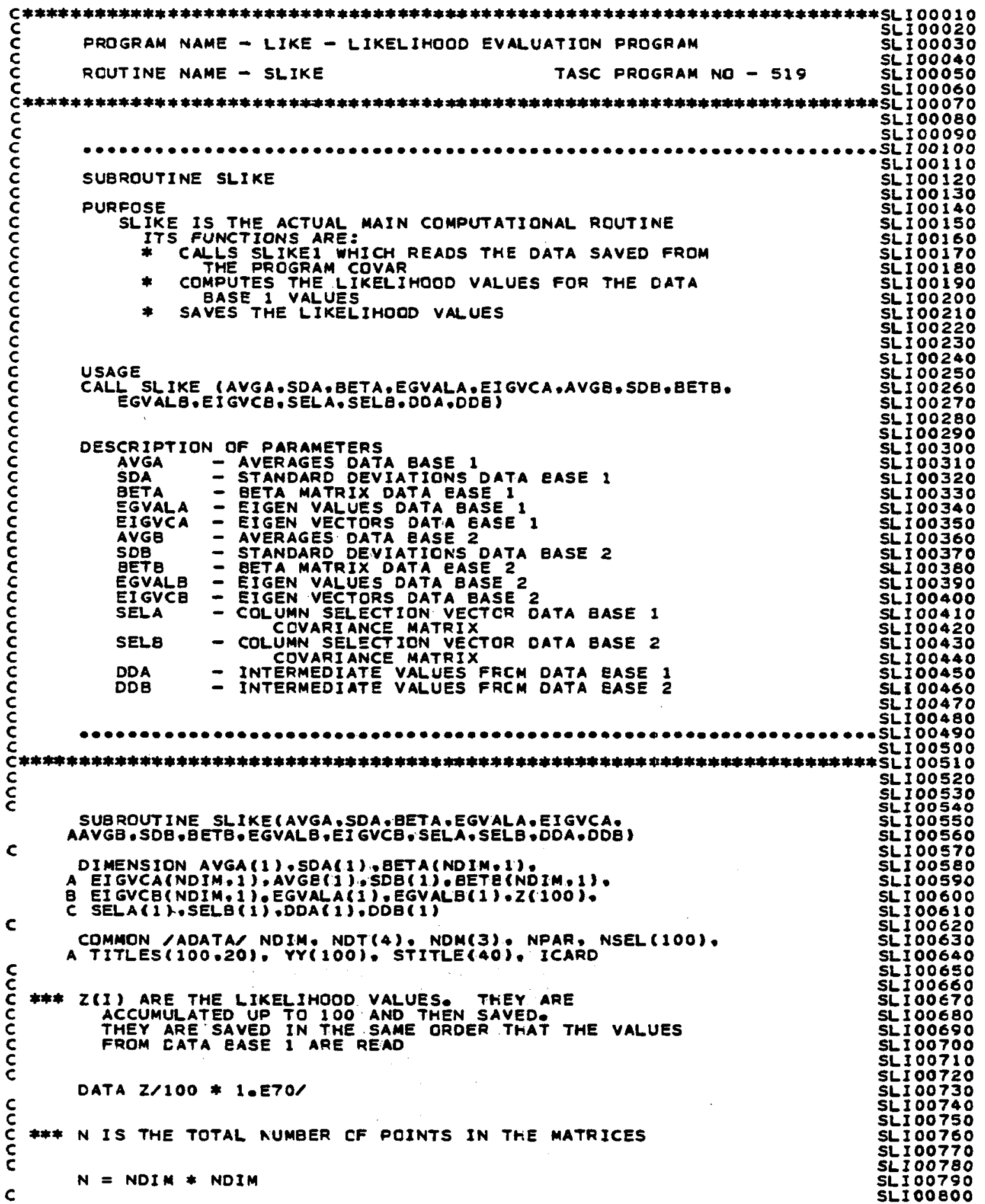




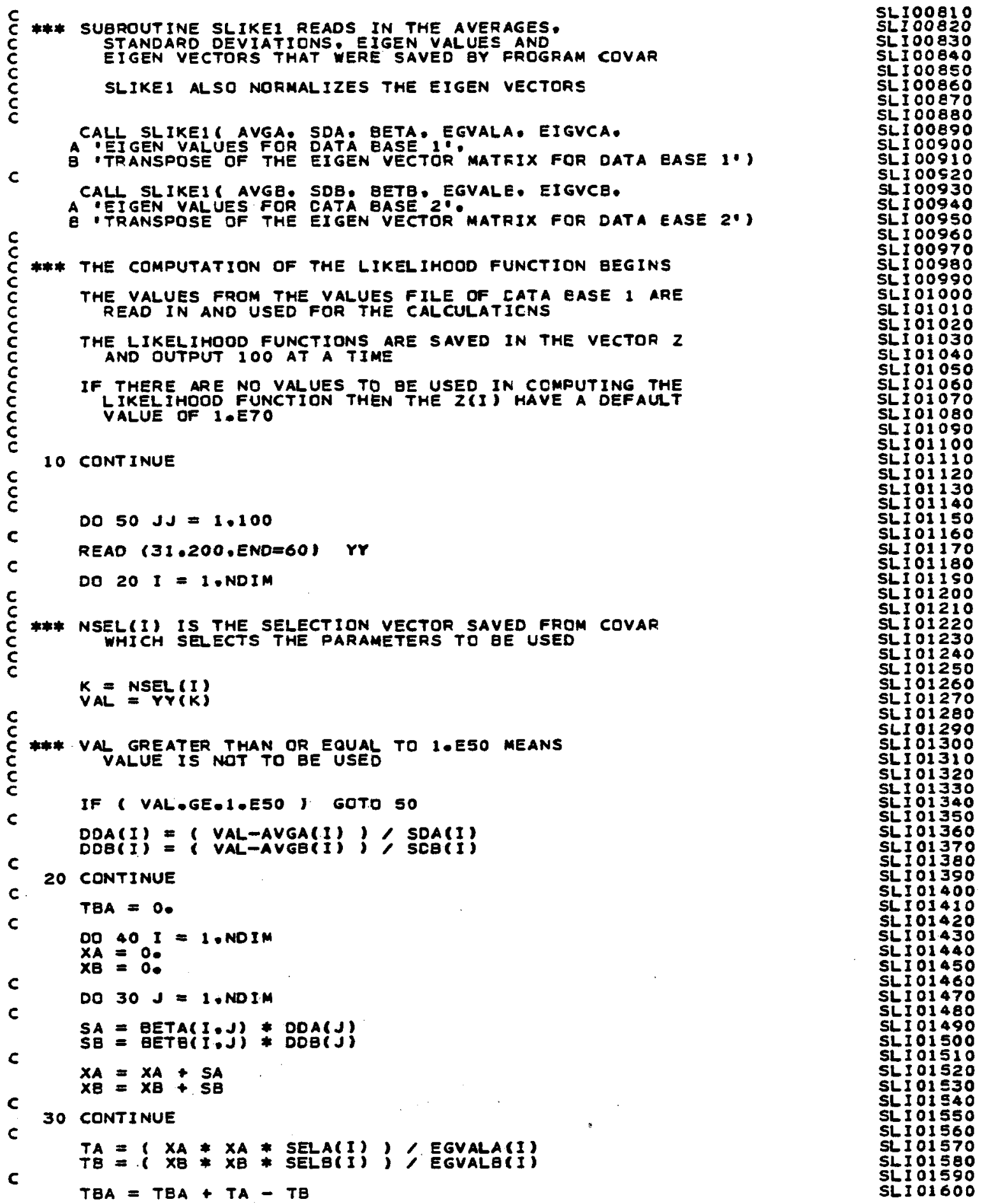



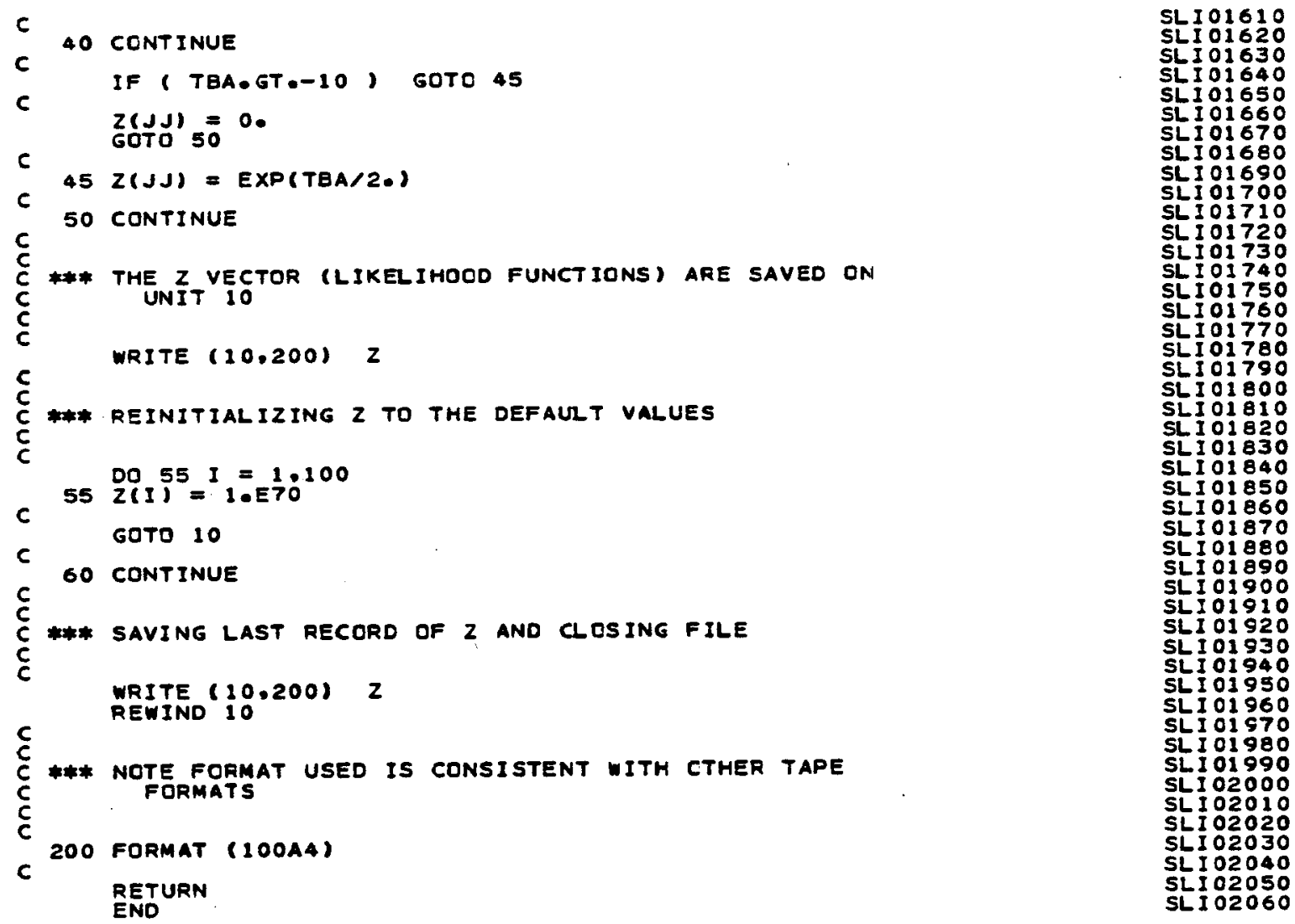


\section{3 SLIKE1}

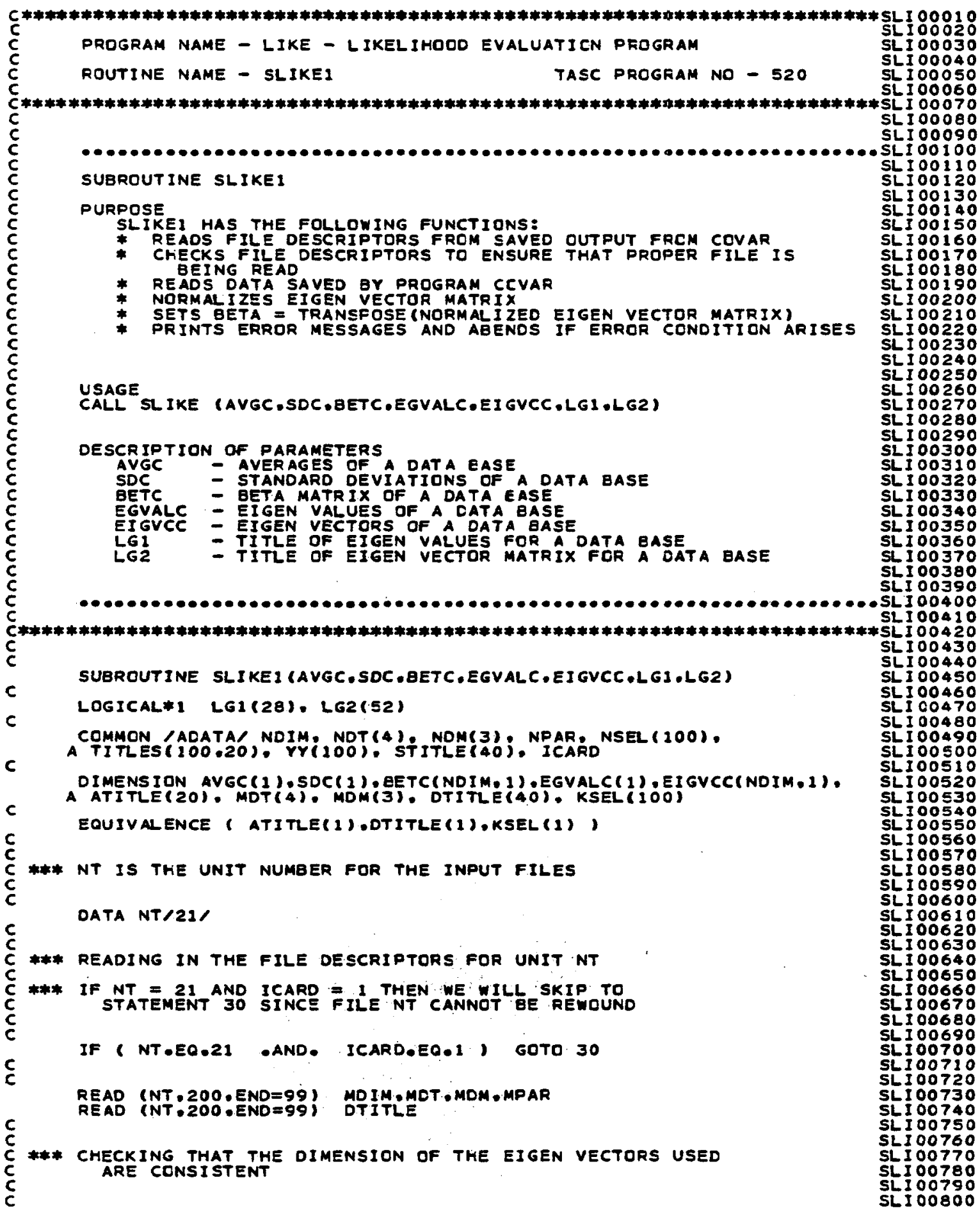




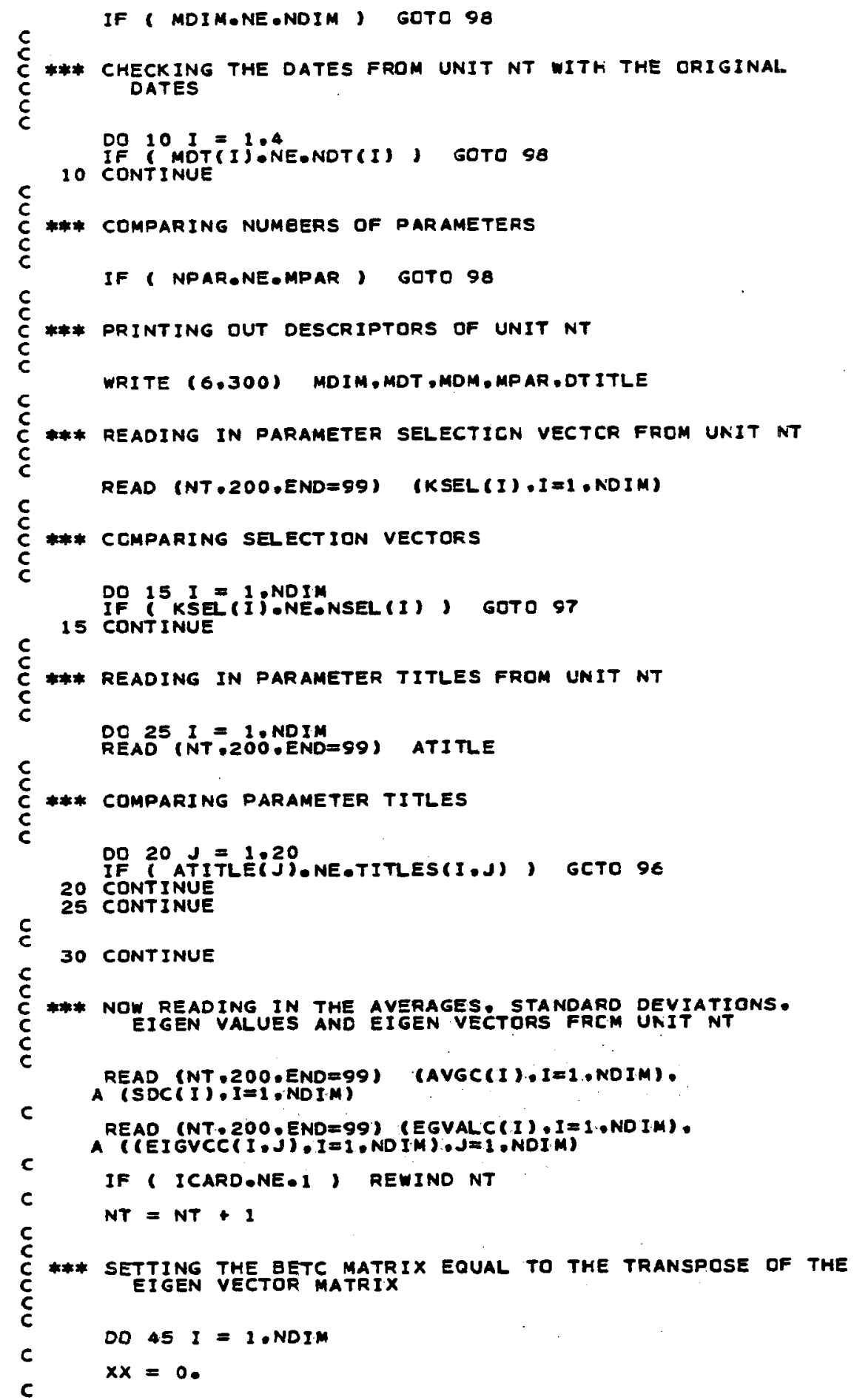


DO $35 \quad J=1$, NDIM

$$
x x=\operatorname{SORT}(x x)
$$

DO $40 J=1$, NOIM

c

45 CONTINUE

c

c

c

$c$

c

c$$
\text { c }
$$

$c$

c

200 FORMAT (20A4)

300 FORMAT ('10IMENSION OF CORRELATICN MATRICES.ETC $=\cdot .15 /$ A: DATE OF DATA EASES USED IN COVAR - $416 /$

- DIMENSIONS OF VALUES DATA BASE I LSED IN COVAR - . 318 C. NUMBER OF PARAMETERS PRESENT ON DATA GASES USED IN COVAR, $14 / /$ D 20X, "TITLE OF DATA SET'Y E (5X.2044))

500 FORMAT ('OPARAMETER', $140^{\circ}$ DOES NOT MAVE THE SAME TITLE ON FILE:

501 FIJ, A ANO THE STANDARDS FILE 21 ' '

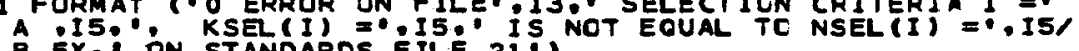
B 5X, ON STANDARDS FILE 21 , ) 作 AR IX: DATES DF FILE UPDATE OR:/5X. THE NUMBER OF PARAMETERS ON THE SLI OLS

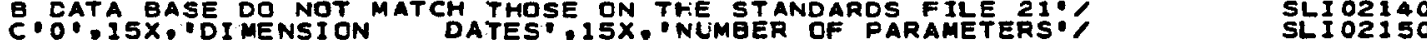

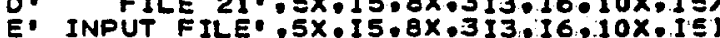

c

503 FORMAT ("OUNEXPECTED END OF FILE REACHED ON FILE",I3) END

SLI 01610

SLI01620

SLIO1640

SLIOI650

SLI 01660

SL 101670

SLI 01690

SLI 01700

SLI 01720

SLI 01730

SLIO1740

SLIOI760

SLI 01770

SLI01780

SLI 01800

SLI 01810

SLI 01820

SLI01840

SLI 01850

SLI 1860

SLI01880

SLI 01890

SLIO1910

SLI 01920

SLI 01930

SLI 01950

SLI 01960

SLI 01970

SLI 01990

SLI 02000

SLI 02010

SLI 02020 SLI 02030 SLI 02040 SLI 02050 SLI 02060 SL SLI 02080 SLI 02160 SLI 02170 SLI02190 SLIO2200 


\section{4 PRNTL}

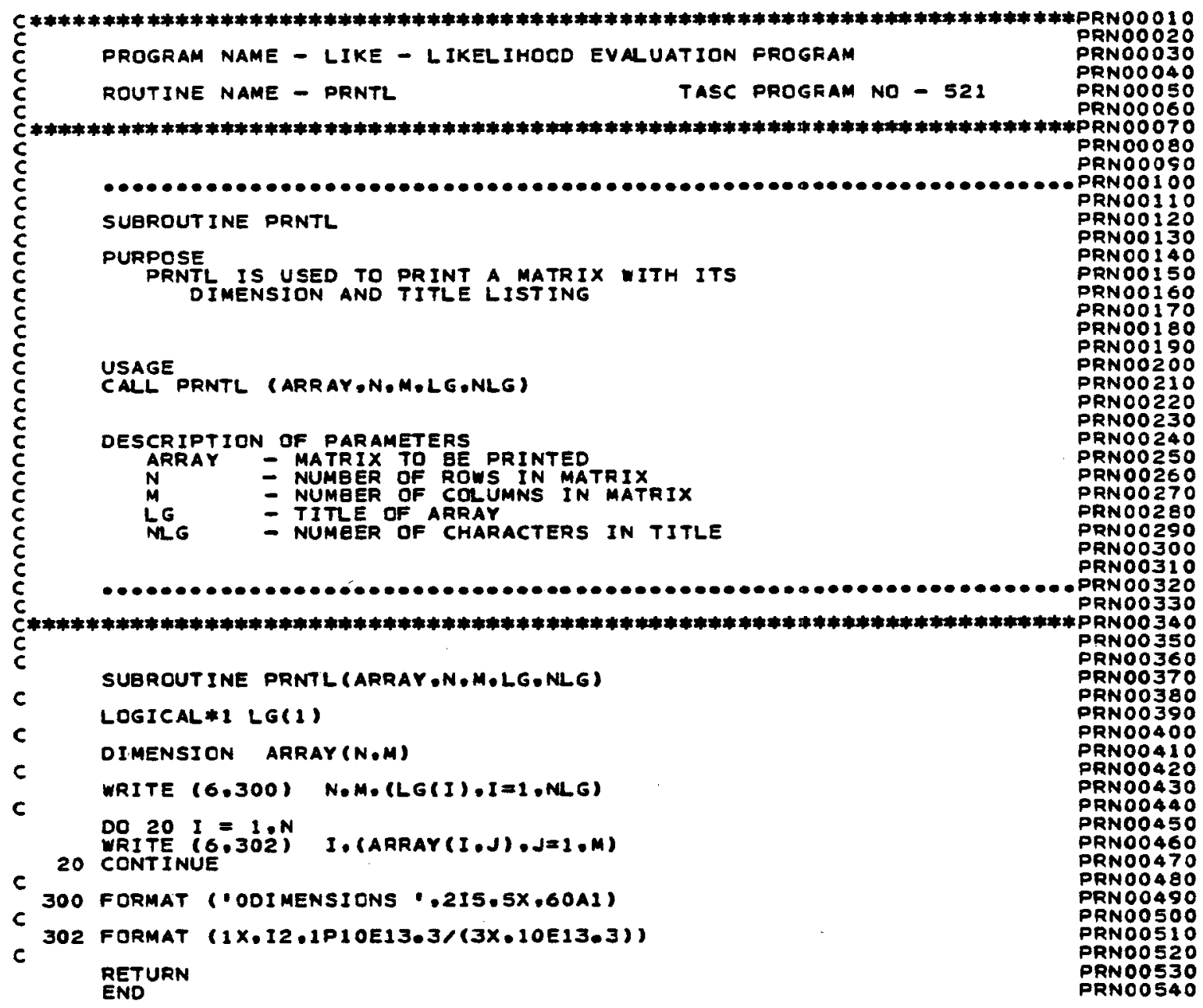


THE ANALYTIC SCIENCES CORPORATION

\author{
APPENDIX D \\ SAMPLE EXECUTION OF HYPOTHESIS TESTING PROGRAM
}

D-1 
DIMENSION OF CORRELATION MATRICES OETC

DATE OF DATA EASES USED IN COVAR

DIMENSIONS OF VALUES DATA GASE I USED IN COVAR

$78 \quad 1070$

NUMBER OF PARAMETERS PRESENT ON DATA EASE USED IN COVAR 100

YALUES OF VARIOUS INDICATORS READ FROM FILE 31 DATA EASE I VALUES

\begin{abstract}
DATE of DATA base 1 Values useo
$5 \quad 31 \quad 78 \quad 1070$
\end{abstract}

DIMENSIONS OF DATA Base USED

91

87

7917

NUMBER OF PARAMETERS PRESENT ON DATA BASE 100

INDICES INPUT FOR LIKELIHOOD RATIO COMPUTATION:

AVERAGE RELEASED STRA1N - 16 KM RAD.

LENGTH OF LINEARS 45 - 50 OEGS

LENGTH OF LINEARS 1110 - $^{115}$ DEGS

TERMS INCLUDED IN LIKELIHOOD SUMATION

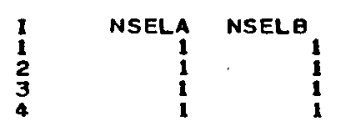




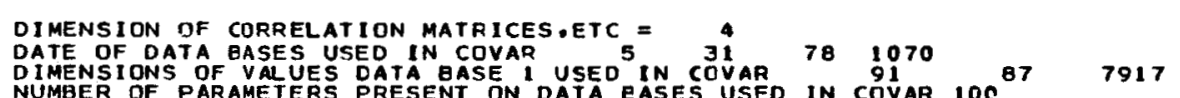

GEOTHERMAL DATA TITLE GF DATA SET GRIONS INSIDE STATE OF NEVADA GEOTHERMAL DATA FOR GR OVDED 1 . E6S ARE NOT USED

DIMENSIONS ${ }^{4} 1$ EIGEN VALUES FCR DATA BASE I

$\frac{1}{2} \quad 1: 013 E \%$

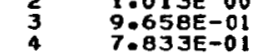

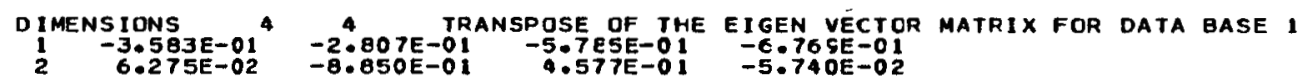

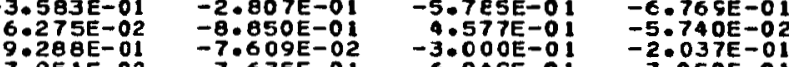

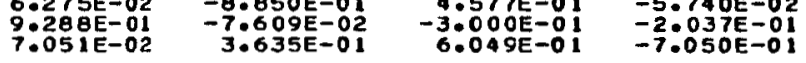




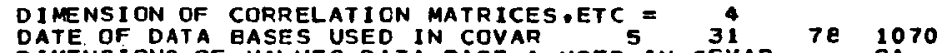

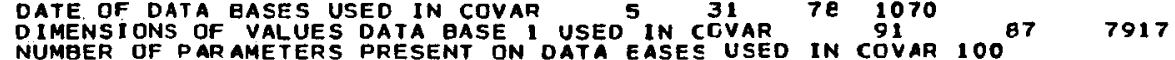
GEOTHERMAL DATA TITLE OF OATA SET LOCATIONS

MENSIONS 4 EIGEN VAlUes for data gase 2

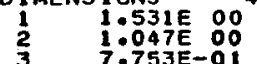

$\begin{array}{lll}3 & 7 \\ 3 & 6.7532 E-01\end{array}$

DIMENSIONS ${ }^{4}$ 5 4.095E-TRANSPOSE OF THE EIGEN VECTOR MATRIX FOR OATA BASE 2

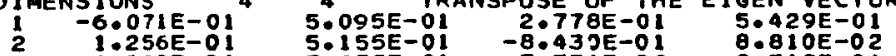

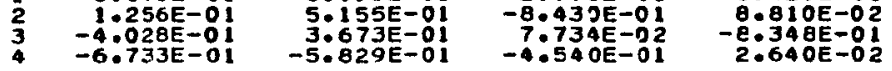




\section{APPENDIX E \\ DESCRIPTION OF THE DELIVERABLE TAPE}

The deliverable tape contains the following six files.

File 1 - Value file (Data Base 1)

File 2 - Average file (Data Base 1)

File 3 - Value file (Data Base 2)

File 4 - Average file (Data Base 2)

File 5 - Program COVAR with all of its subroutines

File 6 - Program LIKE with all of its subroutines

The tape is an unlabeled (NL) tape written in 9-track format at $1600 \mathrm{bpi}$. The DCB characteristics for each file are as follows :

\begin{tabular}{|c|c|c|c|}
\hline & RECFM & LRECL & BLKSIZE \\
\hline File 1 & FB & 400 & 32000 \\
\hline File 2 & FB & 400 & 8000 \\
\hline File 3 & FB & 400 & 8000 \\
\hline File 4 & FB & 400 & 8000 \\
\hline File 5 & $\mathrm{FB}$ & 80 & 32000 \\
\hline File 6 & FB & 80 & 32000 \\
\hline
\end{tabular}




\section{APPENDIX F \\ JOB CONTROL STATEMENTS}

The following JCL statements provide a sample case.

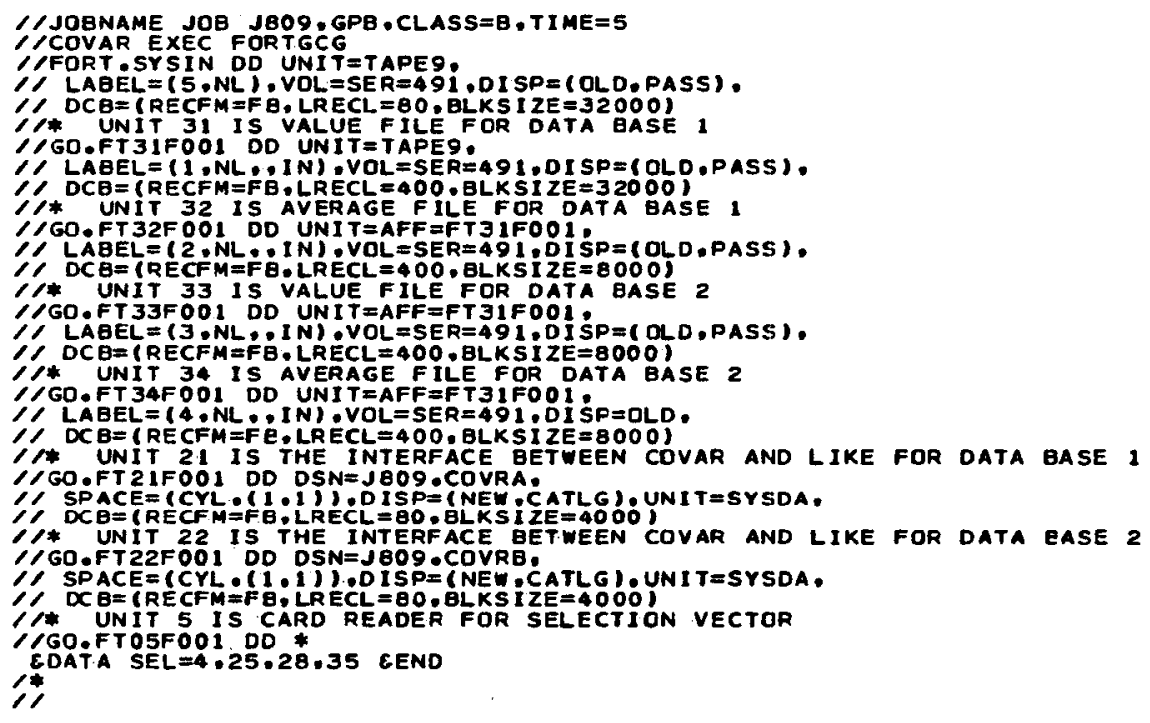




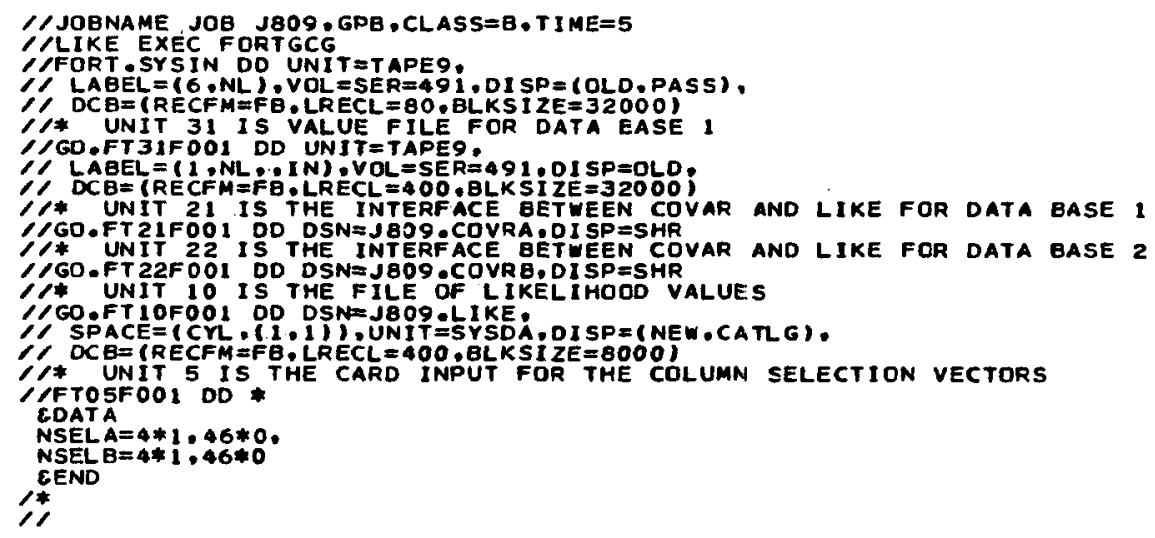

